\title{
Long-Term Unemployment and the Great Recession: The Role of Composition, Duration Dependence, and Nonparticipation
}

\section{Citation}

Kroft, Kory, Fabian Lange, Matthew J. Notowidigdo, and Lawrence F. Katz. 2016. “Long-Term Unemployment and the Great Recession: The Role of Composition, Duration Dependence, and Nonparticipation." Journal of Labor Economics 34 (S1) (January): S7-S54. doi:10.1086/682390.

\section{Published Version}

doi:10.1086/682390

\section{Permanent link}

http://nrs.harvard.edu/urn-3:HUL.InstRepos:27731427

\section{Terms of Use}

This article was downloaded from Harvard University's DASH repository, and is made available under the terms and conditions applicable to Open Access Policy Articles, as set forth at http:// nrs.harvard.edu/urn-3:HUL.InstRepos:dash.current.terms-of-use\#OAP

\section{Share Your Story}

The Harvard community has made this article openly available.

Please share how this access benefits you. Submit a story.

\section{Accessibility}




\title{
Long-Term Unemployment and the Great Recession: The Role of Composition, Duration Dependence, and Non-Participation
}

\author{
Kory Kroft \\ University of Toronto \\ and NBER
}

\author{
Fabian Lange \\ McGill University
}

\author{
Matthew J. Notowidigdo \\ Northwestern University \\ and NBER
}

\author{
Lawrence F. Katz \\ Harvard University \\ and NBER
}

First Version: May 2013

This Version: June $2014^{1}$

\begin{abstract}
We explore the extent to which composition, duration dependence, and labor force non-participation can account for the sharp increase in the incidence of long-term unemployment (LTU) during the Great Recession. We first show that compositional shifts in demographics, occupation, industry, region, and the reason for unemployment jointly account for very little of the observed increase in LTU. Next, using panel data from the Current Population Survey for 2002-2007, we calibrate a matching model that allows for duration dependence in the exit rate from unemployment and for transitions between employment (E), unemployment (U), and non-participation $(\mathrm{N})$. We model the job-finding rates for the unemployed and non-participants, and we use observed vacancy rates and the transition rates from E-to-U, E-to-N, N-to-U, and U-to-N as the exogenous "forcing variables" of the model. The calibrated model can account for almost all of the increase in the incidence of LTU and much of the observed outward shift in the Beveridge curve between 2008 and 2013. Both negative duration dependence in the job-finding rate for the unemployed and transitions to and from non-participation contribute significantly to the ability of the model to match the data after 2008.
\end{abstract}

\footnotetext{
${ }^{1}$ E-mail: kory.kroft@utoronto.ca; fabian.lange@mcgill.ca; noto@alum.mit.edu; lkatz@harvard.edu. We thank Barbara Petrongolo for extremely useful and thoughtful comments as a discussant and David Card, Alex Mas, and Jim Poterba for helpful feedback, and we thank Mark He for excellent research assistance.
} 


\section{Introduction}

This paper investigates whether a search and matching model can explain important features of the U.S. labor market in the Great Recession and its aftermath. In particular, we ask whether such a model can account for the rise in the unemployment rate and the increase in the incidence of long-term unemployment (LTU) among the unemployed. ${ }^{2}$

To motivate our analysis, we begin by decomposing the overall unemployment rate by unemployment duration. Figure 1 plots the unemployment rate for the short-term unemployed ( $<15$ weeks), the mediumterm unemployed (15-26 weeks) and the long-term unemployed (>26 weeks) from 1948 to 2013. The short-term unemployed typically represent the vast majority of the unemployed with the short-term unemployment rate around 4 percent in normal times. The medium- and long-term unemployed account for much less of total unemployment, with rates typically near 1 percent. During the Great Recession, unemployment rates increased across all duration groups. However, the long-term unemployment rate reached record levels and remains historically high: unemployment rates for both the short-term and longterm unemployed were around 3.5 percent in 2013. Although short-term and medium-term unemployment rates were roughly back to their normal pre-recession levels by 2012, long-term unemployment remains persistently high.

Another way to see this is in Panel A of Figure 2, which shows the share of unemployed workers who are long-term unemployed among prime-aged workers (aged 25-55 years). This share increased from around 20 percent in 2008 to roughly 45 percent in 2013. Panel B of Figure 2 shows that the Beveridge curve - the relationship between unemployment and job vacancies - shifted outward during the Great Recession. This paper attempts to account for these two facts - the rise in the LTU share and the shift in the Beveridge curve - by exploring the role of shifts in the composition of the unemployed, duration dependence in jobfinding rates for the unemployed, and transitions in and out of the labor force (between unemployment, employment, and non-participation). To preview our main result, we find that an enriched matching model - incorporating duration dependence and non-participation - can account for almost all of the increase in the incidence of LTU and most of the outward shift in the Beveridge curve during the Great Recession. By contrast, we do not find any evidence that compositional shifts play an important role.

We begin our analysis by showing that between 2008 and 2013, compositional shifts towards groups with traditionally longer unemployment durations account for very little of the overall rise in the incidence of LTU documented in Figure 2. We show that LTU increased for virtually all groups and that compositional

\footnotetext{
${ }^{2}$ By "incidence of long-term unemployment", we mean the share of total unemployed individuals at a point in time who are currently experiencing long unemployment durations (typically defined as either above 26 weeks or 52 weeks).
} 
shifts do not go very far in accounting for the rise in LTU. For this exercise, compositional shifts refer to changes in observed characteristics of unemployed workers - specifically, variables in the Current Population Survey (CPS) related to demographics, occupation, industry, region, and the reason for unemployment. We emphasize that this analysis cannot account for changes in the composition of the unemployed along unobserved characteristics.

We next examine the extent to which a matching model along the lines of Mortensen and Pissarides (1994) and Shimer (2005) can account for the observed increase in LTU and the observed shift in the Beveridge curve. To do this, we enrich a standard matching model along three dimensions. First, we allow for duration dependence in the job-finding rate of the unemployed. Second, we allow for flows between employment $(\mathrm{E})$, unemployment $(\mathrm{U})$, and non-participation $(\mathrm{N})$, instead of focusing exclusively on flows between $\mathrm{E}$ and $\mathrm{U}$, as in a standard matching model. Third, we allow flows from employment and non-participation into unemployment to occur not just into short durations, but into long unemployment durations, as well, consistent with observed flows in the CPS.

Our rationale for exploring duration dependence in the unemployed job-finding rate is based on several recent resume audit studies which show that callbacks from employers to set up an interview decline with the current non-employment duration on a job applicant's resume (Kroft, Lange, and Notowidigdo 2013; Eriksson and Rooth 2013; Ghayad 2013). This form of employer discrimination could arise from human capital depreciation or employer screening, whereby employers perceive the long-term unemployed to be less productive employees. Negative duration dependence in the job-finding rate could also be due to lower search effort among the unemployed at longer durations due to discouragement.

Negative duration dependence in the exit rate from unemployment can potentially "amplify" the effects of a downturn in the labor market and increase LTU. According to a recent report by the Congressional Budget Office (CBO), long-term unemployment may "produce a self-perpetuating cycle wherein protracted spells of unemployment heighten employers' reluctance to hire those individuals, which in turn leads to even longer spells of joblessness" (CBO 2012). As a result, negative duration dependence in the job-finding rate from unemployment would appear to be a promising candidate explanation for understanding the recent sharp rise increase in LTU. As more workers are pushed into longer unemployment spells, negative duration dependence lowers the average job-finding rate and thus increases the overall unemployment rate. Therefore, duration dependence can potentially explain both the rise in LTU as well as the observed outward shift in the Beveridge curve during the Great Recession, as documented in Elsby, Hobijn, and Sahin (2010).

Our rationale for exploring the non-participation margin is motivated by previous work demonstrating 
the fluid boundary between non-participation and unemployment (Clark and Summers 1979; Flinn and Heckman 1983; Card and Riddell 1993; Jones and Riddell 1999; Elsby, Hobijn and Sahin 2013) as well as recent research on the effects of unemployment insurance (UI) benefit extensions on transitions between unemployment, employment, and non-participation (Rothstein 2011; Farber and Valetta 2013). The recent UI research finds significant effects of extended UI in reducing the exit rate from unemployment to nonparticipation. The substantial UI benefit extensions during the Great Recession may therefore have induced some jobless individuals to continue to report themselves as unemployed in the CPS, contributing to the observed rise in LTU. Beyond this specific mechanism, we also observe large changes in transition rates to and from non-participation since 2008.

We calibrate our enriched matching model on monthly data in the years before the Great Recession (2002-2007), and study how well the calibrated model fits the data during the Great Recession, holding fixed the calibrated parameters. ${ }^{3}$ In our analysis, we implement a two-step empirical approach. In the first step, we measure transition rates between the different labor market states $(\mathrm{E}, \mathrm{U}$, and $\mathrm{N})$ over the entire 2002-2013 period and estimate duration dependence using data from 2002-2007. In the second step, we calibrate the matching model parameters. By first measuring transition rates without imposing the structure of the matching model, we obtain measured hazard rates (between unemployment, employment, and non-participation) that are robust to model misspecification. ${ }^{4}$ An alternative to our two-step approach would be to estimate the hazard rates and the matching model parameters jointly in a single step. One advantage of our two-step approach is that it clarifies when failures to match the evolution of the job-finding rates over this time period are due to shortcomings in the enriched matching model. Another advantage is that it is straightforward to impose alternative assumptions about the magnitude of "true" duration dependence to explore sensitivity of the results (since the second step takes the duration dependence estimates from the first step as given, allowing alternative duration dependence estimates to be "plugged in" at the second stage).

In all of our analyses, we treat vacancies, transitions from employment to unemployment and nonparticipation, and transitions between non-participation and unemployment as the exogenous "forcing variables" of the model. By contrast, we allow the job-finding rates (for both the unemployed and nonparticipants), the labor market states, and the distribution of unemployment durations to all evolve endogenously (holding constant the calibrated parameters from the 2002-2007 period). Clearly, a more complete model of the economy would endogenize these variables. However, we treat these variables as exogenous

\footnotetext{
${ }^{3}$ The NBER's Business Cycle Dating Committee dates the beginning of the Great Recession to be December 2007 and the end to be June 2009.

${ }^{4}$ The assumptions required to estimate the transition rates are laid out in the Data Section and in Appendix B.
} 
because endogenizing them would require a model of vacancy creation as well as a model of labor demand, which is beyond the scope of this paper. In our sensitivity analysis, we manipulate the vacancy rates that we use in our counterfactual experiments to examine how the model performs when the strength of labor demand changes. ${ }^{5}$

Summarizing our results, we find that our calibrated model does a very good job of accounting for the increase in the incidence of long-term unemployment and can also account for much of the observed outward shift in the Beveridge curve. These conclusions are fairly robust to a variety of alternative assumptions, such as allowing duration dependence to vary over the business cycle, as suggested by the experimental results in Kroft, Lange and Notowidigdo (2013). On the other hand, our model has difficulty matching the observed relationship between vacancies and non-participation during the Great Recession. In particular, it predicts a job-finding rate for non-participants that is too high after 2008. Why N-to-E transitions fell so much more than expected (and continue to remain so low through 2013) therefore remains an important open question for future work.

To understand the relative importance of duration dependence and changes in (N-to-U, U-to-N, and Eto-N) transition rates in the model's ability to account for the observed increase in LTU and the observed outward shift in the Beveridge curve, we simulate the calibrated model "shutting down" each of these features one-by-one.

First, we shut down duration dependence by re-calibrating the model under the assumption that the job-finding rate is independent of unemployment duration. In this scenario, we find that the model accounts for much less of the rise in LTU and the observed outward shift in the Beveridge curve. We interpret this as evidence that duration dependence plays an important role in accounting for both of these phenomena.

Second, we shut down the exogenous non-participation flows by fixing these flows at the values observed at the end of 2007, and we find that the predicted LTU shares and unemployment rates both deviate substantially from our baseline calibrations. In particular, the counterfactual predictions show much less of an outward shift in Beveridge curve. The E-to-N flows are not central to this result, but U-to-N flows and particularly N-to-U flows play an important role. This closely relates to results in Elsby, Hobijn and Sahin (2013) who find that the flows from unemployment to non-participation explain close to one-third of the cyclical variation in the unemployment rate. Overall, our analysis suggests that changes in the flows from non-participation to unemployment (specifically, flows into long-term unemployment) play an

\footnotetext{
${ }^{5}$ In other words, we can "force" different vacancy rates on the model and evaluate how it performs quantitatively. This leads us to use the term "forcing variables" to describe the exogenous rates in our model.
} 
important role in the increase in the incidence of LTU after 2008.

One explanation for this finding centers around the very large UI extensions that took place during the Great Recession. Our results indicate that flows from unemployment to non-participation declined from about 20 percent monthly in 2008 to about 14 percent monthly in 2009 and only slowly recovered after 2009. We conjecture that many unemployed individuals may have remained in unemployment longer and are now classified as LTU (rather than being classified as non-participants). We also speculate that UI extensions may have played a role in causing many UI recipients to continue to consider themselves as labor force participants, even after many weeks of joblessness. This is consistent with the empirical findings of Rothstein (2011) and Farber and Valletta (2013). Our counterfactual estimates suggest that a large amount of the increase in unemployment with durations longer than 52 weeks might be attributable to the decline in the rate at which the unemployed became non-participants.

While our calibrated model can account for much of the outwards shift in the Beveridge curve, it does not provide a complete accounting of the shift. Davis, Faberman and Haltiwanger (2013) offer a promising explanation for the residual shift in the Beveridge curve not accounted for by our matching model, which focuses on the vacancy rate rather than the unemployment rate in the Beveridge curve . They find a reduction in "recruiting intensity" and in "effective vacancies", which may indicate continuing weak labor demand since the Great Recession. According to their research, employers are listing vacancies but are not recruiting workers as intensively to fill them (as in the recent past), implicitly waiting around for the "perfect" job candidates.

Our work closely relates to Elsby et al. (2011), who provide a thorough empirical exploration of longterm unemployment and non-participation in the Great Recession. An important difference is that our analysis is primarily based on a quantitative exploration of a calibrated matching model. One advantage of our model-based approach is that we can more readily conduct counterfactual scenarios to assess the relative importance of duration dependence and non-participation in accounting for the observed increase in longterm unemployment and the observed outward shift of the Beveridge curve. Our paper is also similar to subsequent research by Krueger, Cramer, and Cho (2014), who build on and extend our matching function to allow for differential effects by unemployment duration within the matching function and also allow for differential labor force withdrawal (i.e., U-to-N transitions) for the short-term and long-term unemployed. They evaluate whether the long-term unemployed exert differential pressure on wage growth and inflation.

Our work also relates to Barnichon and Figura (2013), who estimate a standard matching function over the period 1967-2012 and find that the predicted job-finding rate is much lower than the observed jobfinding rate during the Great Recession. Barnichon and Figura consider a generalized matching function 
incorporating worker heterogeneity (demographics, reason for unemployment and duration of unemployment) and labor market segmentation (geography and occupation group) and find that it matches observed job-finding rates during the Great Recession much more closely. While they consider a two-state model of the labor market and focuses primarily on job-finding rates, our paper considers a three-state model adding non-participation and also focuses more on the incidence of long-term unemployment.

Lastly, our paper is broadly related to an active literature in macroeconomics on the relative contributions of inflows into and outflows from unemployment to unemployment dynamics (Hall 2005; Shimer 2012; Elsby, Michaels and Solon 2009; Fujita and Ramey 2009; Barnichon 2012; Elsby, Hobijn and Sahin 2013). The emerging consensus from this literature is that the outflow contribution is at least 50 percent, but the literature is agnostic as to the factors behind falling outflows from unemployment. Our paper contributes to this literature by explicitly investigating two specific mechanisms behind the fall in the outflow rate: duration dependence and transitions in and out of the labor force. ${ }^{6}$

The remainder of the paper proceeds as follows. Section 2 describes the data. Section 3 investigates the role of composition. Section 4 describes the matching function that we use to investigate the role of duration dependence and non-participation. Section 5 describes the methodology for the model calibration. Section 6 presents the results of the model calibration. Section 7 reports the counterfactual scenarios and discusses alternative explanations. Section 8 concludes

\section{Data}

This section briefly describes our data sources. Appendix A provides more detail on the data used in our analysis.

Current Population Survey (CPS). We use monthly CPS data between 2002 and 2013 (ending in April 2013), limiting the sample to individuals between the ages of 25 to 55 . We focus on this prime-age sample to enable us to ignore issues of delayed labor force entry of younger workers and changes in retirement patterns of older workers. We use these CPS data in several ways. First, we use repeated cross-section data when investigating the role of composition, limiting the sample to unemployed workers. Second, we use both cross-section and panel data (merging individuals across months to build panel data) to investigate the role of duration dependence and non-participation. For this exercise, we use data on all employed,

\footnotetext{
${ }^{6}$ A related paper that takes into account negative duration dependence in job-finding rates is Hornstein (2012). Hornstein extends the framework in Shimer (2012) to allow for two types of unemployed workers: those with high exit rates from unemployment (the short-term unemployed) and those with low exit rates from unemployment (the long-term unemployed). The generalized framework is better able to account for long-term unemployment during recessions, whereas Shimer's framework with a homogenous job-finding rate significantly understates it. The extended framework also increases the inflow contribution to unemployment, relative to Shimer's study.
} 
unemployed, and non-participants. In the cross-section, we keep track of the total population of each category to estimate the "stocks." To create panel data, we match observations across successive months, matching on household identifier, line number, age, gender, and race. We use the matched panel data in addition to the CPS cross-sectional estimates of the unemployed, the employed, and non-participants to estimate the transition rates between unemployment, employment, and non-participation in each month. We also compute overall (pre-2008) transition rates by unemployment duration (into both employment and non-participation). Finally, we compute transition rates from employment and non-participation into unemployment by unemployment duration.

Job Openings and Labor Turnover Survey (JOLTS). We use monthly JOLTS data between 2002 and 2013 to compute the total number of vacancies. We use these vacancy data to calibrate the matching model below during the pre-2008 period. We then use the post-2008 vacancy data as one of the exogenous "forcing variables" for our counterfactual scenarios.

\section{Long-term Unemployment and the Great Recession: Assessing the Role of Composition}

Figure 1 shows that the share of the labor force that are long-term unemployed substantially increased during the Great Recession and has remained elevated. We next examine the rise in the share of the currently unemployed with duration exceeding 26 weeks and investigate the role of composition in accounting for this observed increase.

Figure 2 (Panel A) illustrates the dramatic increase in LTU as a share of overall unemployment. The long-term share increased from around 20 percent at the beginning of 2008 to roughly 45 percent in 2010 . Most of the increase occurred in 2009, a year after the recession began. Moreover, the share remained elevated at around 45 percent well after the recession officially ended. By comparison, the recession which began in 2001 saw this share increase from roughly 12 percent to 25 percent. Similar to the Great Recession, the share increased roughly a year after the recession began and remained elevated for several years after the recession officially ended. Nevertheless, the Great Recession was much deeper than the early 2000s downturn, and it had a substantially larger impact on the structure of unemployment durations.

In this section, we investigate the extent to which the increase in LTU during the Great Recession can be accounted for by shifting composition in observable characteristics of the unemployed. We do this by investigating the incidence of long-term unemployment, over time, for several demographic, industry, occupation, geographic, and reason-for-unemployment groups, along with each group's unemployment 
share.

Panel A of Figure 3 considers the education structure of the unemployed. It shows that the share of LTU in total unemployment is fairly similar across all education groups. During the recession, long-term unemployment uniformly increased across all education groups. Panel B of Figure 3 shows that high school graduates are a larger share of the unemployed than college graduates. During the Great Recession, there is a small increase in the share of college graduates among the unemployed. Despite this, since the rate of long-term unemployment is fairly flat across all education groups, shifts in the education structure of the unemployed cannot account for the changing unemployment duration dynamic during the Great Recession.

Online Appendix Figures OA1 through OA7 consider different observable characteristics. The impact of the Great Recession was widespread increasing the long-term unemployment share in all major demographic groups, industries, occupations, geographic regions, and reasons for unemployment. The long-term unemployment share also increased in groups by reason for unemployment (job losers, those on temporary layoff, job leavers, new entrants, and re-entrants). To quantify how much compositional shifts overall could have explained the rise in long-term unemployment, we hold fix the long-term unemployment rates for each group in the pre-2008 period, and investigate how much observed shifts in group shares can explain the overall rise in long-term unemployment. The aggregated evidence presented in Figure 4 shows that compositional changes in the unemployed account for virtually none of the observed rise in long-term unemployment. The rise in long-term unemployment is found for all major labor market groups and is not a demographically-isolated phenomenon.

\section{Matching Framework}

In this section, we outline our matching framework, which augments a standard matching model to allow for duration dependence in unemployment and flows to and from non-participation. We begin with a standard matching model of the labor market (Pissarides 1985; Mortensen and Pissarides 1994), which models fluctuations in the job-finding probability through a reduced-form matching function. We enrich this standard matching model to allow for duration dependence in unemployment and we allow a full set of transitions between employment $(\mathrm{E})$, unemployment $(\mathrm{U})$, and non-participation $(\mathrm{N}) .^{7}$

Our goal is to calibrate this model using data from before the Great Recession and assess how well it accounts for outflows from unemployment and non-participation into employment between 2008 and 2013. Throughout all of our analysis, we take the number of vacancies and inflows into unemployment and

\footnotetext{
${ }^{7}$ Recent research by Elsby et al. (2011) has highlighted the important role played by non-participants in understanding the dynamics of long-term unemployment during the Great Recession.
} 
non-participation as given. These are the exogenous "forcing variables" of the model. The endogenous variables are the full distribution of unemployment durations, the population shares in each labor market state, and the job-finding rates of the unemployed and non-participants.

To introduce the model, we begin with the following notation:

1. $P_{t}=$ population size ( $t$ is monthly calendar time), $\left\{E_{t}, U_{t}\right\}=$ number of employed and unemployed individuals with associated rates $\left\{e_{t}=\frac{E_{t}}{P_{t}}, u_{t}=\frac{U_{t}}{P_{t}}\right\}$. Note that the unemployment rate is defined relative to the total population (rather than the labor force), which imposes symmetry with the non-participation rate defined below.

2. $N_{t}=P_{t}-E_{t}-U_{t}=$ number of non-participants. Let the size of the labor force be denoted by $L_{t}=E_{t}+U_{t}$ and the non-participation rate by $n_{t}=\frac{N_{t}}{P_{t}}$.

3. $V_{t}=$ total number of job vacancies. The number of job vacancies is an exogenous forcing variable during 2008-2013 in the counterfactual scenarios we describe below.

4. Flows to unemployment: $\lambda_{t}^{E U}$ (employment $\rightarrow$ unemployment), $\lambda_{t}^{N U}$ (non-participation $\rightarrow$ unemployment). Both of these transition rates are forcing variables during 2008-2013.

5. Flows to employment: $\lambda_{t}^{U E}$ (unemployment $\rightarrow$ employment), $\lambda_{t}^{N E}$ (non-participation $\rightarrow$ employment). These job-finding rates are allowed to endogenously evolve during 2008-2013.

6. Flows to non-participation: $\lambda_{t}^{E N}$ (employment $\rightarrow$ non-participation), $\lambda_{t}^{U N}$ (unemployment $\rightarrow$ nonparticipation). Both of these transition rates are forcing variables during 2008-2013.

The Appendix provides more detail on how each of these transition rates are computed.

\subsection{Labor Market Flows During the Great Recession}

We begin by presenting descriptive evidence on labor market flows over time. Figure 5 plots the monthly transition rates to and from employment, unemployment, and non-participation. The measured transition rates are adjusted to be consistent with observed changes in stocks between months; Appendix B provides the details of this procedure. We also account for seasonality by residualizing out month fixed effects, and we smooth the series by taking three-month moving averages.

First, we see in Panel A that the monthly transition rates from unemployment to employment and non-participation dropped significantly during 2008. Starting in 2010, the flows from unemployment into non-participation began to recover and by the end of 2013 were close to their pre-recession levels. On 
the other hand, the job-finding rates of the unemployed (flows from unemployment to employment) have remained low following the Great Recession.

Second, Panel B shows that flows from employment to non-participation remained relatively flat during the Great Recession. Job losses leading to unemployment (employment to unemployment flows) spiked up in the Great Recession in 2008-9 and have slowly come back down in the recovery.

Third, Panel C shows that job-finding rates of non-participants (flows from non-participation to employment) dropped in 2008 and remained low through the end of 2013. While the job-finding rate for the unemployed declined sharply and bottomed out in 2009, the job-finding rate for non-participants fell more smoothly, and bottomed out in 2010. On the other hand, flows from non-participation to unemployment increased substantially in 2008 and remained high until the end of 2013. Interestingly, in the pre-Great Recession period, the outflow rate from non-participation to employment always exceeded the outflow rate to unemployment; however, during the Great Recession and at least through 2013, the opposite was true. We show below that accounting for flows from non-participation to unemployment during the Great Recession is important for understanding the dynamics of the unemployment rate. In particular, we find that ignoring changes in the $\mathrm{N}$-to- $\mathrm{U}$ and $\mathrm{U}$-to- $\mathrm{N}$ transition rates after 2008 results in a much smaller outward shift in the Beveridge curve according to our calibrated model. ${ }^{8}$

Flows from unemployment to employment are in part affected by flows from unemployment to nonparticipation. For example, if more of the unemployed individuals were to withdraw from the labor force, these individuals do not go from unemployment to employment at the same rate. To explore this issue, we define labor market flows for "indomitable job seekers" (Clark and Summers 1979) to be the ratio of U-to-E flows to the sum of U-to-E and U-to-U flows. This conceptually corresponds to a hypothetical unemployed job seeker who is unable to exit the labor force (and thus can only either transition to employment or remain unemployed, perhaps indefinitely). This "re-scaled" U-to-E transition rate is (mechanically) higher for indomitable job seekers as illustrated in Panel D of Figure 5; however, we also see a similarly sharp drop in the job-finding rate for this group during the Great Recession.

\subsection{Matching Function}

We adapt the standard matching function to allow non-participants to find jobs. We assume that nonparticipants and unemployed individuals meet job openings according to the function $M(U+s N, V)=$

\footnotetext{
${ }^{8}$ Additionally, we discuss below how many individuals flowing from non-participation to unemployment report longer unemployment durations after 2008.
} 
$m_{0}(U+s N)^{\alpha} V^{1-\alpha} \cdot{ }^{9} \quad$ One may interpret $s$ as the share of the non-participants that are "marginally attached" or alternatively as the search efficiency of non-participants relative to the unemployed, following Jones and Riddell $(1999,2006)$. According to their estimates, $s N$ is about 25-30 percent of the unemployed population, and they also find that $\lambda_{t}^{U E}$ is roughly twice as large as $\lambda_{t}^{N E}$.

We assume that the share of meetings with unemployed individuals is given by $U /(U+s N)$, while the remaining share is with non-participants. In addition, we assume (for the unemployed) that the probability that a meeting results in a hire depends on the duration of unemployment. In particular, $A(d)$ gives the relative hiring probability of an individual with unemployment duration $d$ as compared to a newly unemployed individual (with duration $d=0$ ). These assumptions imply that the job-finding rates for the unemployed and non-participants are given, respectively, by the following expressions:

$$
\begin{aligned}
\lambda_{t}^{U E}\left(x_{t} ; d\right) & =A(d) m_{0} x_{t}^{1-\alpha} \\
\lambda_{t}^{N E}\left(x_{t}\right) & =s m_{0} x_{t}^{1-\alpha}
\end{aligned}
$$

where $x_{t}=\frac{V_{t}}{U_{t}+s N_{t}}$ is a measure of labor market tightness and $d$ is the duration of unemployment. The parametric specification for $\lambda_{t}^{U E}(d)$ assumes that there is "true" duration dependence in job-finding rates out of unemployment; i.e., a genuine causal effect of longer unemployment durations on the hazard rate of exit out of unemployment (Heckman and Singer 1984).

We propose a parametric specification for $A(d)$ and estimate this function in the pre-Great Recession period, as we describe below. Let the probability density and distribution of ongoing unemployment durations be given by $\theta_{t}(d)$ and $\Theta_{t}$, respectively. By integrating over the duration distribution, we get the average job-finding rate for the unemployed:

$$
\begin{aligned}
\lambda_{t}^{U E}\left(x_{t}\right) & =\int \lambda_{t}^{U E}\left(x_{t} ; \tau\right) \theta_{t}(\tau) d \tau \\
\lambda_{t}^{U E}\left(x_{t}\right) & =m_{0} x_{t}^{1-\alpha} \int A(\tau) \theta_{t}(\tau) d \tau
\end{aligned}
$$

How does a recession affect the unemployment job-finding rate? In a recession, $x_{t}$ falls lowering $\lambda_{t}^{U E}\left(x_{t}, \tau\right)$ and hence $\lambda_{t}^{U E}\left(x_{t}\right)$. The fall in $\lambda_{t}^{U E}\left(x_{t}\right)$ affects $\theta_{t}(\tau)$ which can feed back into a lower $\lambda_{t}^{U E}\left(x_{t}\right)$ through duration dependence, and consequently a higher unemployment rate.

\footnotetext{
${ }^{9}$ Note that this equation is to be interpreted as a meeting function, not a matching function. Job meetings are converted into job matches according to equations (1) and (2) below.
} 
Note that

$$
\frac{\lambda_{t}^{U E}}{\lambda_{t}^{N E}}=\frac{\bar{A}_{t}}{s}
$$

where $\bar{A}_{t}=\int A(\tau) \theta_{t}(\tau) d \tau$. With empirical estimates for $\bar{A}_{t}$ and the job-finding rates, we can solve for $s=\bar{A}_{t} \frac{\lambda_{t}^{N E}}{\lambda_{t}^{U E}}$. The right-hand side varies with $t$, but we assume that $s$ is time-invariant, so we can simply take the average of this expression in the 2002-2007 to produce an estimate of $s$ to use in our calibrations. Note that we also assume that both $m_{0}$ and $A(d)$ are time-invariant: there are no cyclical changes in matching efficiency or cyclical variation in the magnitude of duration dependence. We explore alternative assumptions on how $A(d)$ varies over the business cycle in sensitivity analysis below, while cyclical variation in the matching efficiency parameter is studied in detail in Sahin et al. (2014).

\subsection{Labor Market Dynamics}

Given the transition rates between employment, unemployment and non-participation, we can express the dynamics of each of these populations as follows:

$$
\begin{aligned}
N_{t+1} & =N_{t}\left(1-\lambda_{t}^{N U}-\widehat{\lambda}_{t}^{N E}\right)+E_{t} \lambda_{t}^{E N}+U_{t} \lambda_{t}^{U N} \\
U_{t+1}(0) & =E_{t} \theta_{t}^{E U}(0) \lambda_{t}^{E U}+N_{t} \theta_{t}(0) \lambda_{t}^{N U} \\
U_{t+1}(d+1) & =U_{t}(d)\left(1-\widehat{\lambda}_{t}^{U E}(d)-\lambda_{t}^{U N}\right)+E_{t} \theta_{t}^{E U}(d) \lambda_{t}^{E U}+N_{t} \theta_{t}^{N U}(d) \lambda_{t}^{N U} \\
E_{t+1} & =P_{t}-U_{t+1}-N_{t+1}
\end{aligned}
$$

In these dynamic equations, we have placed carets ("^") above $\widehat{\lambda}_{t}^{N E}$ and $\widehat{\lambda}_{t}^{U E}(d)$ to emphasize that these rates are endogenous in our counterfactual simulations. When we construct the counterfactual scenarios, we assume that if non-participants move to unemployment, they draw an unemployment duration from the (empirical) distribution of unemployment durations estimated from observed N-to-U transitions (where the empirical distribution is re-estimated each quarter for three unemployment categories: [0-6) months, [6-12) months, and $\geq 12$ months). Similarly, we also account for the fact that a share of entrants into unemployment from employment report unemployment durations of 6 months or longer, so when employed workers move into unemployment, they draw an unemployment duration from the empirical distribution of unemployment durations (estimated analogously as for non-participants above). These two empirical distributions are $\theta_{t}^{N U}(d)$ and $\theta_{t}^{E U}(d)$, respectively. Since this share changes over time and increased during the Great Recession, we estimate these distributions in each year-quarter, and we use this time-varying distribution in our counterfactual simulations. 
In the next section, we examine the incidence of long-term unemployment and the Beveridge curve. The share of unemployed individuals at calendar time $t$ who have been out of work longer than $\tau$ weeks is given by:

$$
L T U_{t}^{\tau}=\frac{\sum_{d \geq \tau} U_{t}(d)}{U_{t}}
$$

where $U_{t}(d)$ is defined by equations (3) and (4). We use this as our measure of the share of unemployed individuals who are long-term unemployed, and we focus on $\tau=26$ weeks and $\tau=52$ weeks. When we plot the Beveridge curve, we plot the the total unemployed individuals as predicted by our model against the total observed number of job vacancies, normalizing both measures by the total population (i.e., $U_{t} /\left(E_{t}+U_{t}+N_{t}\right)$ and $\left.V_{t} /\left(E_{t}+U_{t}+N_{t}\right)\right)$. Since our matching model focuses on capturing job-finding rates of both unemployed and non-participants, we include the total population rather than the total labor force in the denominator.

\subsection{Counterfactual Scenarios}

The goal of our calibrations is to assess how far our enriched matching model can go in accounting for the rise in long-term unemployment and the outward shift in the Beveridge curve during the Great Recession. We also investigate the relationship between the non-participation rate and the vacancy rate. Our approach is to estimate the model fundamentals during 2002-2007 on monthly CPS (panel and pooled cross-sectional) data and then assess the model by comparing our counterfactual predictions to observed labor market outcomes during 2008-2013. We estimate duration dependence in the job-finding rate from unemployment (how $\lambda_{t}^{U E}$ varies with duration), the search effectiveness of the marginally attached $(s)$, and the overall matching efficiency $m_{0}$ and matching technology parameter $\alpha$. Our model uses as exogenous forcing variables shifts in labor demand - where labor demand is proxied for by $\left(V_{t}, \lambda_{t}^{E U}, \lambda_{t}^{E N}\right)$ - and shifts between unemployment and non-participation vs. unemployment, $\left(\lambda_{t}^{U N}, \lambda_{t}^{N U}\right)$. Thus, we fix the pattern of duration dependence, as reflected in $A(d)$, and we allow the job-finding rates $\lambda_{t}^{U E}(d)$ and $\lambda_{t}^{N E}$ - and consequently the entire distribution of unemployment durations - to evolve endogenously during the Great Recession. Our methodology follows Shimer (2005) by treating the separation rates of employed workers from their jobs, $\lambda_{t}^{E U}$ and $\lambda_{t}^{E N}$, as exogenous. Shimer also considers exogenous productivity shocks in his model which affects the equilibrium level of vacancies. We do not explicitly model the determination of vacancies; rather, we take a more reduced-form approach and instead treat vacancies as exogenous. Finally, we view flows between non-participation and unemployment as being "outside the model" since they may 
reflect factors such as the extension of UI benefits.

In terms of predicting the incidence of long-term unemployment, we rely on the cross-sectional share of workers with ongoing unemployment spells exceeding 26 and 52 weeks respectively. For predicting stocks of unemployment, employment, and non-participation over time, we use the dynamic equations above to simulate the model.

\section{Calibration Methodology}

We calibrate the model in the following steps:

1. We use data to estimate $\left\{\Theta_{t},\left\{\lambda_{t}^{U N}, \lambda_{t}^{U E}(d), \lambda_{t}^{E N}, \lambda_{t}^{E U}, \lambda_{t}^{N E}, \lambda_{t}^{N U}\right\}, V_{t}, U_{t}, N_{t}\right\}$. The Appendix describes how we estimate the transition rates $\lambda_{t}^{i j}$ from the monthly CPS cross-sections and the (matched) panel data component of the CPS.

2. An important issue is how we allocate flows from non-participation to unemployment of various durations. Elsby et al. (2011) show that roughly 60 percent of the inflows into unemployment at reported durations longer than 1 month originate from non-participation. It appears that there are marginally attached workers that alternate between unemployment and non-participation and when these workers return to unemployment, they often report a duration which may include time since they separated from their last employer, as opposed to duration of unemployment spell since last leaving non-participation. Panel A of Figure 6 sheds light on this issue by plotting the share of flows from non-participation to unemployment of a particular duration. We see that in the prerecession period, roughly half of the flows had durations less than or equal to one month; however, during the Great Recession, this share dropped substantially to around 30 percent. On the other hand, the share of flows with durations longer than 12 months increased from roughly 20 percent to over 30 percent. In light of this, we collapse the 2002-2013 data quarterly and each quarter we estimate the empirical distribution of unemployment durations that non-participants transition into. Therefore, for our post-2008 counterfactuals, we use this empirical distribution for each $\mathrm{N}-$ to- $\mathrm{U}$ transition implied by the dynamic equations of the model and the observed unemployment durations that the non-participants are transitioning into.

3. Another important issue is how we allocate flows from employment to unemployment of various durations. Panel $\mathrm{B}$ of Figure 6 plots the share of E-to-U flows going to a given unemployment duration. In interpreting the shares in this figure, note that the scale of the left (right) axis is for 
durations less than or equal to (greater than) one month. We see that in the pre-recession period, roughly 80 to 85 percent of the transitions from employment to unemployment report durations less than or equal to one month. However, this share falls to 70 percent during the Great Recession. We follow analogous procedure as in previous step, estimating the empirical distribution of unemployment durations that employed workers transition into (for each quarter), and we use this distribution in our counterfactual scenarios for each E-to-U transition.

4. We use the measured relative job finding rates at different durations $\left(\lambda_{t}^{U E}(d)\right)$ to estimate $A(d)$. For 2002-2007, we fit a curve through the empirical estimates of $\lambda_{t}^{U E}(d)$, normalized by $\lambda_{t}^{U E}(0)$, using the following functional form: $A(d)=\left(1-a_{1}-a_{2}\right)+a_{1} \exp \left(-b_{1} \times d\right)+a_{2} \exp \left(-b_{2} \times d\right)$. See panel A of Figure 7 for our preferred estimate of $\widehat{A}(d)$. The estimates reported in Table 1 are $\widehat{a_{1}}=0.314$, $\widehat{a_{2}}=0.393, \widehat{b_{1}}=1.085$ and $\widehat{b_{2}}=0.055$. We find that the job-finding rate declines sharply for the first 8-10 months of unemployment and then declines much less steeply after that. The declining job-finding rate with duration of unemployment can reflect "true" negative duration dependence in which the longer any individual is unemployed, the lower becomes the job-finding rate. Alternatively, it could reflect heterogeneity among the unemployed with the remaining pool of the unemployed being more negatively selected at longer durations. To investigate this, we re-estimate $A(d)$ controlling for a very rich set of observable characteristics available in the CPS: gender, fifth-degree polynomial in age, three race categories (white/black/other), five education groups (high school dropout, high school graduate, some college, college graduate, advanced degree), and gender interactions for all of the age, race, and education variables. When we control for these observable characteristics, we continue to find that the job-finding rate (conditional on observables) declines sharply with unemployment duration; moreover, the estimated decline is very similar to the results from estimating $A(d)$ without controls, as can be seen by comparing the solid line (with controls) to the dashed line (without controls) in Panel A of Figure 7.

Of course, these results do not rule out existence of unobserved heterogeneity - such as differences in recall rates to one's previous job as documented by Katz (1986), Katz and Meyer (1990), and Fujita and Moscarini (2013), which could partially explain the apparent negative duration dependence after controlling for standard CPS observables. Additionally, declining employer perceptions of the quality of the unemployed at longer unemployment durations could also play an important role and would be consistent with recent resume audit studies finding that job applications with longer employment gaps (longer duration of unemployment) get lower callback rates than those with implied shorter 
unemployment duration (Kroft, Lange, and Notowidigdo 2013; Eriksson and Rooth 2013; Ghayad 2013). We note that the pattern of negative duration dependence after controlling for the observables in the CPS in panel A of Figure 7 is fairly similar to the results of declining employer callback rates with unemployment duration in the audit study of Kroft, Lange and Notowidigdo (2013), which we also use in alternative counterfactual scenarios below. In our main results, we use the estimates of $A(d)$ which includes the large set of controls described above. The results of the alternative duration dependence estimates are reported in Table 2. Given the concerns about $A(d)$ not representing the causal effect of longer unemployment durations, we also make adjustments to $A(d)$ assuming that, say, $50 \%$ of the observe duration dependence reflects a genuine causal effect.

5. Next, we estimate the parameters of the matching function by minimizing the distance between the observed job-finding rates and the job-finding rates implied by the matching functions using monthly CPS and JOLTS data for 2002 to 2007. The implied job-finding rates for a given parameter vector $\left(s, m_{0}, \alpha\right)$, taking estimated parameters of $A(d)$ as given are the following:

$$
\begin{aligned}
& \lambda_{t}^{U E}\left(s, m_{0}, \alpha\right)=m_{0} \bar{A}_{t}\left(\frac{V_{t}}{U_{t}+s N_{t}}\right)^{1-\alpha} \\
& \lambda_{t}^{N E}\left(s, m_{0}, \alpha\right)=m_{0} s\left(\frac{V_{t}}{U_{t}+s N_{t}}\right)^{1-\alpha}
\end{aligned}
$$

The minimum distance estimates are reported in Table 1 and are as follows: $\widehat{\alpha}=0.753, \widehat{m_{0}}=0.435$, and $\widehat{s}=0.218$.

6. Finally, we use $\left\{V_{t}, \lambda_{t}^{E U}, \lambda_{t}^{E N}, \lambda_{t}^{U N}, \lambda_{t}^{N U}\right\}_{t \geq 1 / 2008}$ as the exogenous forcing variables to form our counterfactual predictions below.

\section{Calibration Results}

\subsection{Predicted Job-Finding Rates}

During the Great Recession, average job finding rates declined in part because average unemployment durations increased. Panel B in Figure 7 shows what happened to average job-finding rates due to the

increase in durations by plotting $\bar{A}_{t}=\int A(\tau) \theta_{t}(\tau) d \tau$ from 2002 to 2013 . $\bar{A}_{t}$ is a useful measure of the duration structure of unemployment since is summarizes how the duration structure affects the average job finding rate assuming that $A(d)$ describes the effect of unemployment duration on the job-finding rate. 
We use the estimated $A(d)$ which controls for the rich set of observable characteristics available in the CPS (gender, age, race, and education). To the extent that the recession shifted the unemployed towards longer durations, this will lower $\bar{A}_{t}$ since $A^{\prime}(\tau)<0 .{ }^{10}$

We see that starting in 2008 , there was a sharp drop in $\bar{A}_{t}$ from around 0.75 to roughly 0.63 (where $A(0)$ is normalized to 1 so that $A(d)$ can be interpreted as the relative job finding rate for high durations compared to the newly unemployed). This figure therefore shows that the indirect effect of a drop in market tightness on the average job-finding rate is quantitatively important, and suggests the possibility of a prominent role for negative duration dependence in the job-finding rate out of unemployment in accounting for changes in long-term unemployment share as well as outward shift in Beveridge curve.

In panels $\mathrm{A}$ and $\mathrm{B}$ of Figure 8, we plot the predicted and observed job-finding rates for the unemployed and non-participants, respectively. ${ }^{11}$ These transition rates are the two key endogenous variables of the model. By construction, the predicted rates match the observed rates in the pre-Great-Recession period. During the Great Recession, we see that the model does a reasonable job of predicting the job-finding rate for the unemployed; however, non-participants were not filling jobs at the rate they were predicted to during this time period. This suggests that there was something fundamentally different about the Great Recession in terms of its impact on individuals out of the labor force that is at odds with the behavior of this group in the pre-recession period. We investigate this issue below.

\subsection{Long-term Unemployment}

Panel A in Figure 9 investigates how well our calibrated model matches the observed increase in incidence of long-term unemployment. The calibrated model fits the data by construction up to the final quarter of 2007. From 2008 onwards, we use the job-finding rates for the unemployed and non-participants that are predicted by our model. We label the data generated by model as "Counterfactual." Panel A of Figure 9 shows that our model does very well in accounting for the observed increase in share of unemployed that are long-term unemployed, when long-term unemployment is defined to be $>26$ weeks. In panel B of Figure 9 , long-term unemployment is now defined to be $>52$ weeks. In this case, our model does not do quite as well, although it still accounts for a large share of the actual increase in long-term unemployment. The relatively poorer fit for LTU $>52$ weeks could be partly due to the fact that the estimated $A(d)$ - which controls how job-finding probability falls with unemployment duration - declines sharply during the first

\footnotetext{
${ }^{10}$ Note that this variable does not include the direct effect of market tightness on the average job-finding rate through the matching function; rather, it only includes the mechanical effect of changes in duration distribution on average job-finding rates.

${ }^{11}$ We refer to the job-finding rates estimated according to the method in Appendix B as "observed job finding rates" throughout the text.
} 
several months and declines much less steeply after that.

\subsection{Beveridge Curve}

Panel C of Figure 9 plots the Beveridge curve using unemployment and vacancy rates, where the denominator in each case is defined as total population between ages 25 and 55 . We plot two curves in this figure. The solid curve, labeled "Observed", plots the actual unemployment and vacancy rate in a given quarter. Next, the dotted curve, labeled "Counterfactual", plots the predicted unemployment along with the observed vacancy rate for the quarters starting with 2008Q1. The figure shows a significant spike in unemployment during the first quarter of 2008. At this point, vacancies were very low compared to the 2002-2007 period. However, even as vacancy rates recovered during 2010 and 2011, the number of unemployed declined only very slowly. It seems as if the Beveridge curve has shifted out. This is a manifestation of what has been dubbed the "jobless recovery." Overall, we see that our model also predicts an outward shift in the Beveridge curve during the Great Recession, although by not as much as observed. This is because while our model accounts for the rise in the long-term unemployed share of total unemployment, it somewhat under-predicts the overall unemployment rate.

\subsection{Non-Participation and Vacancies}

We next investigate the relationship between non-participation and vacancy rates. Panel D of Figure 9 is identical to panel $\mathrm{C}$ of Figure 9, except that we consider rates of non-participation instead of unemployment rates (where again the total population $P=L+N=E+U+N$ is the denominator). Although our model does a reasonably good job of describing the relationship between unemployment and vacancies, it does a very poor job of fitting the relationship between vacancy and non-participation rates. In particular, the model substantially under-predicts non-participation rates during the Great Recession. This is primarily due to the fact that the predicted job-finding rate for non-participants is too high.

\subsection{Alternative Assumptions Regarding Duration Dependence}

Our last sensitivity analysis examines whether our results are sensitive to using alternative estimates of duration dependence. These results are reported in Figure 10 where we compare the predicted increase in LTU defined as share of the unemployed with ongoing durations exceeding 26 weeks under several scenarios. In Panel A, we report results which estimate $A(d)$ from the CPS controlling for a rich set of observables as well as results which impose the $A(d)$ function which most closely matches the experimental 
estimates in Kroft, Lange and Notowidigdo (2013). One of the scenarios uses the experimental estimates from the overall sample, while another scenario allows $A(d)$ to vary with the unemployment rate. In our baseline calibration we assume that $A(d)$ is stable over the business cycle, while Kroft et al. (2013) present evidence which suggests that magnitude of duration dependence is smaller when the unemployment rate is relatively high. We therefore allow $A(d)$ to vary with the unemployment based on experimental estimates and calibrate model with this alternative assumption on duration dependence. Overall, we find that the predictions are fairly similar across these scenarios, reflecting the fact that the estimate of duration dependence in the CPS (with and without controls) is fairly similar to the experimental estimates in Kroft et al. (2013).

Next, in Panel B of Figure 10, we re-scale the CPS estimate of $A(d)$ by assuming that only a fixed percentage represents "true" duration dependence (i.e., a genuine causal effect of unemployment duration on job-finding rate). When we assume that only $50 \%$ of observed duration dependence is causal, we still find that our calibrated model can account for a large of the rise in LTU. This is because even in this scenario the job-finding rate still falls sharply over the first six months of unemployment.

\section{Counterfactual Scenarios}

\subsection{Ignoring Duration Dependence}

We next demonstrate that accounting for duration dependence in job-finding rates is crucial for this success in matching the data. To do this, we re-estimate the matching model setting $A(d)=1$. The results of this exercise are reported in Figure 11 where panels A and B report LTU shares and panels C and D report the Beveridge curve and the curve relating non-participation rates to vacancy rates, respectively. Panels A and B show that the predicted LTU from model calibration ignoring duration dependence is much lower than the predicted LTU we get when accounting for negative duration dependence in the exit rate from unemployment. Thus, duration dependence in job-finding rates is empirically important in understanding the historical increase in LTU during the Great Recession.

Turning to the Beveridge curve in Panel C, we see that the model does worse when ignoring duration dependence in terms of predicting the observed unemployment rate during the Great Recession. This is clear visual evidence that a standard matching model - without negative duration dependence - underpredicts unemployment. On the other hand, Panel D shows that the magnitude of duration dependence does not substantially affect predicted non-participation rates, although duration dependence does appear 
to begin to matter for calibrations during the last few quarters of the sample period. ${ }^{12}$

\subsection{Counterfactual Scenarios Ignoring Non-Participation}

Figure 12 considers a counterfactual which holds all flows to and from non-participation constant at their 2007 values (except for the N-to-E flow, which is determined endogenously by the matching function). It is evident from Panels A through $\mathrm{C}$ that ignoring the non-participation margin leads one to substantially under-predict overall unemployment and the structure of unemployment during the Great Recession. We also see in Panel D that rather than under-predicting non-participation rates as in baseline calibration, we now substantially over-predict these rates. Intuitively, by ignoring the increase in N-to-U flows and the decrease in U-to-N flows that occurred during the Great Recession, we instead predict non-participation rates that are much too high. Therefore, accounting for non-participation flows is crucial in understanding the dynamics of unemployment during the Great Recession. This is related to (and consistent with) the findings in Elsby, Hobijn and Sahin (2013) who report that the participation margin accounts for onethird of the cyclical variation in the unemployment rate. We next consider ignoring flows to and from non-participation one-by-one.

\subsubsection{Ignoring Changes in N-to-U}

We saw in Figure 5 that transitions from non-participation to unemployment rose significantly during the Great Recession. Moreover, we know from research by Elsby et al. (2011) that some of the transitions from non-participation to unemployment go to long durations. We next examine the importance of these flows by holding N-to-U rates fixed at their values in December 2007. Panels A and B of Online Appendix Figure OA8 show that the predicted long-term shares fall somewhat relative to the counterfactual which does not fix these flows. Additionally, when the N-to-U flows are fixed at their 2007 values, the model is less able to match the outward shift in the Beveridge curve. Overall, these transitions appear to be somewhat important to understanding the rise in long-term and overall unemployment during the Great Recession. ${ }^{13}$ Interestingly, the evidence in panel D suggests the alternative model is better able to explain the dynamics of non-participation.

\footnotetext{
${ }^{12}$ We also explored a counterfactual scenario where the distribution of unemployment durations is fixed at the level prevailing in December 2007. That is, we do not allow individuals to be pushed into longer durations by the recession, which would lower the average job-finding rate since the long-term unemployed have lower job-finding rates than the short-term unemployed. The results of this exercise are similar to those reported in Figure 11.

${ }^{13}$ It is worth emphasizing however, that if one were to form the counterfactuals by assuming that all transitions from non-participation to unemployment go to 0 months of duration, the prediction would be very poor.
} 


\subsubsection{Ignoring Changes in U-to-N}

Another fact about the Great Recession is that flows from unemployment to non-participation significantly declined, at least from 2008-2010. Elsby, Hobijn and Sahin (2013) document the procyclicality of these flows during recessions since 1970. They argue that in recessions, the composition of the unemployed shifts to those who are more "attached" to the labor market and that this explains three-quarters of the drop in the flow rate from unemployment to non-participation. ${ }^{14}$ We examine the importance of this change during the Great Recession by holding U-to-N rates fixed at their values in December 2007. The results are reported in Online Appendix Figure OA9 and show that the model somewhat under-predicts long-term unemployment and also the overall level of unemployment, at least until the end of 2010. Why are these flows so important for understanding long-term unemployment and the movement of the Beveridge Curve? Intuitively, if we assumed more transitions from unemployment to non-participation than was actually the case, this would lower the stock of the unemployed and lead to a lower unemployment rate.

\subsubsection{Ignoring Changes in E-to-N}

Finally, Online Appendix Figure OA10 investigates the flows from E-to-N, which were largely stable during the Great Recession, according to the results in Figure 5. Therefore, it is not surprising to see that the model predictions do not substantively change when we "shut down" changes in E-to-N flows by holding them at their December 2007 values.

\subsection{Comparison to 1981 Recession}

The 1981-82 recession generated double-digit unemployment similar to peak unemployment in the Great Recession, but long-term unemployment did not rise nearly as much in the early 1980s downturn. It is useful to consider what would have happened to long-term unemployment if vacancies had evolved as in the early 1980s recession as opposed to the way they evolved during the Great Recession. ${ }^{15}$ Panel A of Figure 13 shows the (relative) differences in evolution of vacancies between the two recessions. The vacancy data for the 1981 recession are filtered data from Help Wanted Index from Elsby et al. (2011). Compared to vacancies during the Great Recession, in the early 1980s vacancies fell by roughly the same order of magnitude but rebounded much more quickly. Panel B in Figure 13 displays the model predictions for LTU using vacancies in 1981 recession as the forcing variable in the model (in place of 2008 recession). We

\footnotetext{
${ }^{14}$ Their novel measure of labor market attachment is based on whether an individual was employed one year prior to the CPS survey.

${ }^{15}$ We also ignore observed changes in N-to-U, U-to-N, and E-to-N flows in this counterfactual exercise (i.e., fixing values of the flows at their 2007 values).
} 
see that the predicted long-term unemployment share is much lower than the share predicted during the Great Recession. Thus, our model is able to provide an explanation for why LTU rose much more sharply in the Great Recession as compared to the 1981-82 recession, arising from a more sustained decline and much weaker recovery in labor demand (as reflected in the vacancy rate).

\subsection{The Beveridge Curve and Long-term Unemployment}

Ghayad and Dickens (2012) consider the recent outward shift in the Beveridge curve and note that it occurred over a period less than one year as compared to the roughly eight years it took for the Beveridge curve to shift in the recession of the 1970s. They also note that if one constructs separate Beveridge curves, for the short-term and long-term unemployed, all of the movement in the aggregate Beveridge curve is relative to the long-term unemployment rate. This is mechanically related to the duration-specific unemployment rates presented in Figure 1 above.

Our findings can help account for these findings. First, we saw that long-term unemployment increased rapidly over a short-period of time. This change, combined with negative duration dependence in jobfinding rates, helps explain the fast shift in the Beveridge curve. To shed light on the second finding, in Online Appendix Figure OA11 we plot two separate Beveridge curves, one for the short-term unemployed (Panel A) and one for the long-term unemployed (Panel B). Similar to Ghayad and Dickens (2012), we see that the shift in the overall Beveridge curve is due to the shift in the Beveridge curve for the long-term unemployed. We also see that our model is unable to completely account for this shifts in both curves. In particular, it tends to predict too large a drop in unemployment for the later years of the Great Recession for both curves. The next section provides some explanations for the difficulty of the model to fully explain some of the stylized facts of the Great Recession.

\subsection{Alternative Explanations}

Our results indicate that our model can account for unemployment dynamics reasonably well but has a harder time matching dynamics among non-participants. One possibility is that those who drop out of the labor force during the Great Recession may be less marginally attached (less likely to be interested in work) than those who drop out during normal times. In other words, it might be the case that $s$ falls during the Great Recession in a way that we are not accounting for in the matching framework and this could explain some of the discrepancy.

We examine this possibility in Panel A of Figure 14 which plots the share of non-participants who 
are "discouraged" and the share of non-participants who report that they want a job. The figure shows that, starting in 2008, both increased sharply. This suggests that $s$ actually increased during the Great Recession, and that if we were to account for this change in our matching framework, then our modelbased predictions would likely be even worse. Panel B of Figure 14 plots the transition rates from nonparticipation to employment - for those who report that they want to work. We see that for this group, the job-finding rate fell during the Great Recession. We are thus left with an incomplete understanding of why non-participants did not find jobs at the rate predicted by our calibrated model.

We conclude with several speculative thoughts regarding other possible explanations of the lowerthan-expected job-finding rate of non-participants. First, our model does not capture the possibility of negative duration dependence in job-finding rates for non-participants; the model only allows for duration dependence in unemployment. Recent work by Autor et al. (2013) reports strong evidence that additional months out of the labor force has a negative causal effect on probability of employment. ${ }^{16}$ Unfortunately, we cannot readily estimate such duration dependence in the job-finding rate of labor market non-participants since the CPS does not record time spent out of the labor force. Second, our model ignores factors such as the recent rise in SSDI applications and SSDI rolls in the Great Recession. Third, the dynamics of our calibrated matching model may possibly obscure other changing features of the labor market during times of weak aggregate demand. For example, models of "queuing" and "ranking" may feature discouraged and/or marginally attached workers ending up at the end of the queue and this could lead to long-term joblessness (Okun 1973; Blanchard and Diamond 1994). Finally, some adult workers may be returning to school and/or job training and not looking for work (Barr and Turner 2012). This would represent a compositional change that would reduce the job-finding rate for non-participants in a way that could potentially account for the residual decline not accounted for by our calibrated model.

\section{Conclusion}

Both short-term and long-term unemployment increased sharply in 2008-9 during the Great Recession. But while short-term unemployment returned to normal levels by 2013, long-term unemployment remains at historically high levels in the aftermath of the Great Recession. We showed that long-term unemployment increased for virtually all groups, and shifts in observable characteristics of the unemployed do not go very far in accounting for the rise in long-term unemployment.

\footnotetext{
${ }^{16}$ While this surely can account for some of the discrepancy, we showed that ignoring duration dependence for the unemployed causes us to under-predict unemployment, but the gap between predicted and observed in this case is less than the gap between predicted and observed for non-participants.
} 
By contrast, an enriched matching model that allows for duration dependence in unemployment and transitions between employment (E), unemployment (U), and non-participation (N) can account for almost all of the increase in the incidence of LTU and much of the observed outward shift in the Beveridge curve between 2008 and 2013. We emphasize that duration dependence is not the primary force behind rising LTU in the Great Recession per se; rather, duration dependence serves to reinforce and amplify the initial labor demand shock which shifted the distribution of unemployment durations. Our results suggest that both negative duration dependence in the job-finding rate out of unemployment and transitions to (and from) non-participation may play an important part in understanding both the rise in LTU as well as the observed outward shift in the Beveridge curve.

Much evidence suggests that there is sizeable causal negative duration dependence in the escape rate from unemployment. The longer one has been unemployed, the less likely one is to get a callback from an employer and job search effort also is likely to decline. A strong negative labor demand shock like from a major financial crisis and/or from consumer, firm, and lender behaviors can build up the stock of the long-term unemployed. Negative duration dependence means that the long-term unemployed are less effective job seekers than the short-term unemployed. Thus, the rise in long-term unemployment itself can help explain much of the outward shift in the traditional Beveridge curve following the Great Recession. Essentially, the overall matching efficiency of labor market is reduced when the incidence of long-term unemployment is high. This is not the whole story, however. Firms continue to worry about demand conditions and have lowered their recruiting intensity for posted vacancies (Davis, Faberman, and Haltiwanger 2013), further contributing to the outward Beveridge Curve shift and the persistence of the low flows from unemployment to employment in the aftermath of the Great Recession. 


\section{References}

Autor, David, Nicole Maestas, Kathleen Mullen and Alexander Strand (2013). "Does Delay Cause Decay? The Effect of Administrative Decision Time on the Labor Force Participation and Earnings of Disability Applicants," Working Paper.

Barnichon, Regis (2012). "Vacancy Posting, Job Separation, and Unemployment Fluctuations," Journal of Economic Dynamics and Control, 36(3): 315-330.

Barnichon, Regis and Andrew Figura (2013). "Labor Market Heterogeneity and the Aggregate Matching Function," Working Paper.

Barr, Andrew and Sarah Turner (2012). "Down and Enrolled: An Examination of the Enrollment Response to Cyclical Trends and Job Loss," University of Virgina, December.

Blanchard, Olivier J. and Peter Diamond (1994). "Ranking, Unemployment Duration, and Wages," Review of Economic Studies, 61(3), 417-434.

Card, David and W. Craig Riddell (1993). "A Comparative Analysis of Unemployment in Canada and the United States," NBER Chapters, in: Small Differences That Matter: Labor Markets and Income Maintenance in Canada and the United States, 149-190.

Clark, Kim B. and Lawrence H. Summers (1979). "Labor Market Dynamics and Unemployment: A Reconsideration," Brookings Papers on Economic Activity, 1: 13-60.

Congressional Budget Office (2012). "Understanding and Responding to Persistently High Unemployment." http://www.cbo.gov/publication/42989.

Davis, Steven J., R. Jason Faberman, and John C. Haltiwanger (2013). "The Establishment-Level Behavior of Vacancies and Hiring," Quarterly Journal of Economics, 128(2): 581-622.

Elsby, Michael W., Ryan Michaels, and Gary Solon (2009). "The Ins and Outs of Cyclical Unemployment," American Economic Journal: Macroeconomics, 1(1): 84-110.

Elsby, Michael W., Bart Hobijn, and Aysegul Sahin (2010). "The Labor Market in the Great Recession," Brookings Papers on Economic Activity, Spring, 1-69.

Elsby, Michael W., Bart Hobijn, Aysegul Sahin, and Robert G. Valletta (2011). "The Labor Market in the Great Recession - An Update to September 2011," Brookings Papers on Economic Activity, 353-371.

Elsby, Michael W., Bart Hobijn, and Aysegul Sahin (2013). "On the Importance of the Participation Margin for Labor Market Fluctuations," Working Paper.

Eriksson, Stefan and Dan-Olof Rooth (2013). "Do Employers Use Unemployment as a Sorting Criterion When Hiring? Evidence from a Field Experiment." American Economic Review, forthcoming.

Farber, Henry S. and Robert G. Valletta (2013). "Do Extended Unemployment Benefits Lengthen Unemployment Spells? Evidence from Recent Cycles in the U.S. Labor Market," Federal Reserve Working Paper.

Flinn, Christopher J. and James J. Heckman (1983). "Are Unemployment and Out of the Labor Force Behaviorally Distinct Labor Force States?" Journal of Labor Economics, 1(1): 28-42.

Fujita, Shigeru and Garey Ramey (2009). "The Cyclicality of Separation and Job Finding Rates," International Economic Review, 50(2): 414-430.

Fujita, Shigeru and Giuseppe Moscarini (2013). "Recall and Unemployment." http://conference. 
nber.org/confer/2013/EFGs13/Fujita_Moscarini.pdf.

Ghayad, Rand and William Dickens (2012). "What Can We Learn by Disaggregating the UnemploymentVacancy Relationship?" Federal Reserve Working Paper.

Ghayad, Rand (2013). "Why is it so Hard for Job-Seekers With Valuable Experience to Find Work? Evidence from a Field Experiment," Northeastern Working Paper.

Hall, Robert E. (2005). "Job Loss, Job Finding, and Unemployment in the U.S. Economy Over the Past Fifty Years," NBER Macroeconomics Annual 20: 101-137.

Heckman, James J. and Burton Singer (1984). "The Identifiability of the Proportional Hazard Model," Review of Economic Studies, 51(2): 231-241.

Hornstein, Andreas (2012). "Accounting for Unemployment: The Long and Short of it." Federal Reserve Working Paper.

Jones, Stephen R. G. and W. Craig Riddell (1999). "The Measurement of Unemployment: An Empirical Approach," Econometrica, 67(1): 147-162.

Jones, Stephen R. G. and W. Craig Riddell (2006). "Unemployment and Nonemployment: Heterogeneities in Labor Market States," The Review of Economics and Statistics, 88(2): 314-323.

Katz, Lawrence F. (1986) "Layoffs, Recall and the Duration of Unemployment", NBER WP No. 1825.

Katz, Lawrence F. and Bruce D. Meyer (1990). "Unemployment Insurance, Recall Expections, and Unemployment Outcomes," Quarterly Journal of Economics, 105(4): 973-1002.

Kroft, Kory, Fabian Lange and Matthew J. Notowidigdo (2013). "Duration Dependence and Labor Market Conditions: Evidence from a Field Experiment," Quarterly Journal of Economics, 128(3): 11231167.

Krueger, Alan B., Judd Cramer, and David Cho (2014). "Are the Long-Term Unemployed on the Margins of the Labor Market?" Brookings Papers on Economics Activity, forthcoming.

Mortensen, Dale T. and Christopher A. Pissarides (1994). "Job Creation and Job Destruction in the Theory of Unemployment," Review of Economic Studies, 61(3): 397-415.

Okun, Arthur M. (1973). "Upward Mobility in a High-Pressure Economy," Brookings Papers on Economic Activity, 4(1): 207-262.

Pissarides, Christopher A. (1985). "Short-run Equilibrium Dynamics of Unemployment, Vacancies, and Real Wages," American Economic Review, 75: 676-90.

Rothstein, Jesse (2011). "Unemployment Insurance and Job Search in the Great Recession," Brookings Papers on Economic Activity, 43(2): 143-213.

Sahin, Aysegul, Joseph Song, Giorgio Topa, and Giovanni L. Violante. "Mismatch Unemployment," American Economic Review, forthcoming.

Shimer, Robert (2005). "The Cyclical Behavior of Equilibrium Unemployment and Vacancies," American Economic Review, 95(1): 25-49.

Shimer, Robert (2012). "Reassessing the Ins and Outs of Unemployment," Review of Economic Dynamics, 15: 127-148. 


\section{Appendix A: Data Sources}

These are the data sources used for both calibration (which only uses pre-1/2008 data) and counterfactual estimation (which uses post-1/2008 data):

- $\Theta_{t}$ (duration distribution): CPS monthly data from 1/2002-1/2013. We estimate the unemployment duration distribution monthly for all unemployed adults aged 25-55. We group all unemployment durations greater than or equal to 24 months together in a single category, and the rest of the durations are grouped by month.

- $V_{t}$ (vacancies): JOLTS monthly data between $1 / 2002$ and $1 / 2013$. We use the seasonally unadjusted data released by the BLS and residualize out month fixed effects to account for seasonality.

- $U_{t}, E_{t}, N_{t}$ (stocks of unemployed, employed, and non-participants): CPS monthly data between $1 / 2002$ and $1 / 2013$. We use CPS survey weights to estimate stocks in each month for each group for our baseline sample of adults aged 25-55.

- $\left\{\lambda_{t}^{U E}, \lambda_{t}^{U N}, \lambda_{t}^{E U}, \lambda_{t}^{E N}, \lambda_{t}^{N E}, \lambda_{t}^{N U}\right\}$ (transition rates between E/U/N): CPS monthly data between $1 / 2002$ and 1/2013. See Appendix B below for more details on construction of these panel transition rates, which are based on matching individual across months as in Shimer (2012).

- $A(d)$ (duration dependence function): We estimate $A(d)$ in several ways. For main results, we use job-finding rate for unemployed workers (by unemployment duration in months) pooling all monthly CPS data between $1 / 2002-12 / 2007$. The job-finding rate is defined as the monthly probability that a given unemployed job seeker reports employment in both of the following two months (the requirement of two months follows Rothstein 2011; see references therein for discussion and justification). For robustness, we also use estimates of $A(d)$ from the experimental data in Kroft, Lange, and Notowidigdo (2013); see main text for more details.

Using the data sources above, we calibrate $\alpha, m_{0}, s$ (matching function parameters using data from before $1 / 2008$. See main text for more details.

\section{Appendix B: Identification of Transition Rates from CPS}

In this section, we will describe how we identify the transition rates $\left\{\lambda_{t}^{U E}, \lambda_{t}^{U N}, \lambda_{t}^{E U}, \lambda_{t}^{E N}, \lambda_{t}^{N E}, \lambda_{t}^{N U}\right\}$. The straightforward approach is to recover them from the CPS panel, however we found that these rates are not consistent with the levels of unemployment, employment and non-participation in each period. Here we describe a procedure which ensures consistency by brute force. The only requirement is the assumption that the relative flow rates from the CPS panel are correct. The steps of this procedure are as follows:

1. Normalize the population so that $N_{t}+U_{t}+E_{t}=1$ in each period.

2. Obtain the levels $\left\{N_{t}, U_{t}, E_{t}\right\}$ and net flows $\left\{\Delta N_{t}, \Delta U_{t}, \Delta E_{t}\right\}$ from the data. Note that $\Delta N_{t}+\Delta U_{t}+$ $\Delta E_{t}=0$ so without loss of generality, we will work with $\Delta N_{t}$ and $\Delta E_{t}$. 
3. Obtain $U_{t+1}(d=0)$, the (normalized) number of newly unemployed, as well as $\theta_{t}(d=0)$, from the data.

4. Let the transition rates $\left\{\lambda_{t}^{U E}, \lambda_{t}^{U N}, \lambda_{t}^{E U}, \lambda_{t}^{E N}, \lambda_{t}^{N E}, \lambda_{t}^{N U}\right\}$ be unknown parameters.

5. We have by definition:

$$
\begin{aligned}
\Delta N_{t} & =\lambda_{t}^{U N} U_{t}+\lambda_{t}^{E N} E_{t}-\left(\lambda_{t}^{N U}+\lambda_{t}^{N E}\right) N_{t} \\
\Delta E_{t} & =\lambda_{t}^{U E} U_{t}+\lambda_{t}^{N E} N_{t}-\left(\lambda_{t}^{E U}+\lambda_{t}^{E N}\right) E_{t} \\
U_{t+1}(d & =0)=\lambda_{t}^{E U} \theta^{E U}(d=0) E_{t}+\lambda_{t}^{N U} \theta_{t}(d=0) N_{t}
\end{aligned}
$$

6. This leaves us with six unknown parameters in three equations.

7. To identify the parameters, we will impose three additional restrictions which require that the relative transition rates between states are identified from the panel data. Let the observed relative transition rate for state $X$ in time period $t$ be denoted by $\psi_{t}^{X}$ :

$$
\begin{aligned}
\psi_{t}^{N} & =\frac{\lambda_{t}^{N U}}{\lambda_{t}^{N E}} \\
\psi_{t}^{E} & =\frac{\lambda_{t}^{E N}}{\lambda_{t}^{E U}} \\
\psi_{t}^{U} & =\frac{\lambda_{t}^{U N}}{\lambda_{t}^{U E}}
\end{aligned}
$$

This leaves us with the following system of equations:

$$
\left(\begin{array}{cccccc}
E_{t} & 0 & U_{t} & 0 & -N_{t} & -N_{t} \\
-E_{t} & -E_{t} & 0 & U_{t} & 0 & N_{t} \\
0 & \theta^{E U}(d=0) E_{t} & 0 & 0 & \theta_{t}(d=0) N_{t} & 0 \\
0 & 0 & 0 & 0 & 1 & -\psi_{t}^{N} \\
0 & 0 & 1 & -\psi_{t}^{U} & 0 & 0 \\
1 & -\psi_{t}^{E} & 0 & 0 & 0 & 0
\end{array}\right) \times\left(\begin{array}{c}
\lambda_{t}^{E N} \\
\lambda_{t}^{E U} \\
\lambda_{t}^{U N} \\
\lambda_{t}^{U E} \\
\lambda_{t}^{N U} \\
\lambda_{t}^{N E}
\end{array}\right)=\left(\begin{array}{c}
\Delta N_{t} \\
\Delta E_{t} \\
U_{t+1}(d=0) \\
0 \\
0 \\
0
\end{array}\right)
$$

8. We recover $A(d)$ from the panel data job-finding rates for the unemployed. 


\section{Table 1}

\section{Model-Based Estimates}

Duration Dependence Parameters

$a_{1}$ (intercept parameter 1 )

$a_{2}$ (intercept parameter 2)

$b_{1}$ (slope parameter 1$)$

$b_{2}$ (slope parameter 2)

$$
A(d)=\left(1-a_{1}-a_{2}\right)+a_{1} \exp \left(-b_{1} \times d\right)+a_{2} \exp \left(-b_{2} \times d\right)
$$

\section{Matching Model Parameters}

$\alpha$

$m_{0}$ (scale parameter)

$s \quad$ (relative search intensity of inactive)

$$
M(U+s I, V)=m_{0}(U+s I)^{\alpha} V^{1-\alpha}
$$

Notes: This table reports the model-based estimates using monthly CPS data and JOLTS data from 2002-2007. See main text for more details. These parameter estimates are used to create the counterfactual predictions reported in the figures. 


\section{Table 2}

\section{Alternative Duration Dependence Estimates}

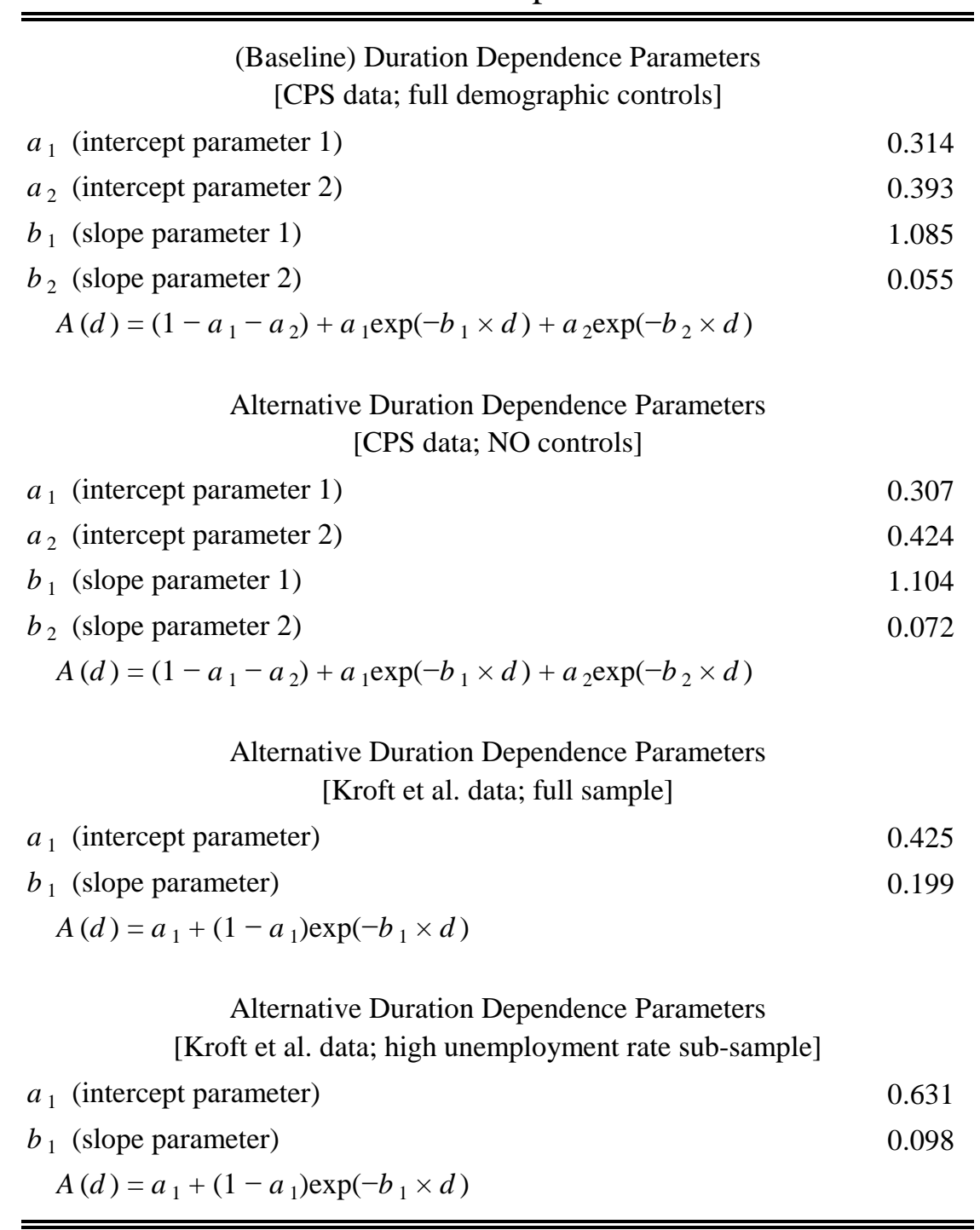

Notes: This table reports the duration dependence estimates used in alternative scenarios reported in main figures. In first two panels, the data used to estimate parametric function listed in panel are monthly CPS data from 2002-2007. In bottom panels, the data are from the resume audit study Kroft et al. (2013). 
Figure 1: Short-term, Medium-term, and Long-term Unemployment in the U.S., 1948-2013

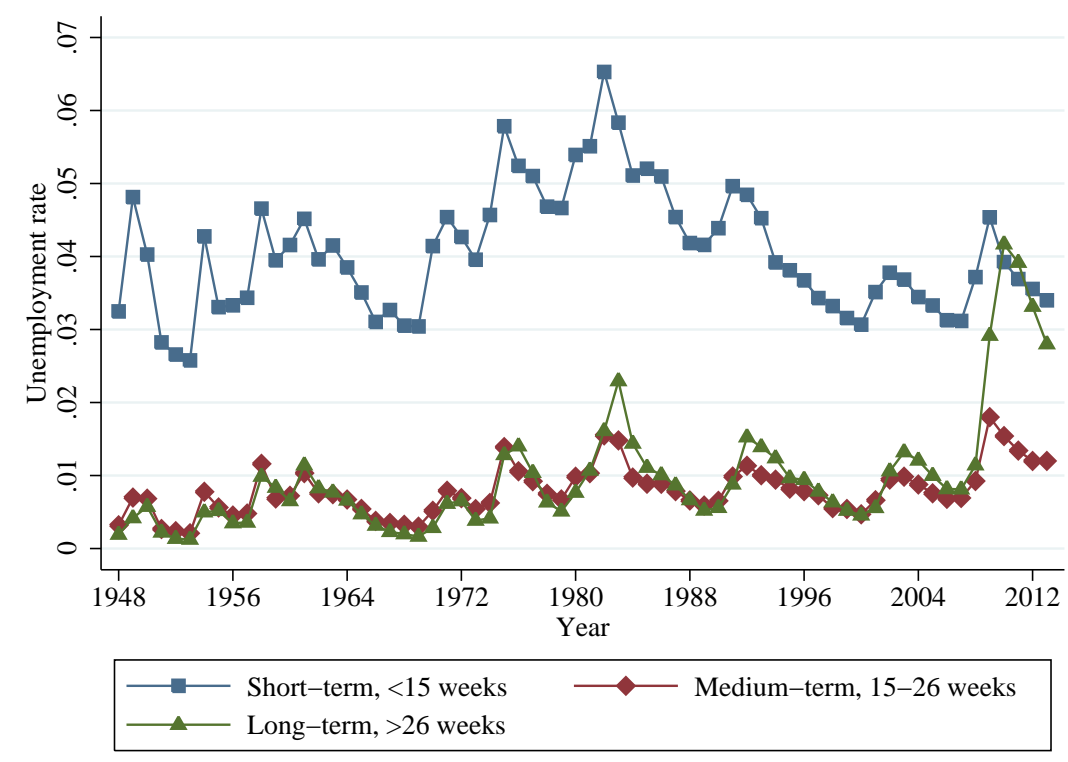

Notes: This figure shows the unemployment rate decomposed into short-term unemployment (less than 15 weeks), mediumterm unemployment (15-26 weeks), and long-term unemployment (greater than 26 weeks). The data come from the BLS. 
Panel A: Long-term Unemployment Share in the U.S., 2000-2013

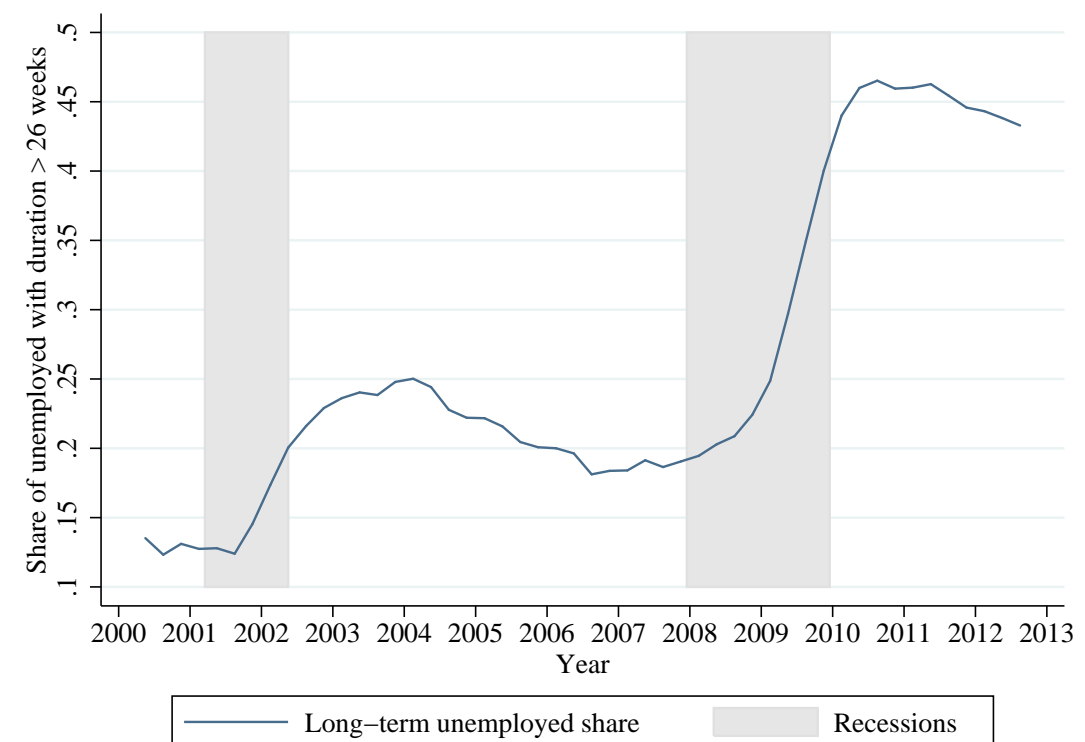

Panel B: The Beveridge Curve in the U.S., 2000-2013

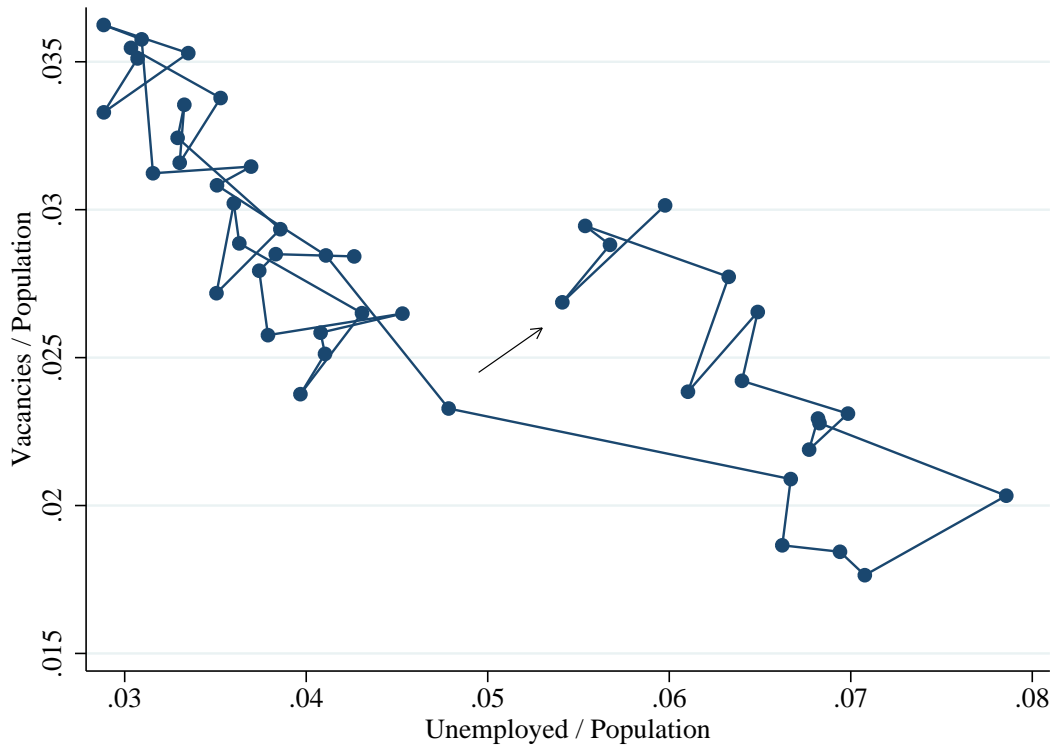

Notes: This figure uses data from the CPS and from JOLTS. Panel A shows the share of unemployed workers aged 25-55 that have unemployment durations of more than 26 weeks. The pooled, cross-sectional data come from monthly CPS surveys. In this panel and in Figures 3 through 5, month fixed effects have been residualized out of the data to account for seasonality, and the data are smoothed by taking a three-month average around each observation. Panel B shows the Beveridge curve, the relationship between unemployment and vacancies, with both series normalized by the total population (i.e., labor force plus non-participants). The arrow in panel B indicates the apparently outward movement of the Beveridge curve after 2008. 
Figure 3: Long-term Unemployment by EduCAtion

Panel A: Long-term unemployment share

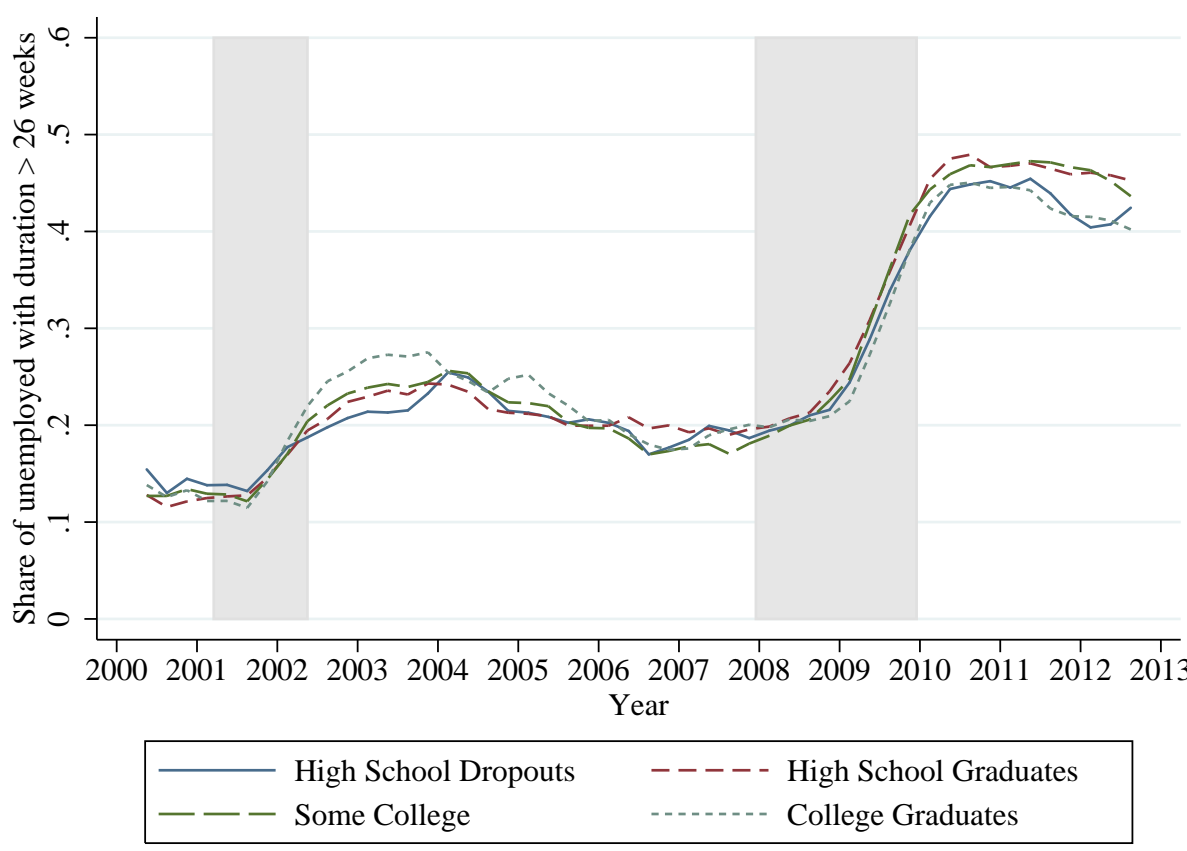

Panel B: Relative share of unemployed

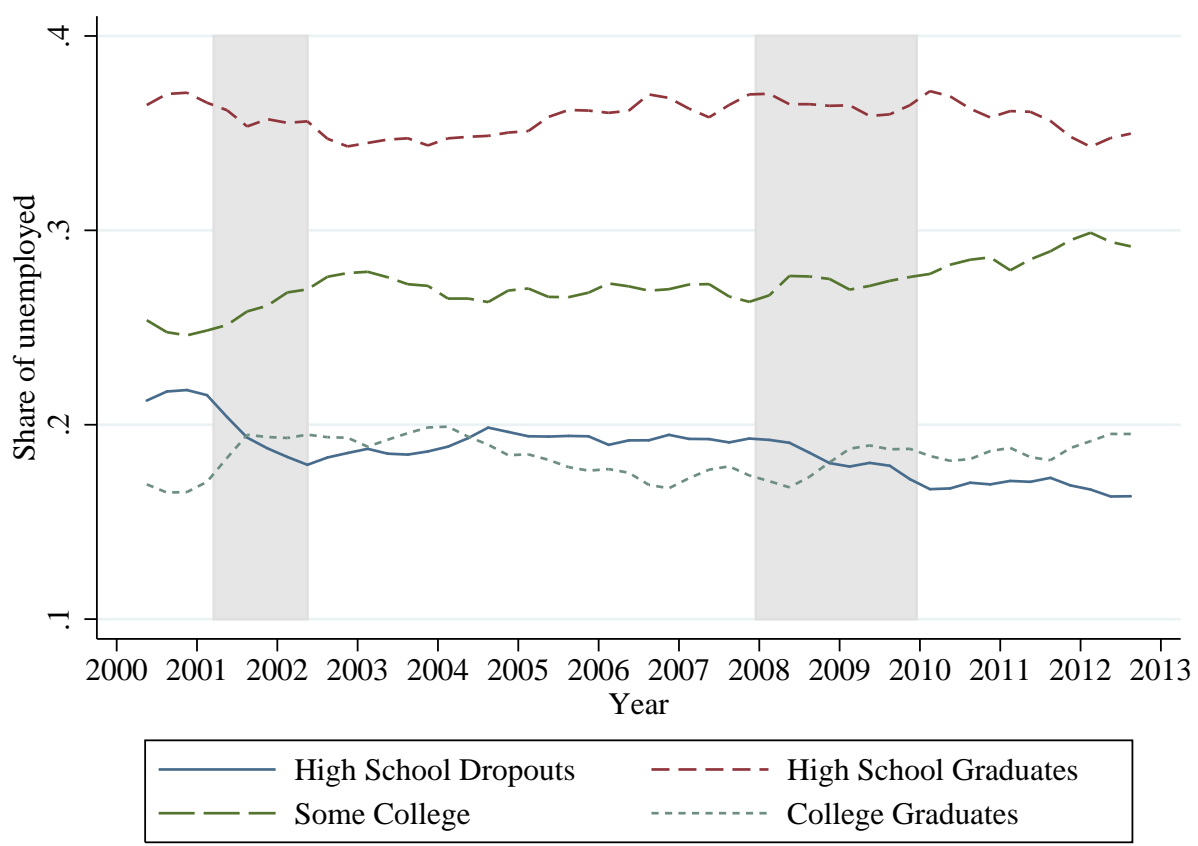

Notes: These figures use data from the CPS. See notes to Figure 2 for more information. 


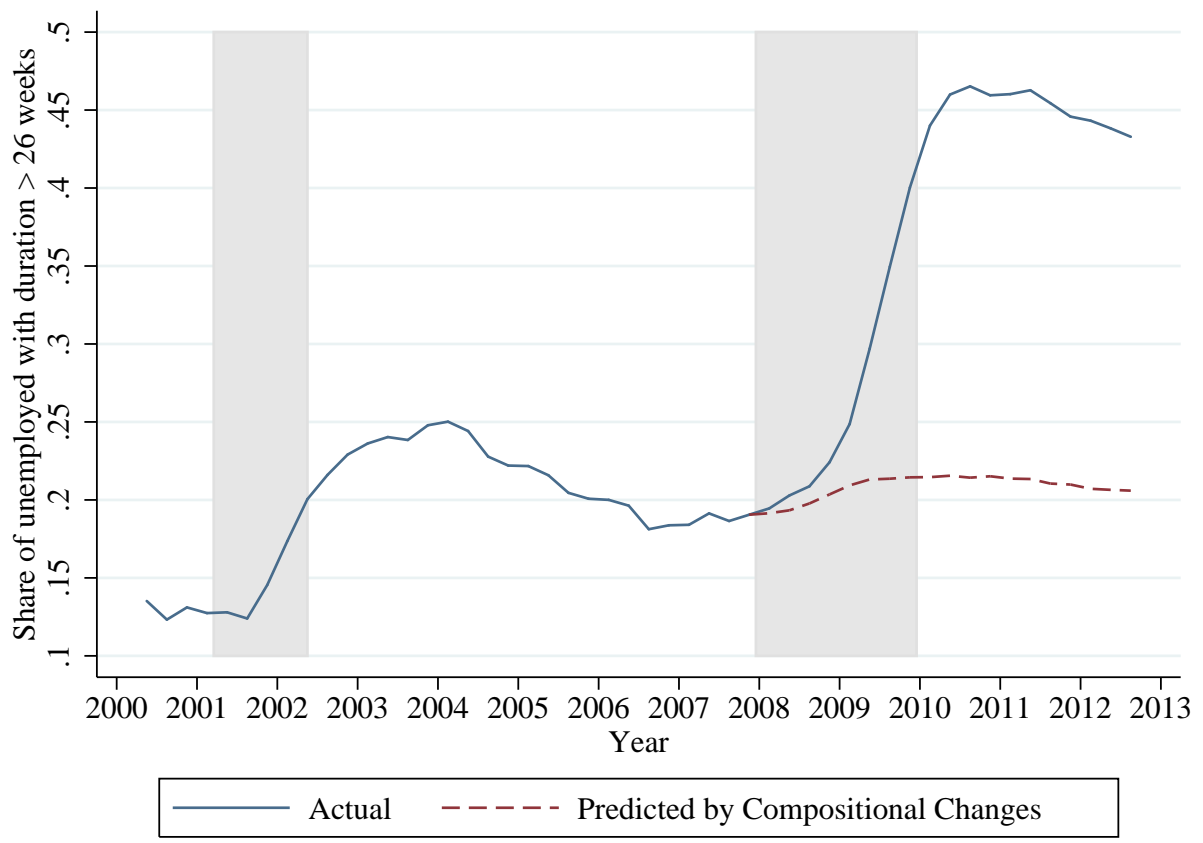

Notes: This figure uses data from the CPS that are summarized in Figure 3 and Online Appendix Figures OA1 through OA7 in order to estimate the role of composition. The predicted long-term unemployment share is calculated by multiplying the pre-2008 average LTU share by demographic group by the change in the share of unemployed with that characteristic. This procedure is repeated for each observable characteristic (e.g., education, age, gender, etc.) described in Figures 3 and OA1-OA7 to construct the prediction shown in this figure. 
Figure 5: Transition Rates Between Employment, Unemployment, and Non-Participation

Panel A: Transitions from Unemployment

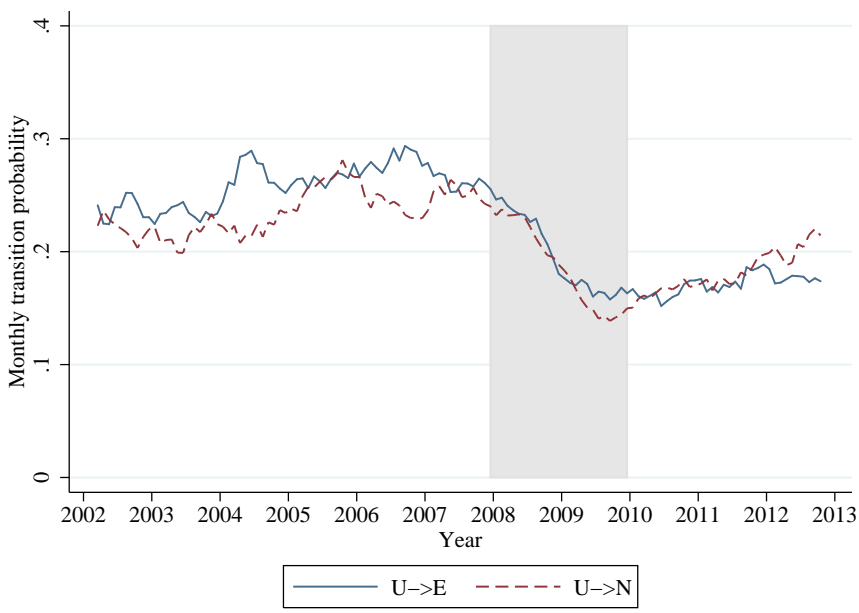

Panel C: Transitions from Non-Participation

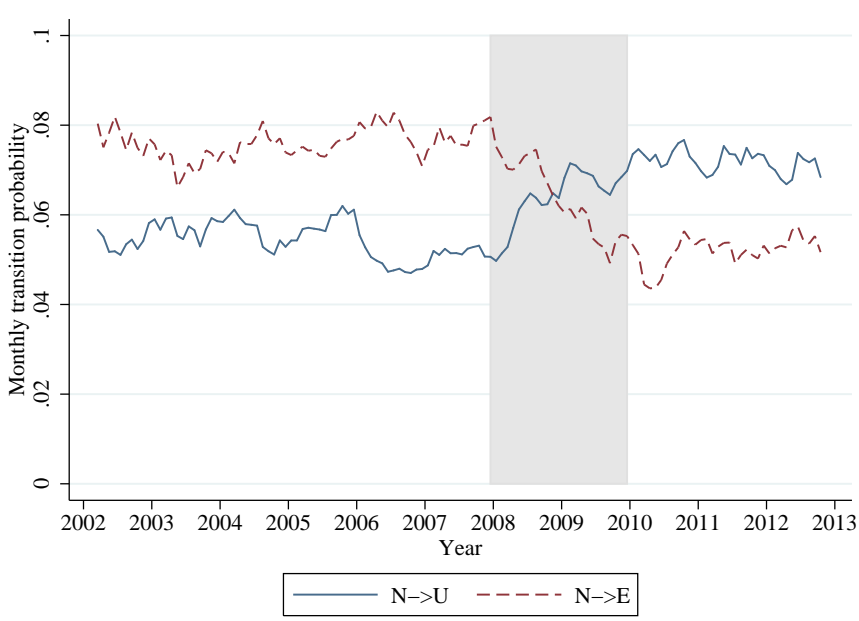

Panel B: Transitions from Employment

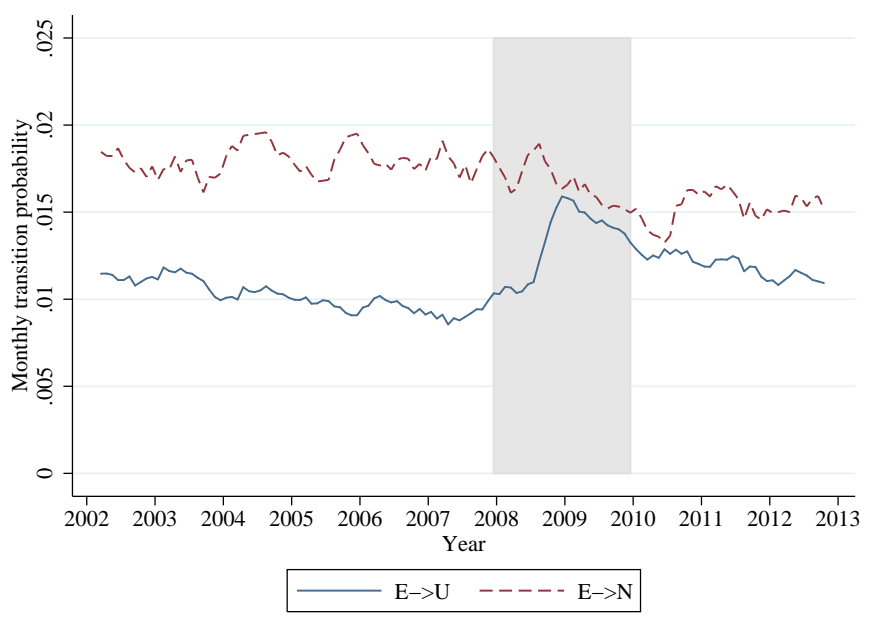

Panel D: Comparing $U \rightarrow E$ to "Indomitable Worker"

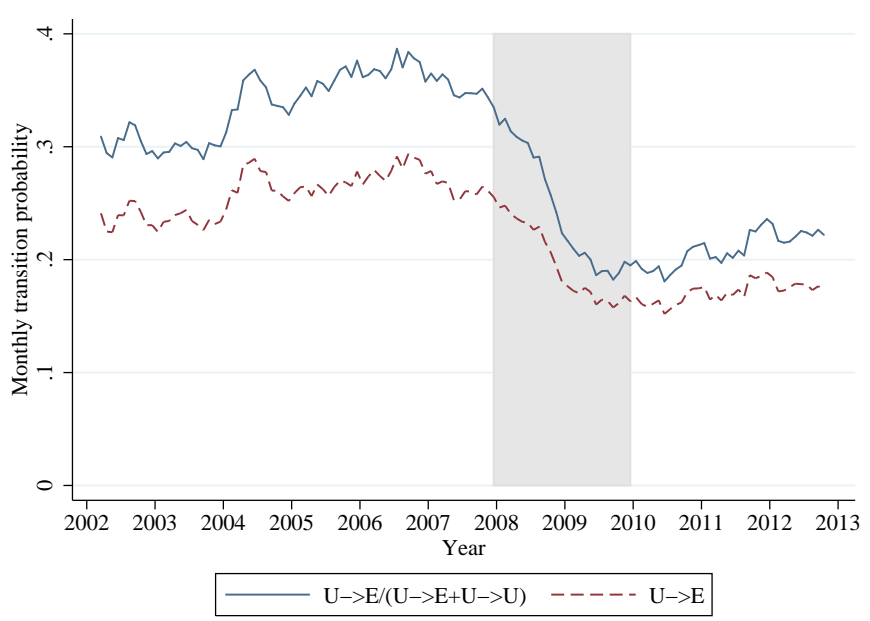

Notes: These figures use data from the CPS. See notes to Figure 2 for more information on the sample construction. 
Figure 6: "Incoming" Unemployment Duration Distributions

Panel A: Transitions from Non-Participation

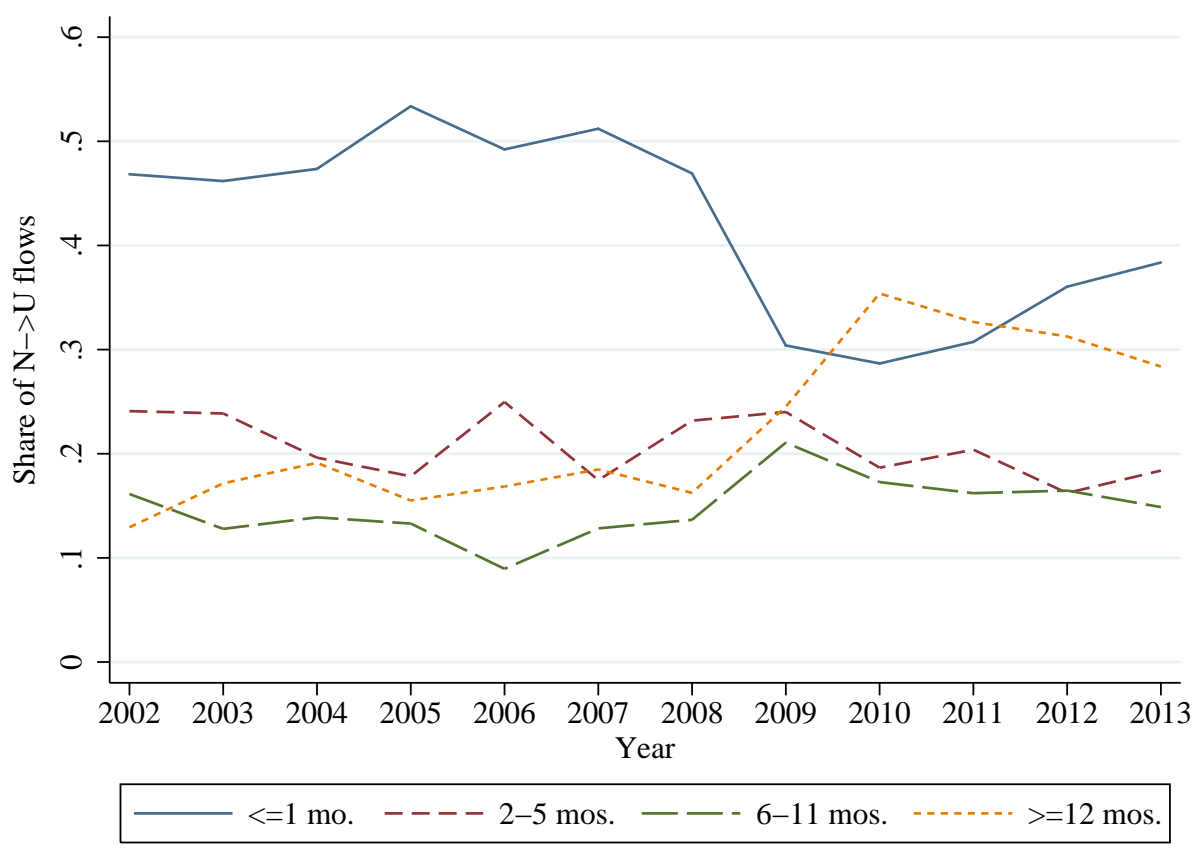

Panel B: Transitions from Employment

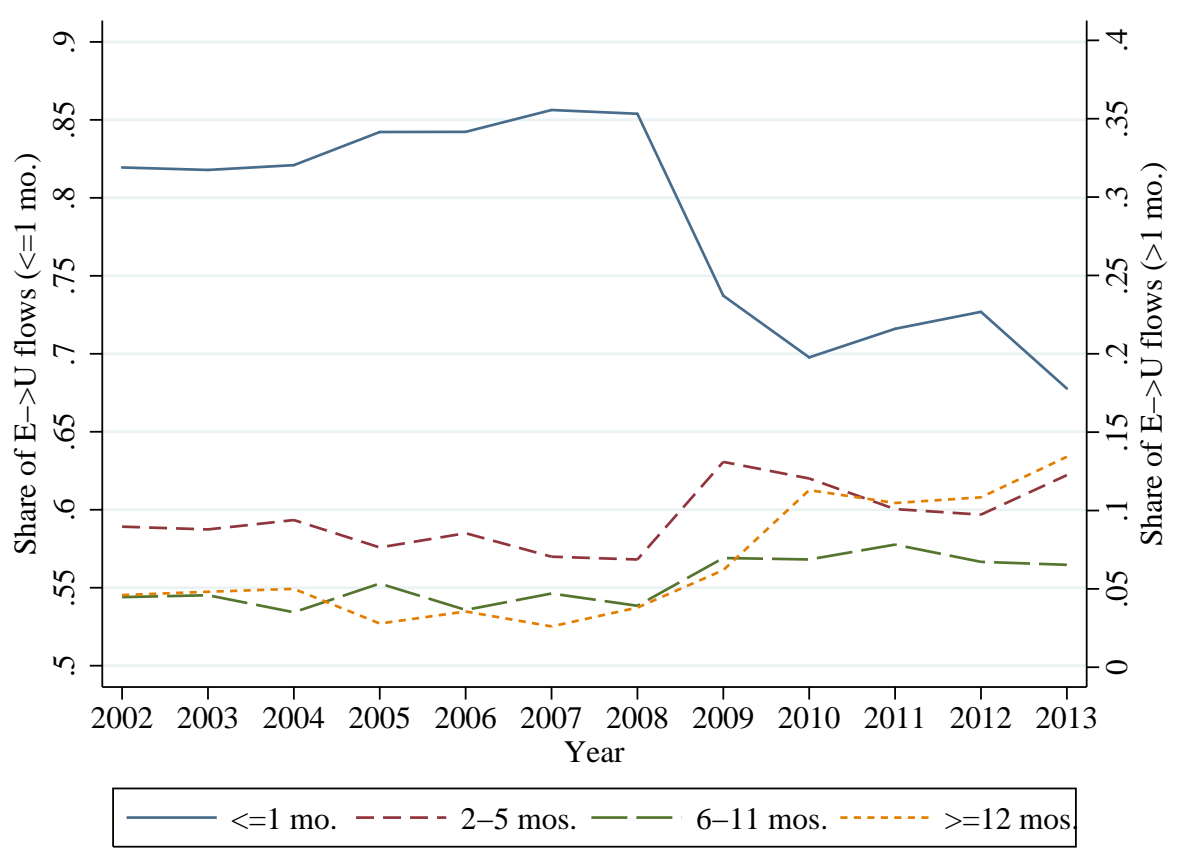

Notes: These figures report the share of individuals transitioning into unemployment from either non-participation (Panel A) or employment (Panel B). The figures show the share of workers transitioning into unemployment by unemployment duration. This reveals the extent to which unemployed individuals who did not report being unemployed in previous month report unemployment durations that are inconsistent with being a newly unemployed worker. We report annual averages in this figure but use quarterly averages in the counterfactual simulations (and group [0,6) months together). 
Panel A: Estimated Duration Dependence $(A(d)$ function)

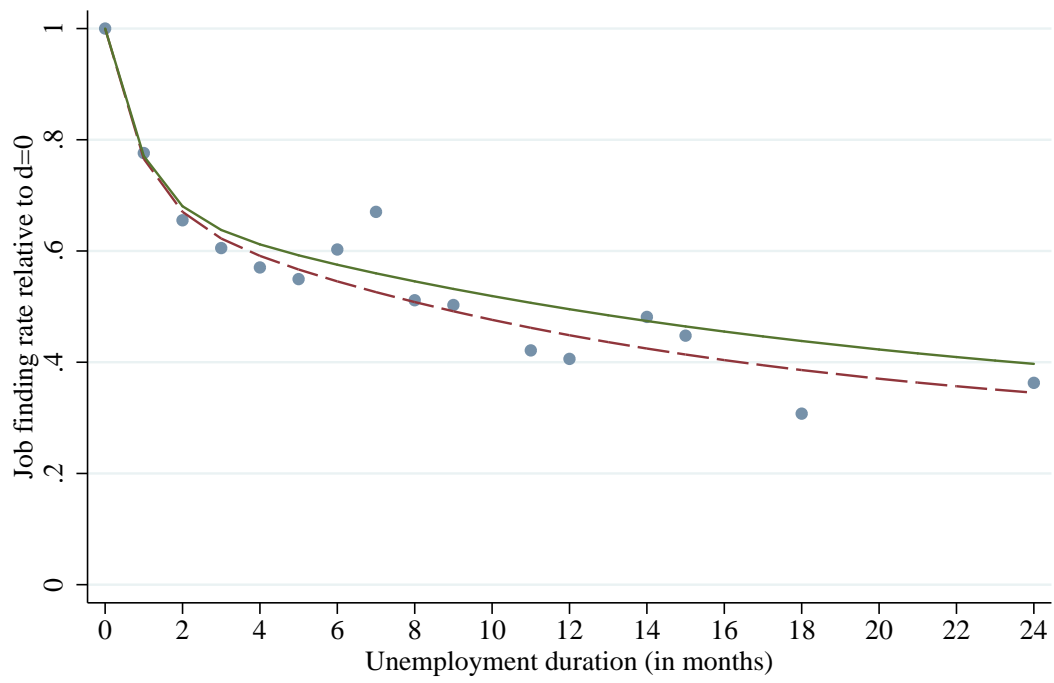

- - weighted NLLS, no X's — weighted NLLS, full controls

Panel B: Predicted Job Finding Probability, $\bar{A}$, Based on Distribution of Unemployment Durations and $A(d)$

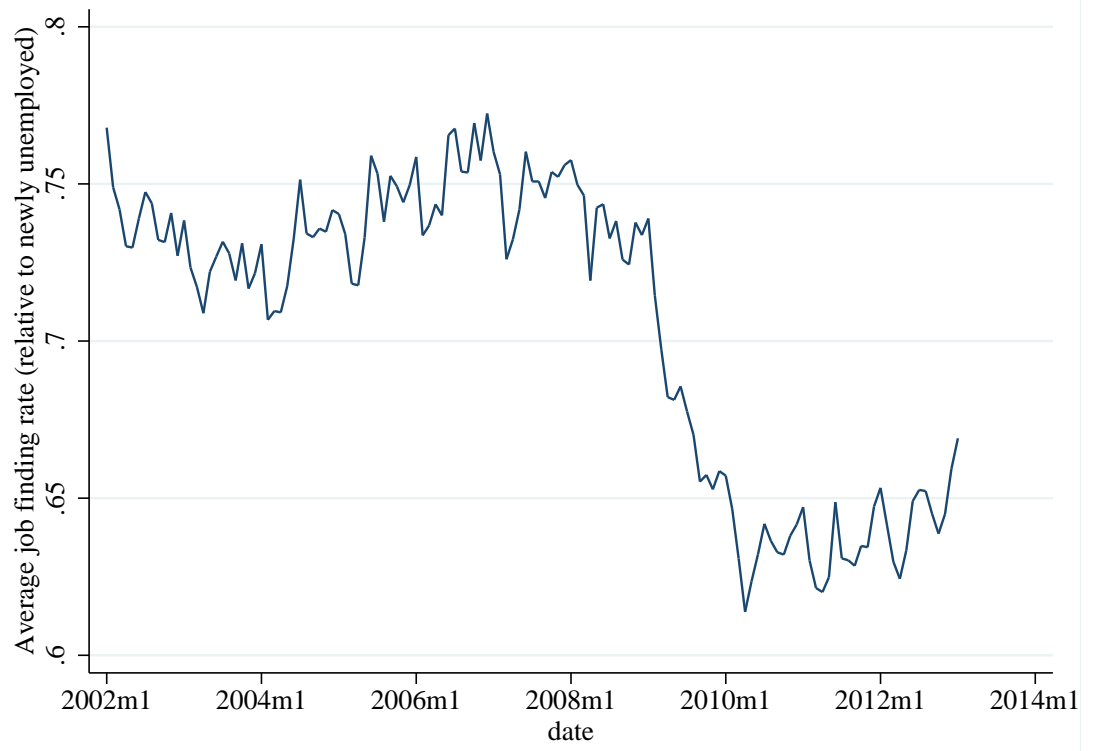

Notes: In Panel A, the figure uses data from the CPS and estimates (via NLLS) the negative exponential relationship between monthly job finding probability and unemployment duration. The NLLS uses CPS sample weights. The following functional form is used to estimate duration dependence: $A(d)=\left(1-a_{1}-a_{2}\right)+a_{1} \exp \left(-b_{1} \times d\right)+a_{2} \exp \left(-b_{2} \times d\right)$. The fitted values from the estimates with controls (solid line) are used to construct the counterfactuals shown in Figures 7 through 10. The controls used are the following: gender, fifth-degree polynomial in age, three race dummies (white/black/other), five education category dummies (high school dropout, high school graduate, some college, college graduate, and other), and gender interactions for all of the age, race, and education variables. Only monthly cell means with at least 30 observations are shown. In Panel B, the figure is generated by using estimates of how job finding probability varies with unemployment duration interacted with observed distribution of unemployment durations. Thus, the line in this figure shows the extent to which we would predict changes in job finding probability based solely on observed changes in distribution of unemployment duration. The $y$-axis scale is normalized so that a value of 1 indicates average job finding probability for a newly unemployed worker. 
Figure 8: Model Predictions for Job-Finding Rates for Unemployed and Non-Participants

Panel A: Job-Finding Rates for Unemployed

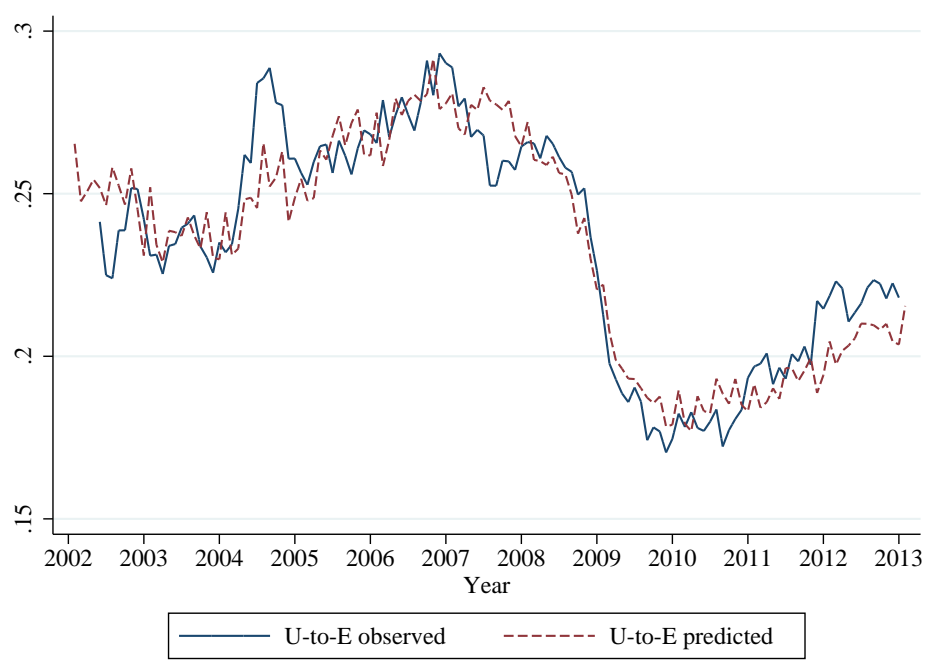

Panel B: Job-Finding Rates for Non-Participants

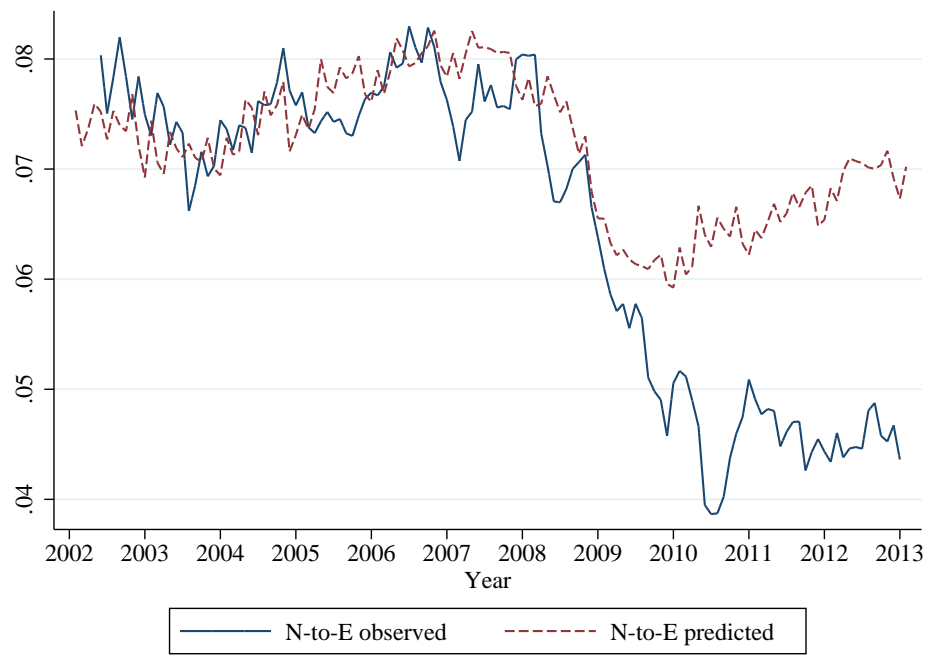

Notes: These figures report the model-generated predicted job-finding rates for unemployed workers and non-participants, where the predictions are based on model estimates calibrated to match 1/2002-12/2007 time period. See main text for more details. 
Panel A: Long-Term Unemployment (> 26 weeks)

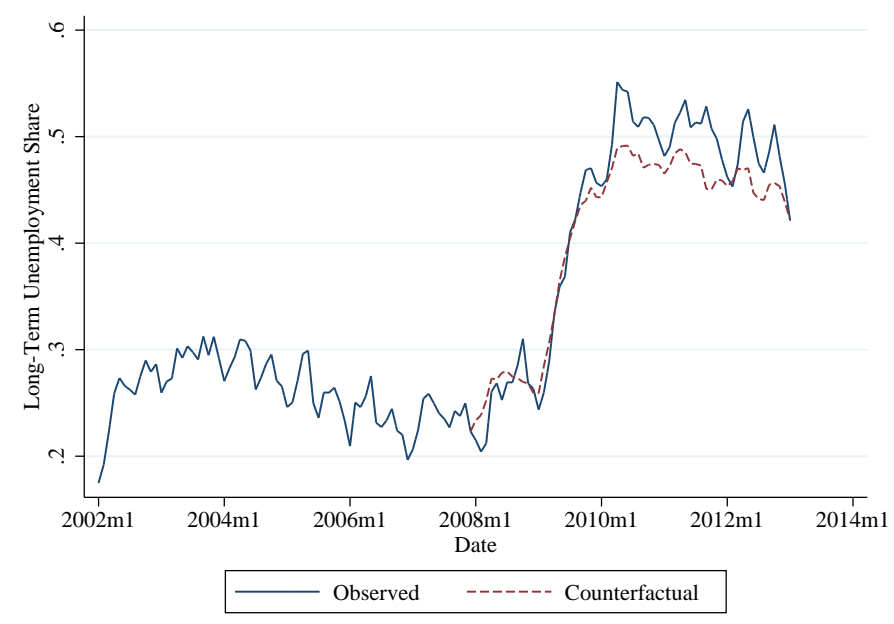

Panel C: Beveridge Curve

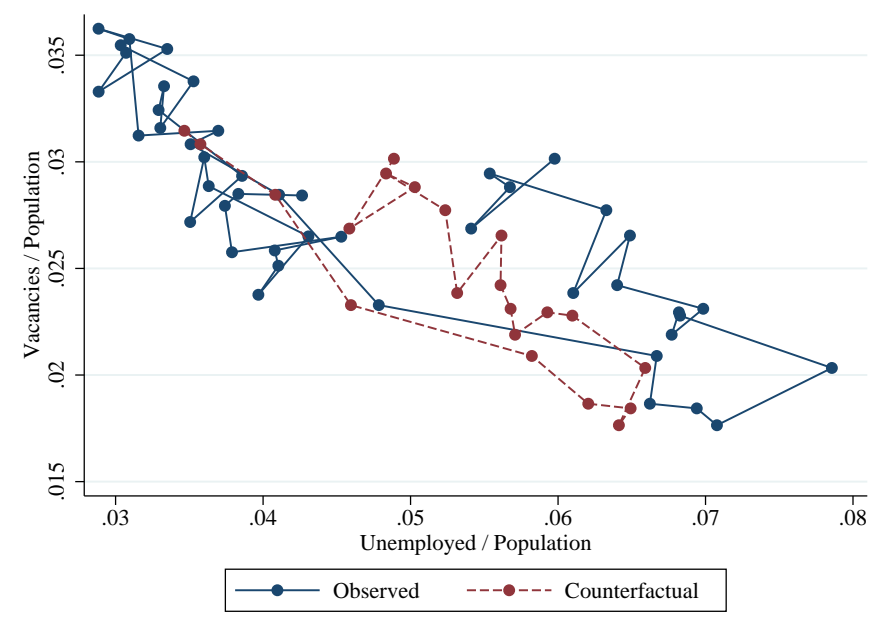

Panel B: Long-Term Unemployment (> 52 weeks)

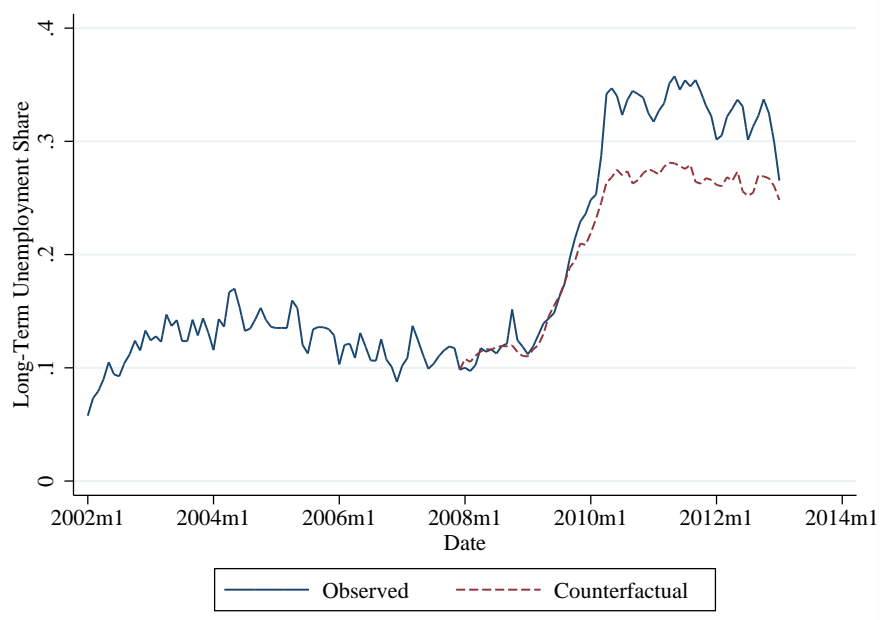

Panel D: Model Predictions for $N-V$ Curve

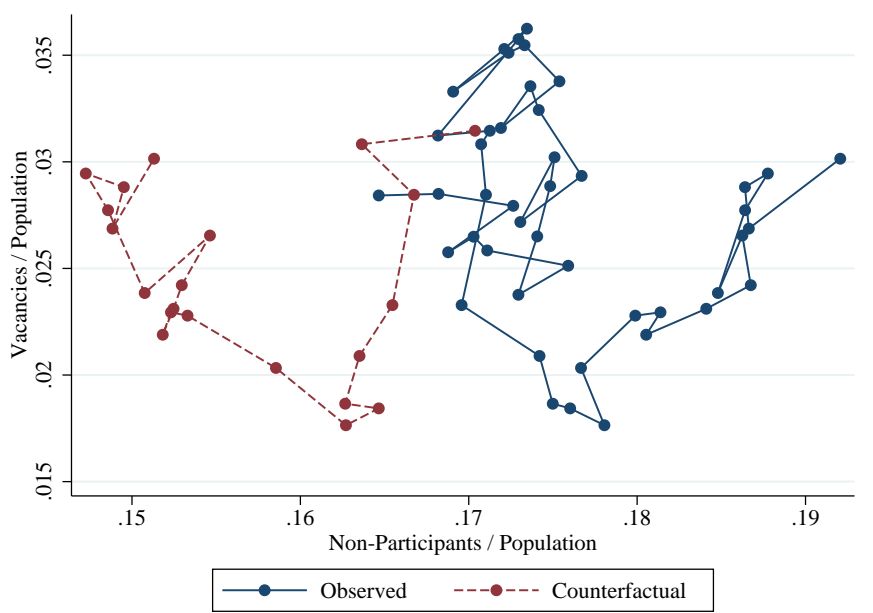

Notes: These figures use data from the CPS and JOLTS. See main text for more details on model calibration. 
Figure 10: Model Predictions Using Alternative Estimates of Duration Dependence

Panel A: Comparing to Kroft et al. (2013) experimental estimates

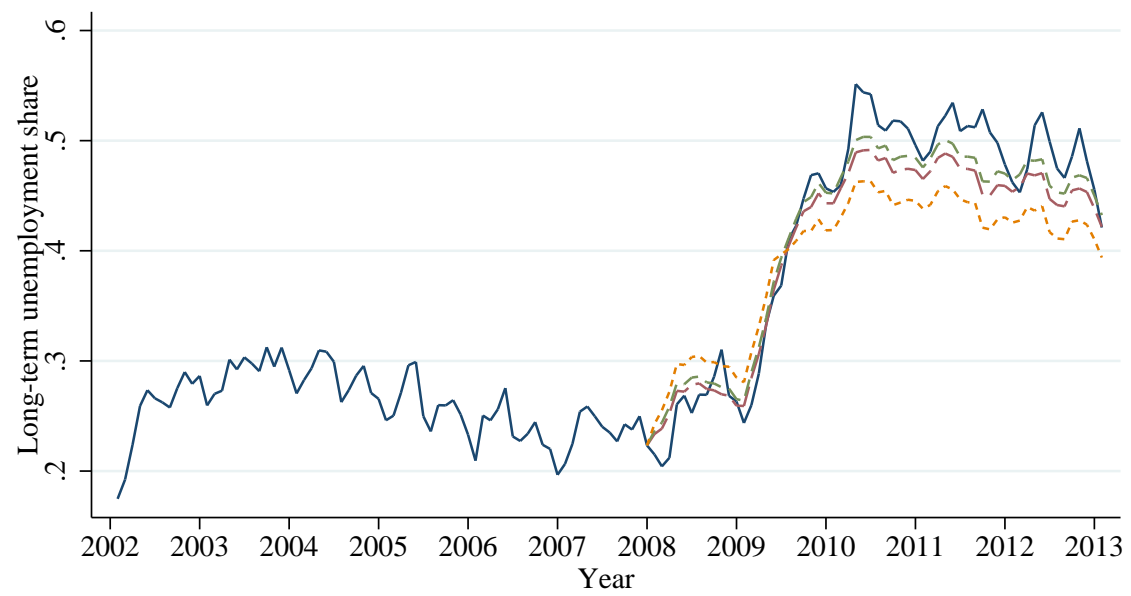

- Observed LTU share

$---A(d)$ from CPS with rich controls

$----\cdot A(d)$ from experimental data

$A(d)$ from experimental data, separate estimate for high/low unemp.

Panel B: Aternative assumptions of "true" duration dependence

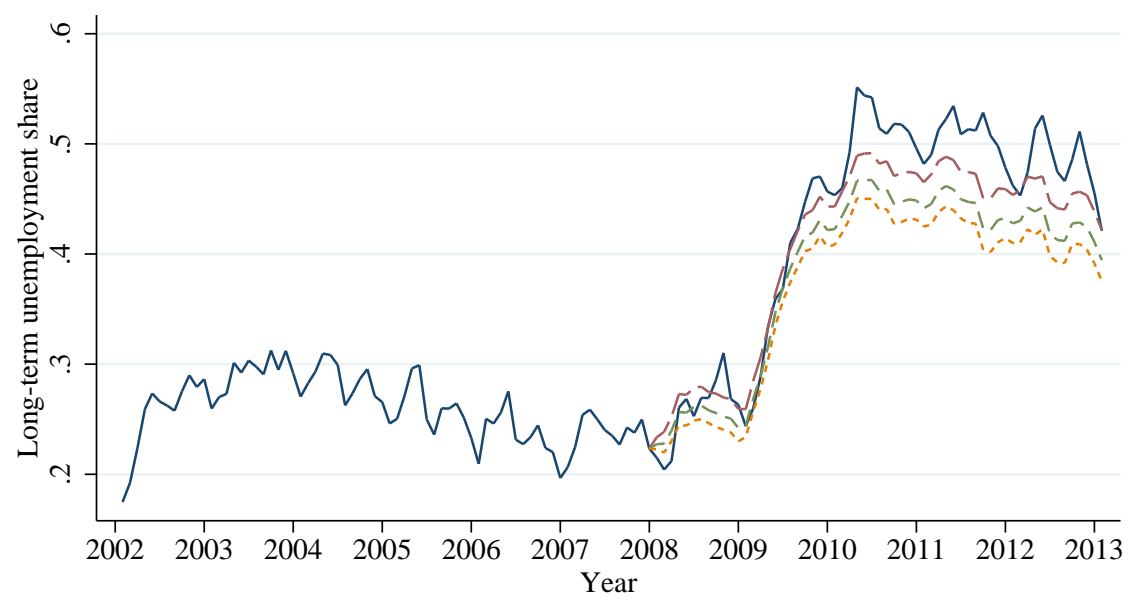

- Observed LTU share

$-1-A(d)$ from CPS with rich controls

- - - - Assume 'true' $A(d)$ is $0.75 *$ CPS estimate

-....- Assume 'true' $A(d)$ is $0.5 *$ CPS estimate

Notes: In Panel A, the figure shows robustness of baseline calibration (long dashed line) to alternative assumptions about magnitude of duration dependence. The medium dashed line shows calibration results based on estimated $A(d)$ function based on the full sample of experimental data from Kroft et al. (2013). The short dashed line allows $A(d)$ to vary with labor market conditions as found in Kroft et al. (2013); specifically, $A(d)$ is flatter than average when unemployment rate exceeds 8.8 percent (in April 2009), and steeper before that point. In Panel B, the figure shows robustness to assuming that estimated $A(d)$ function recovers a mixture of "true" duration dependence and unobserved heterogeneity. By making assumptions on share of unobserved heterogeneity captured by function, the $A(d)$ can be re-scaled to be a measure of "true" duration dependence. 
Panel A: Long-Term Unemployment (> 26 weeks)

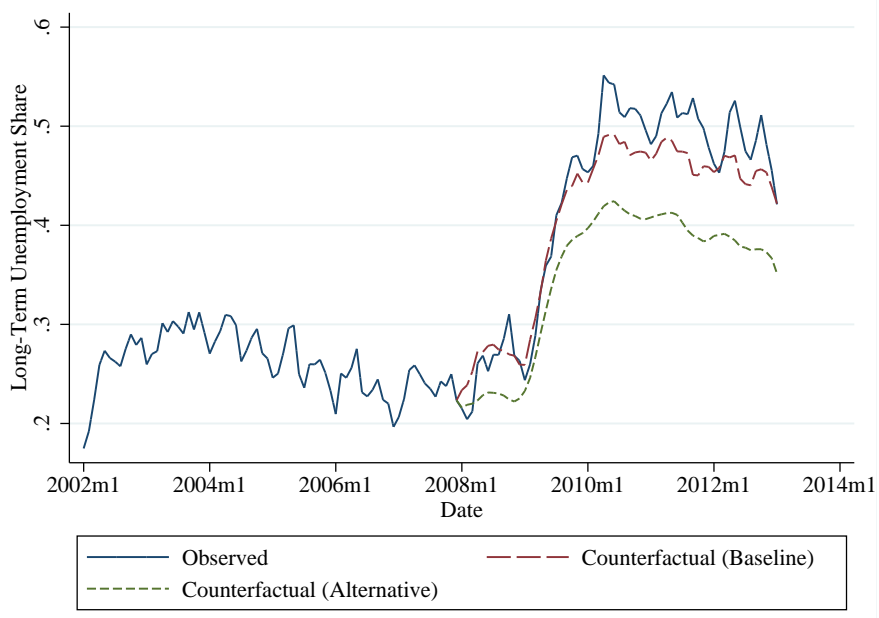

Panel C: Beveridge Curve

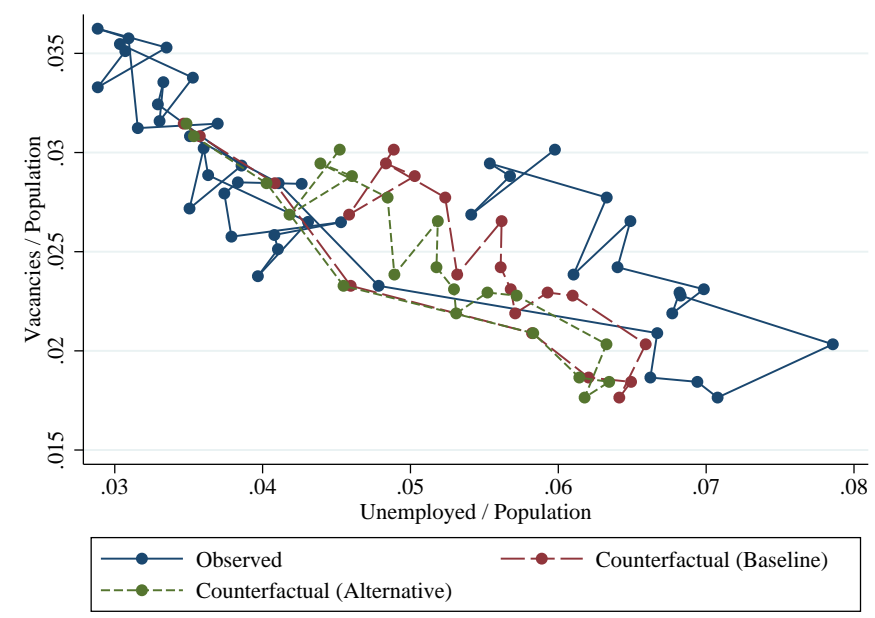

Panel B: Long-Term Unemployment (> 52 weeks)

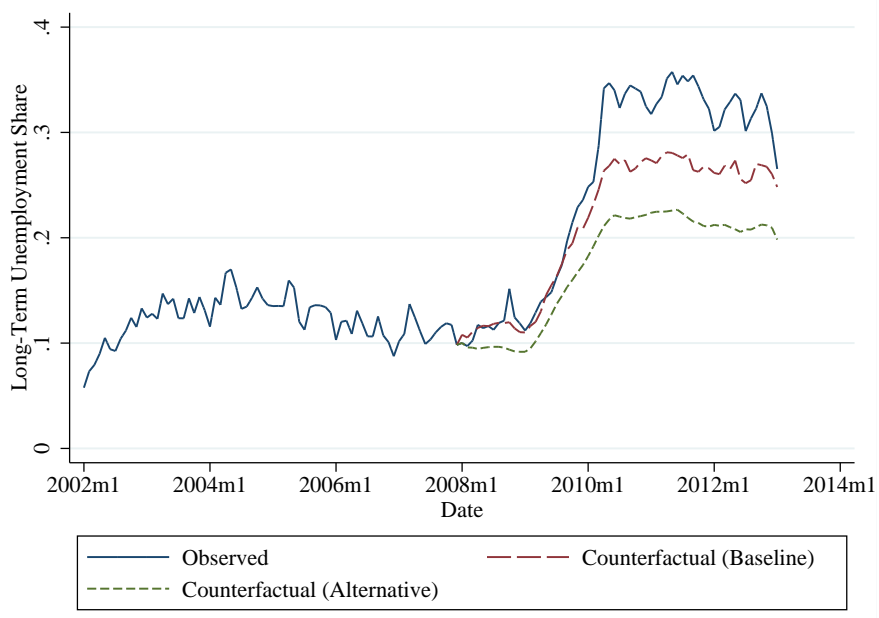

Panel D: Model Predictions for $N-V$ Curve

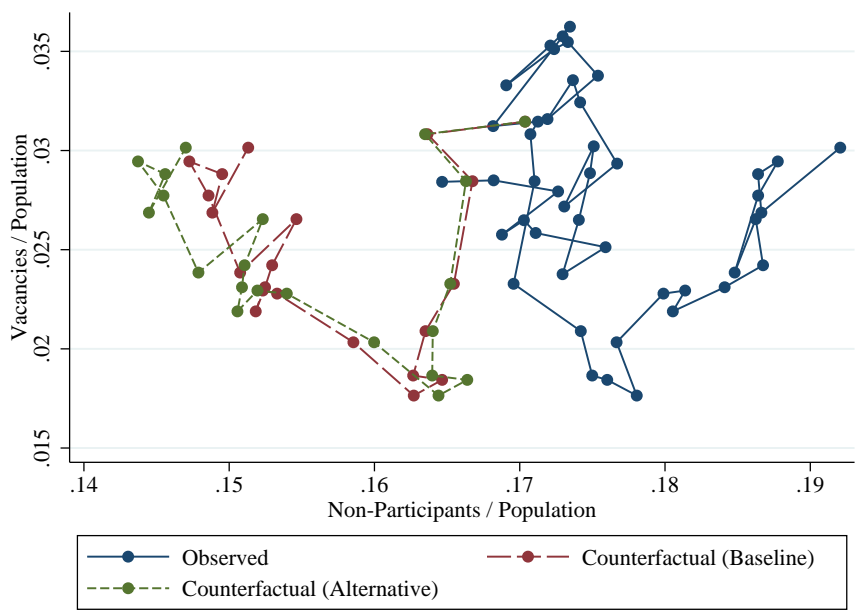

Notes: These figures use data from the CPS and JOLTS. See main text for more details on model calibration. 
Figure 12: Model Predictions Ignoring Changes in $N \rightarrow U, U \rightarrow N$, and $E \rightarrow N$

Panel A: Long-Term Unemployment (> 26 weeks)

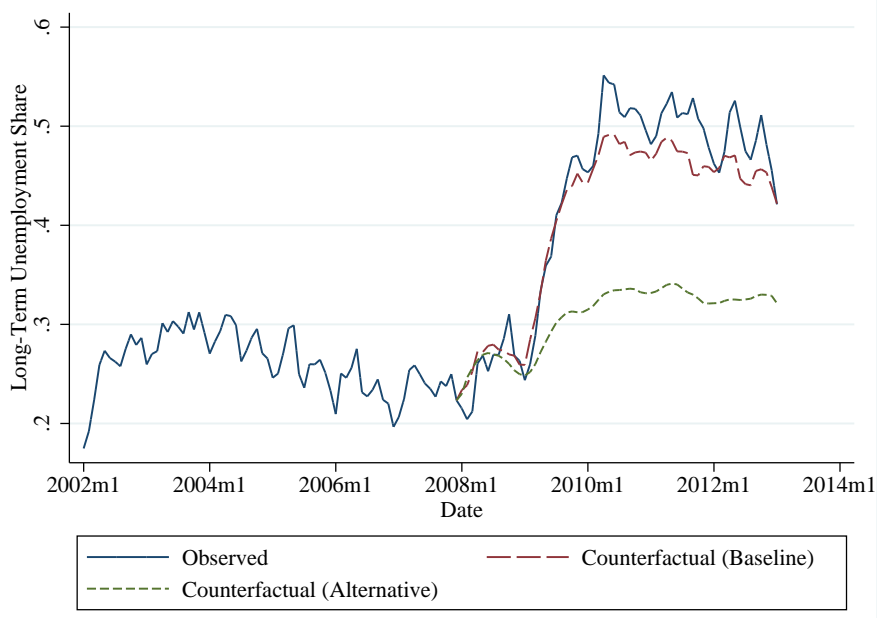

Panel C: Beveridge Curve

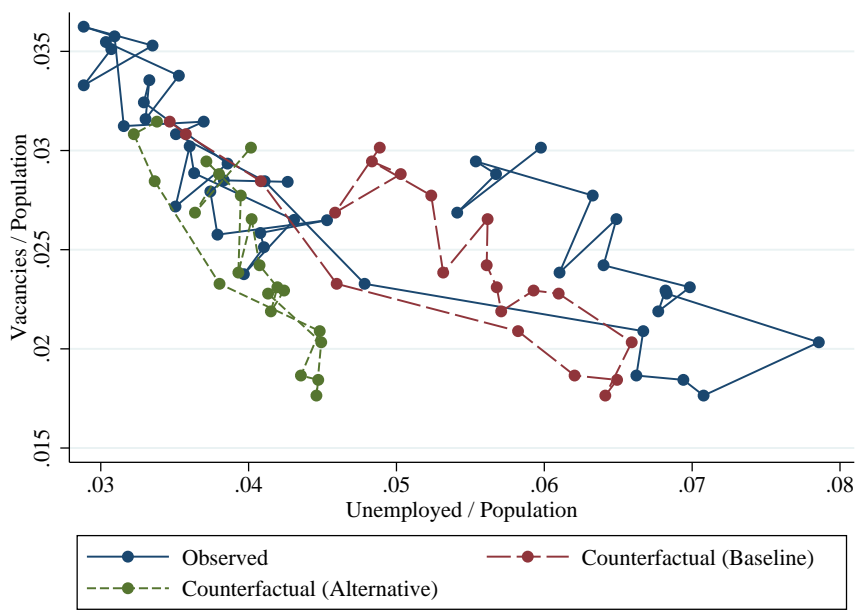

Panel B: Long-Term Unemployment (> 52 weeks)

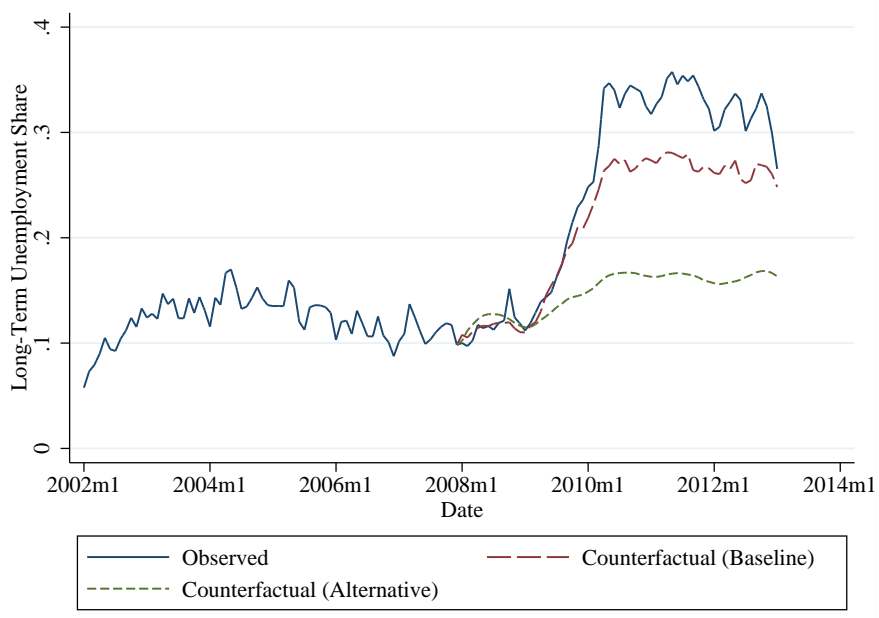

Panel D: Model Predictions for $N-V$ Curve

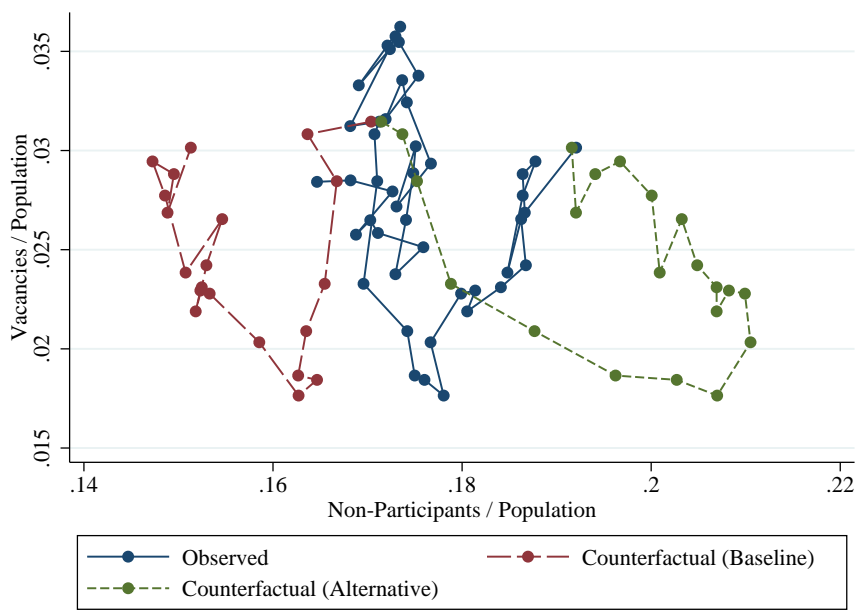

Notes: These figures use data from the CPS and JOLTS. See main text for more details on model calibration. 
Figure 13: Model Predictions Using Vacancy Series During 1981 Recession (Instead of 2008 Recession)

And Ignoring Changes in $N \rightarrow U, U \rightarrow N$, and $E \rightarrow N$

Panel A: Dynamics of Vacancies in 1981 Recession and 2008 Recession

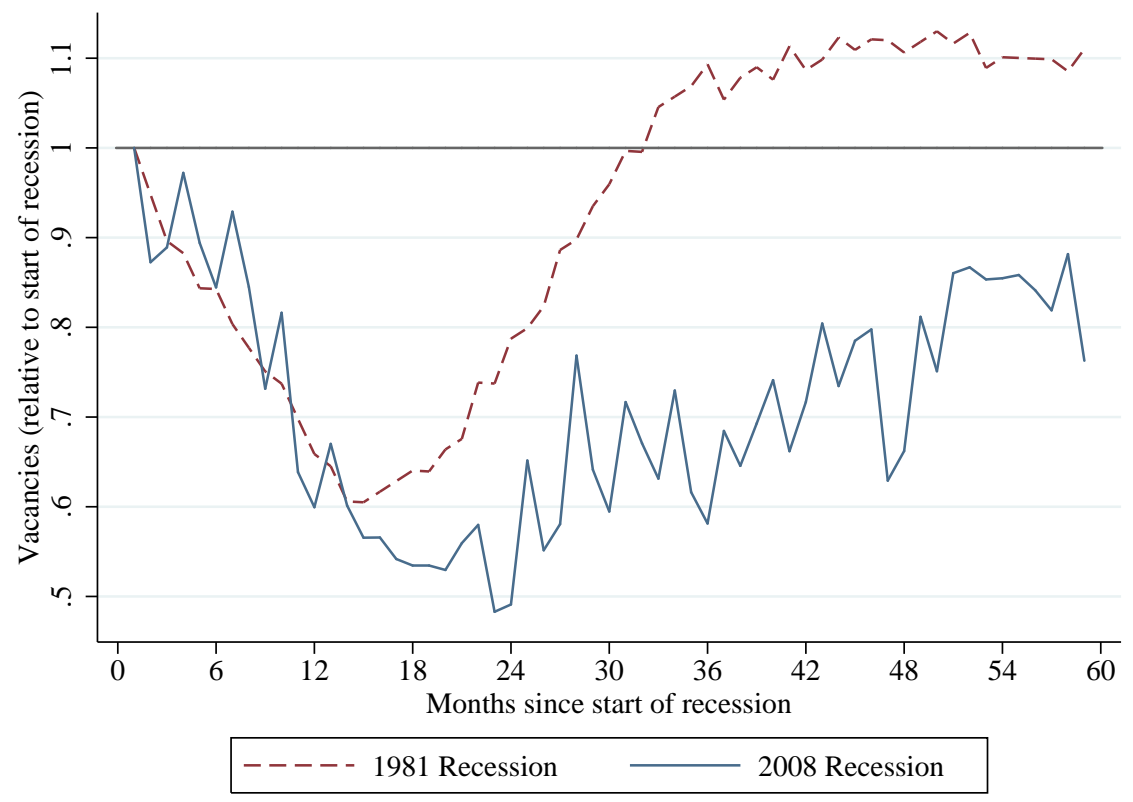

Panel B: Long-Term Unemployment (> 26 weeks)

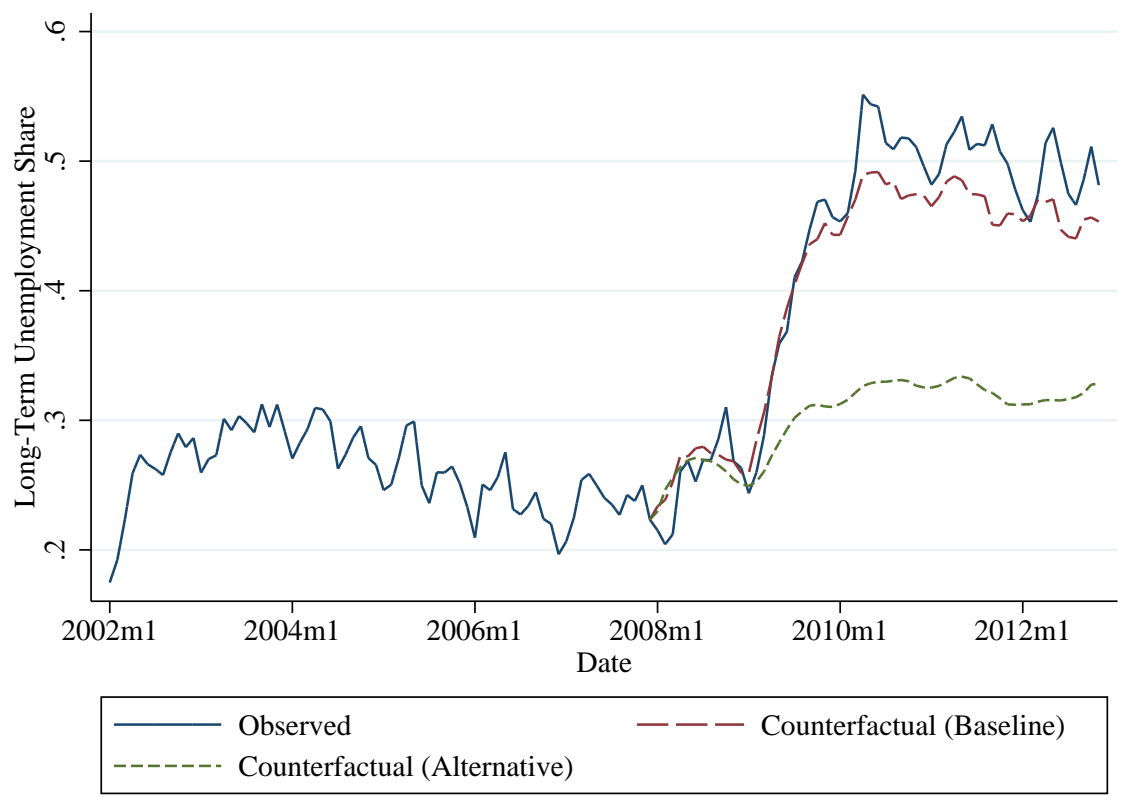

Notes: In Panel A, vacancy data for 2008 Recession come from JOLTS, while vacancy data for 1981 recession are filtered data from Help Wanted Index from Elsby et al. (2011). In Panel B, figure uses data from the CPS. See main text for more details on model calibration in these panels. 
Figure 14: Changing Composition of Labor Force Non-Participants

Panel A: Share of Non-Participants Reporting "Discouraged" or "Want Job"

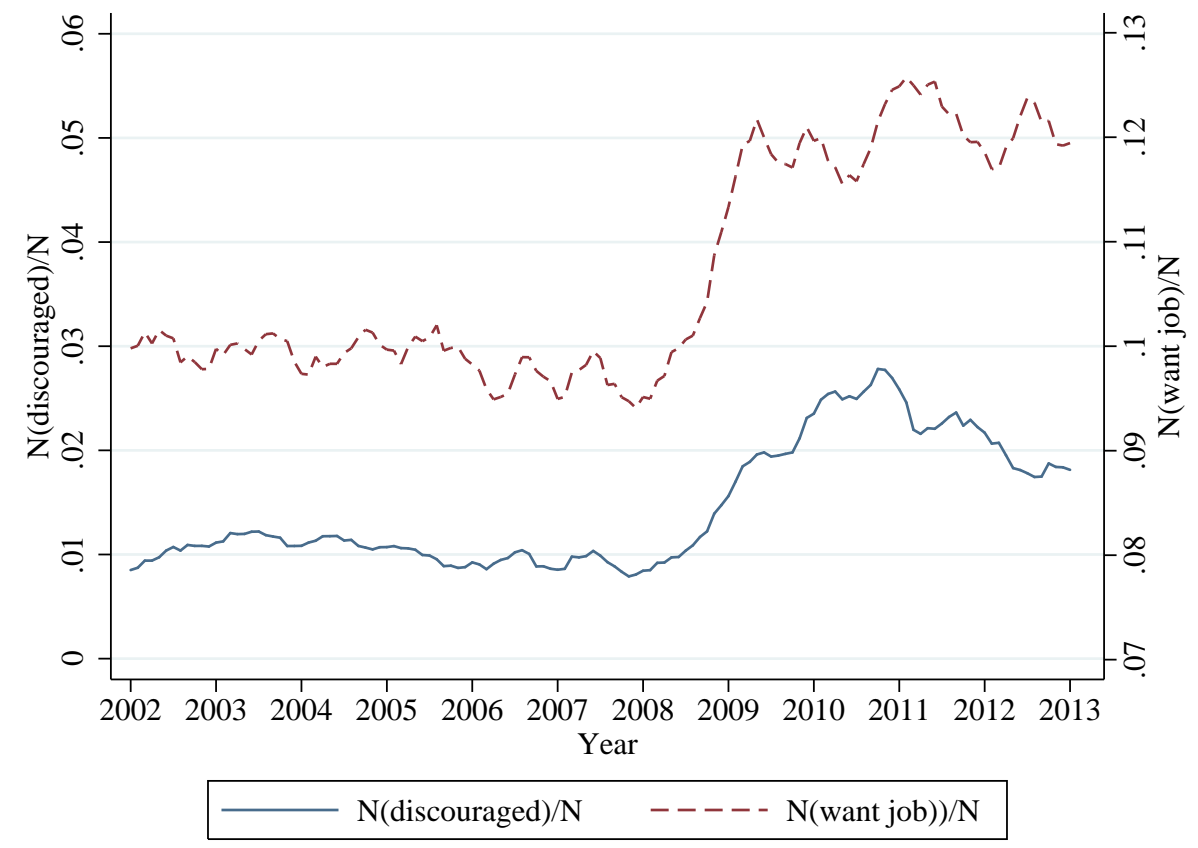

Panel B: Job-Finding Rates for Non-Participants Reporting "Want Job"

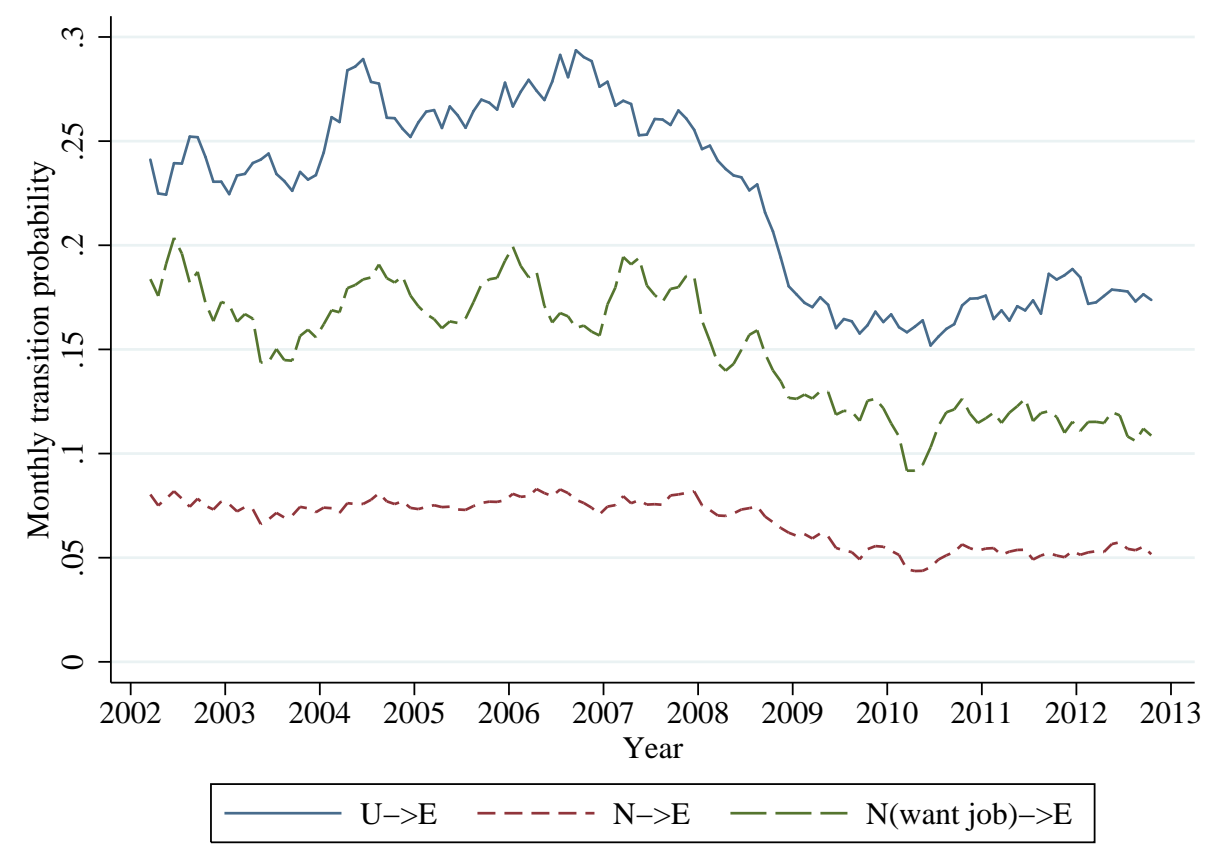

Notes: These figures report statistics from the CPS on the share of non-participants who report either being "discouraged" or saying that they "want a job." In Panel B, the monthly job-finding rates for unemployed, non-participants (overall), and non-participants (who are in "want a job" category) are displayed between 2002 and 2013. 
Panel A: Long-term unemployment share

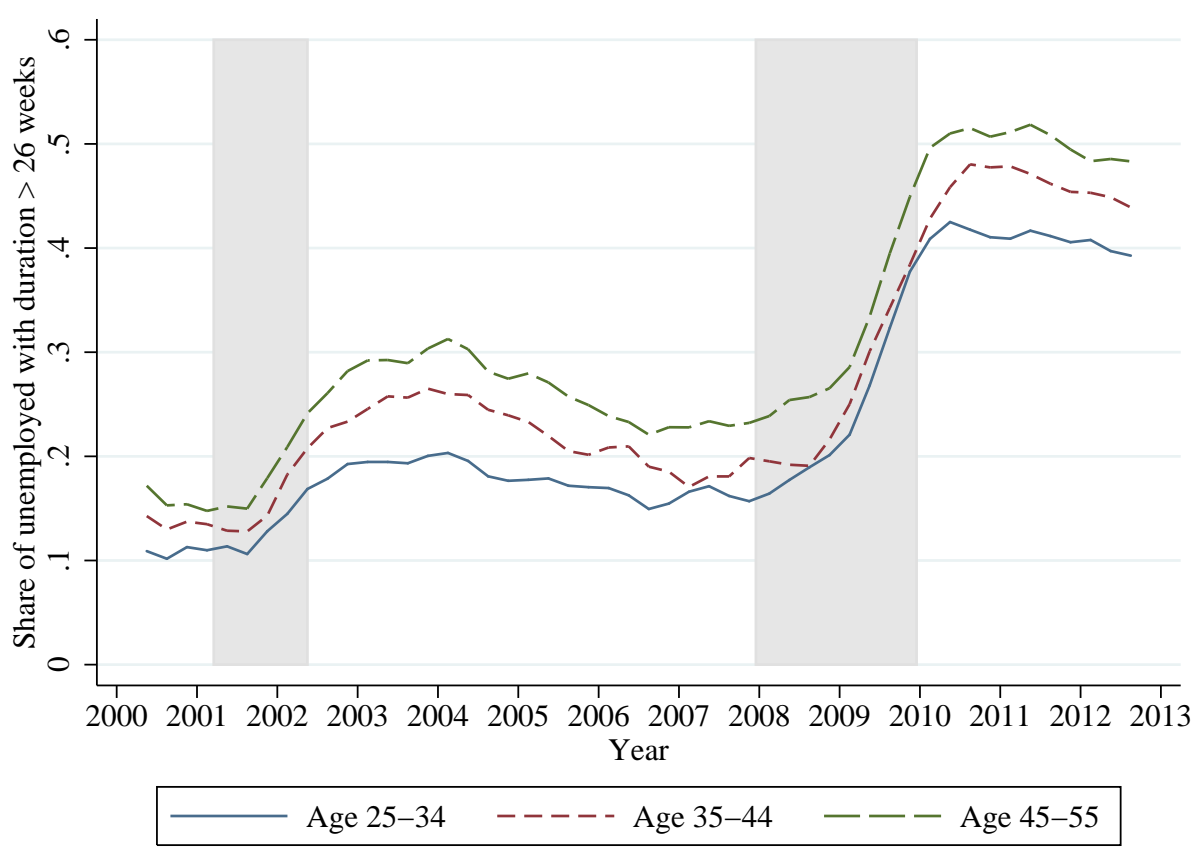

Panel B: Relative share of unemployed

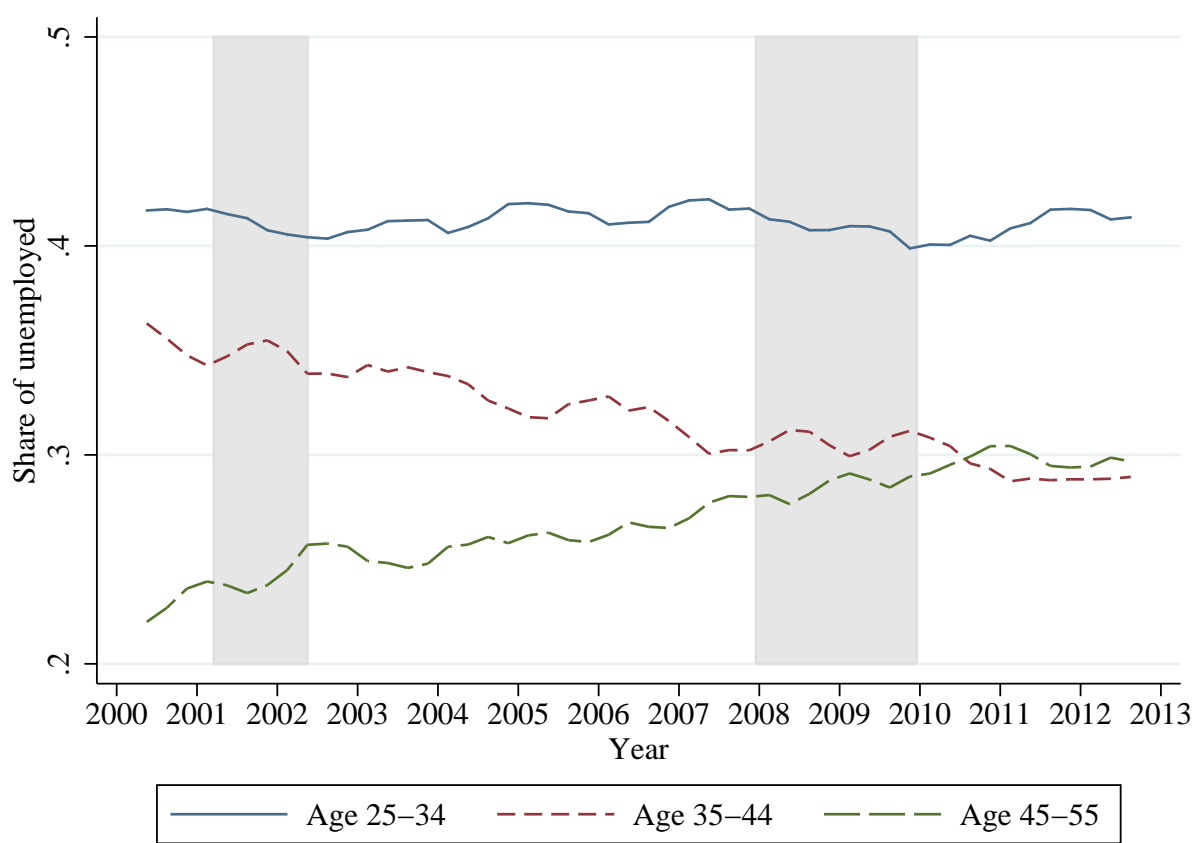

Notes: These figures use data from the CPS. See notes to Figure 2 for more information. 
Online Appendix Figure A2: Long-term Unemployment by Gender

Panel A: Long-term unemployment share

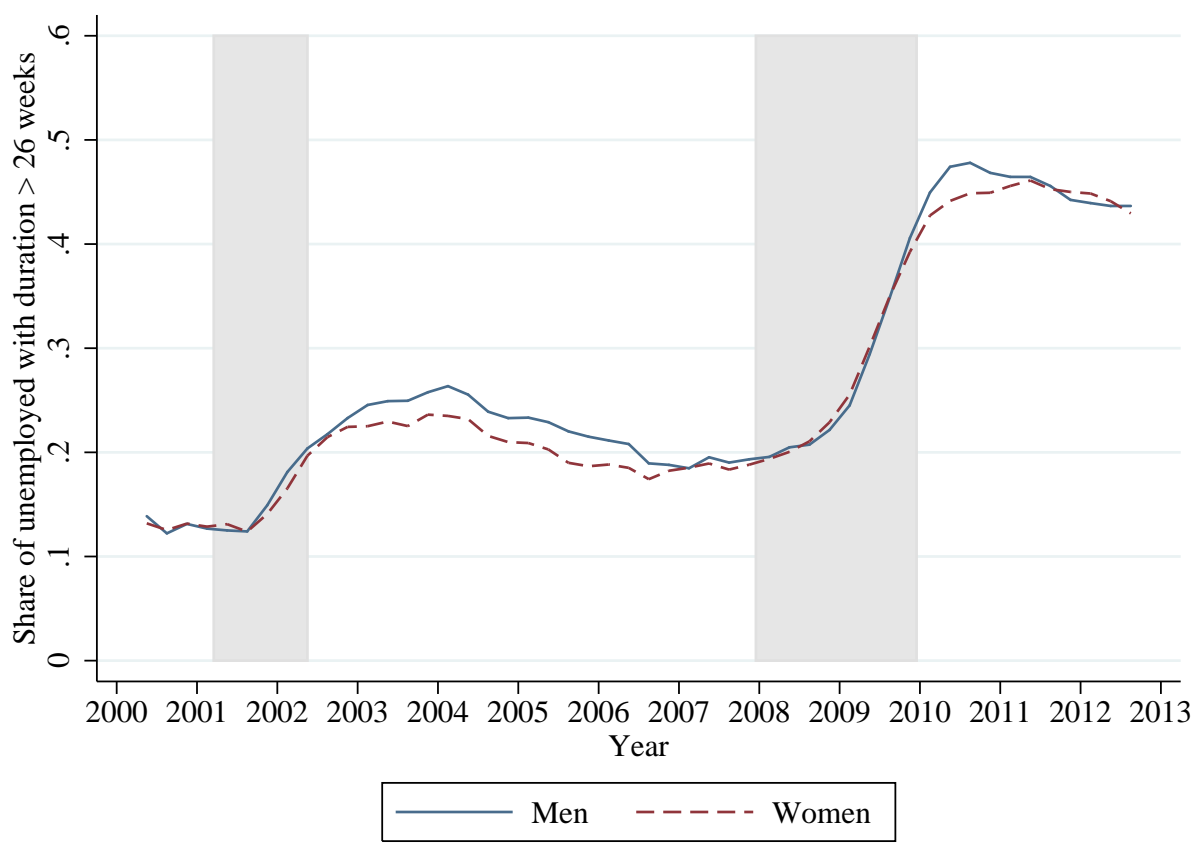

Panel B: Relative share of unemployed

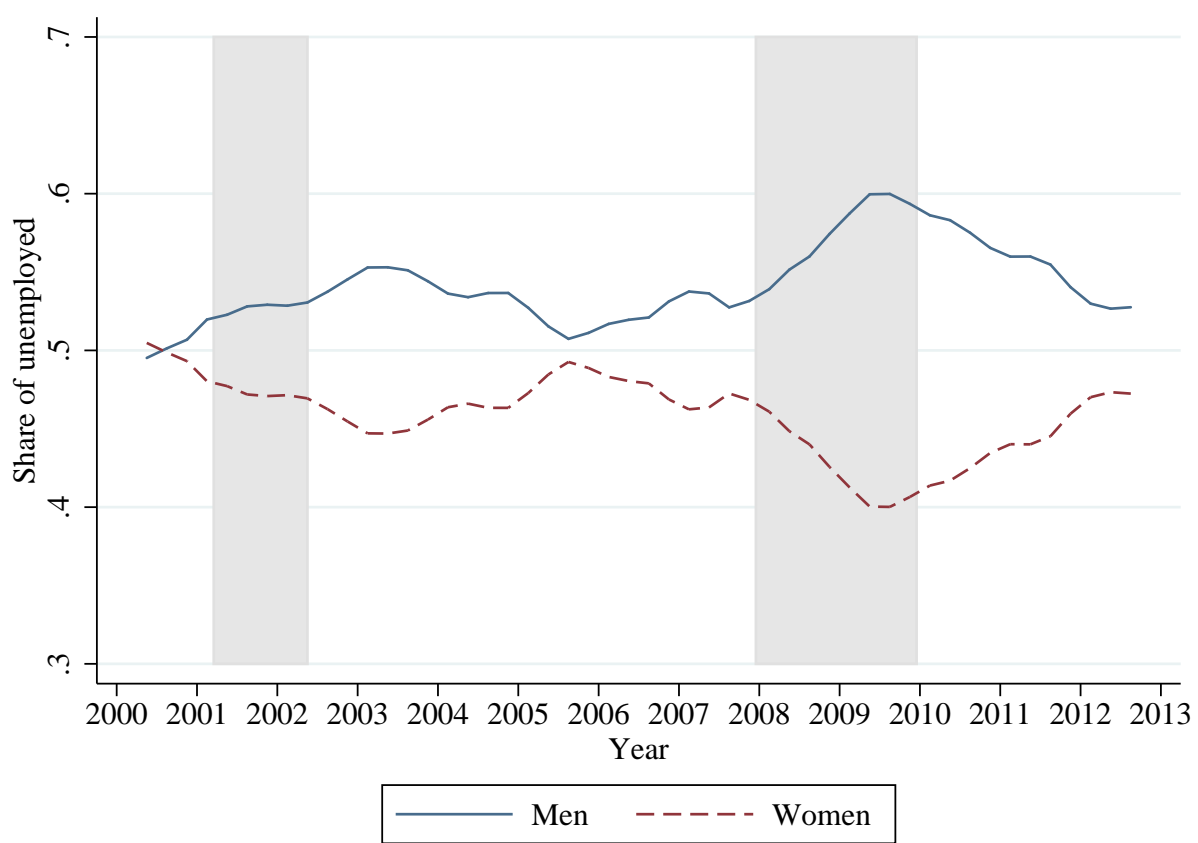

Notes: These figures use data from the CPS. See notes to Figure 2 for more information. 
Online Appendix Figure A3: Long-term Unemployment by RaCe

Panel A: Long-term unemployment share

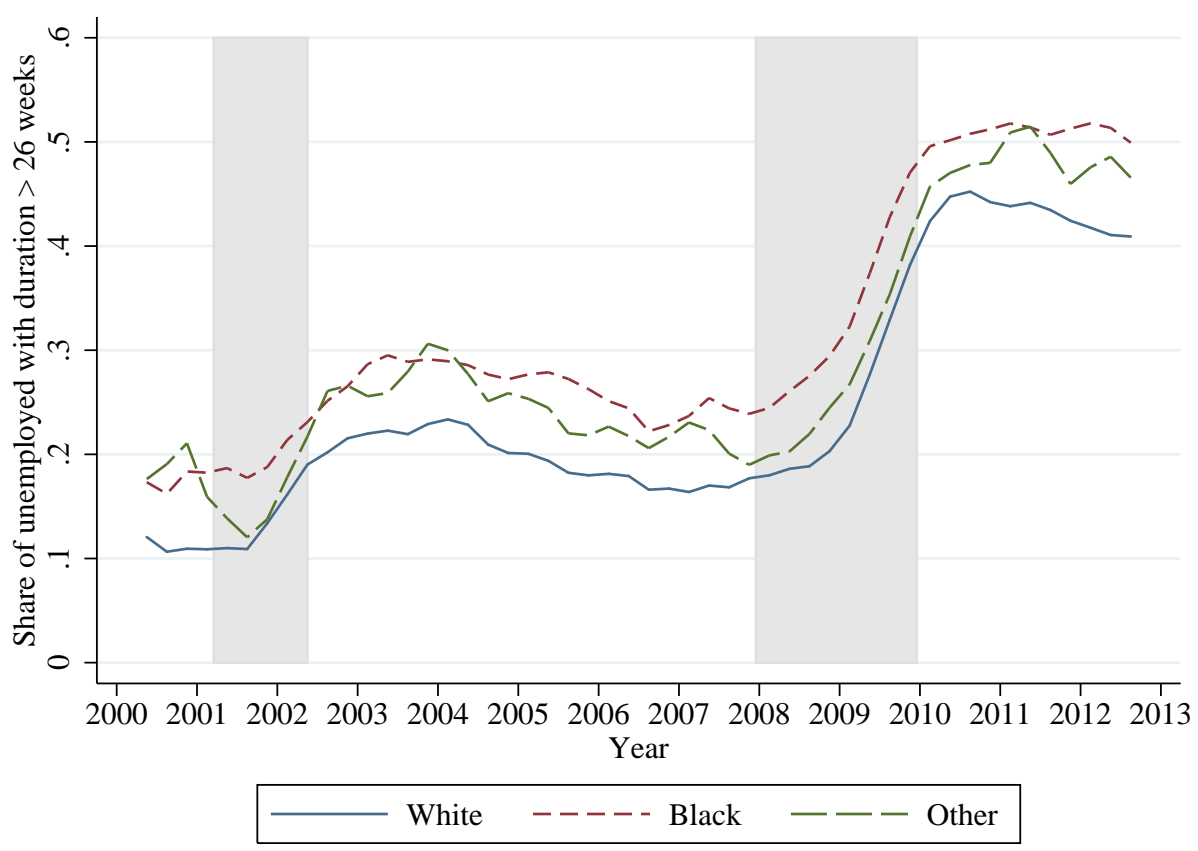

Panel B: Relative share of unemployed

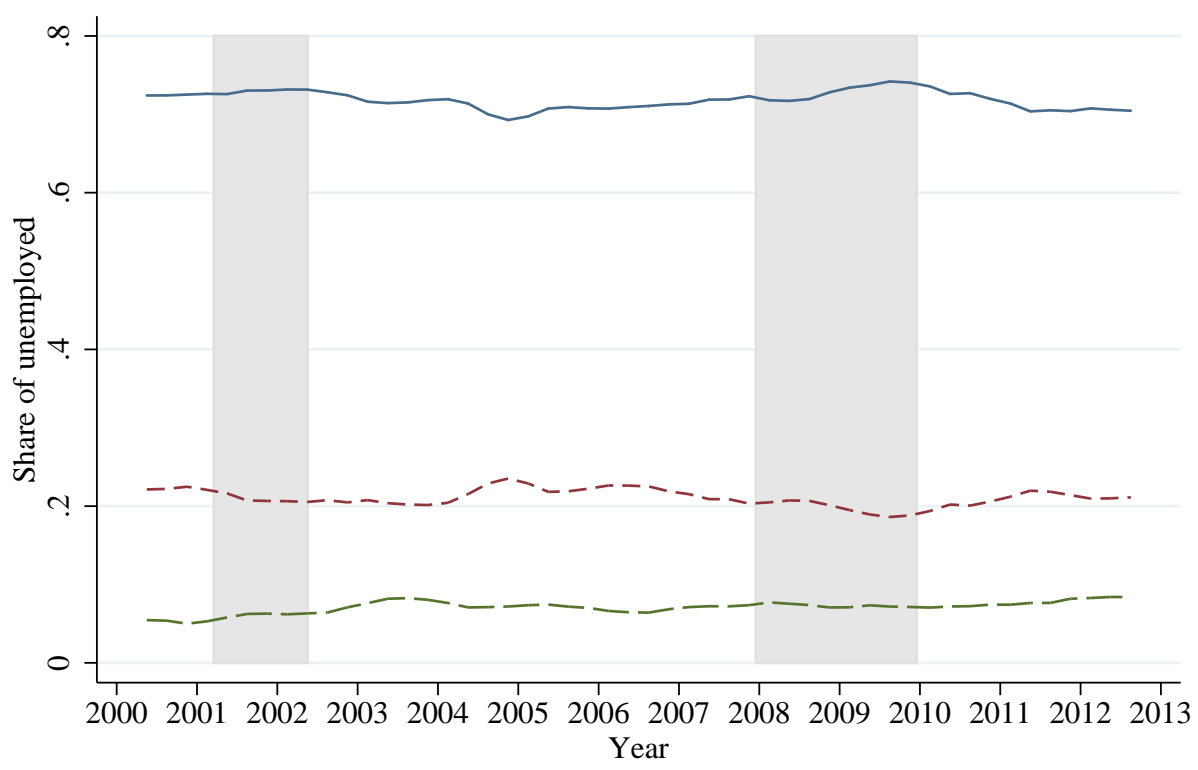

White ----- Black - - Other

Notes: These figures use data from the CPS. See notes to Figure 2 for more information. 
Panel A: Long-term unemployment share

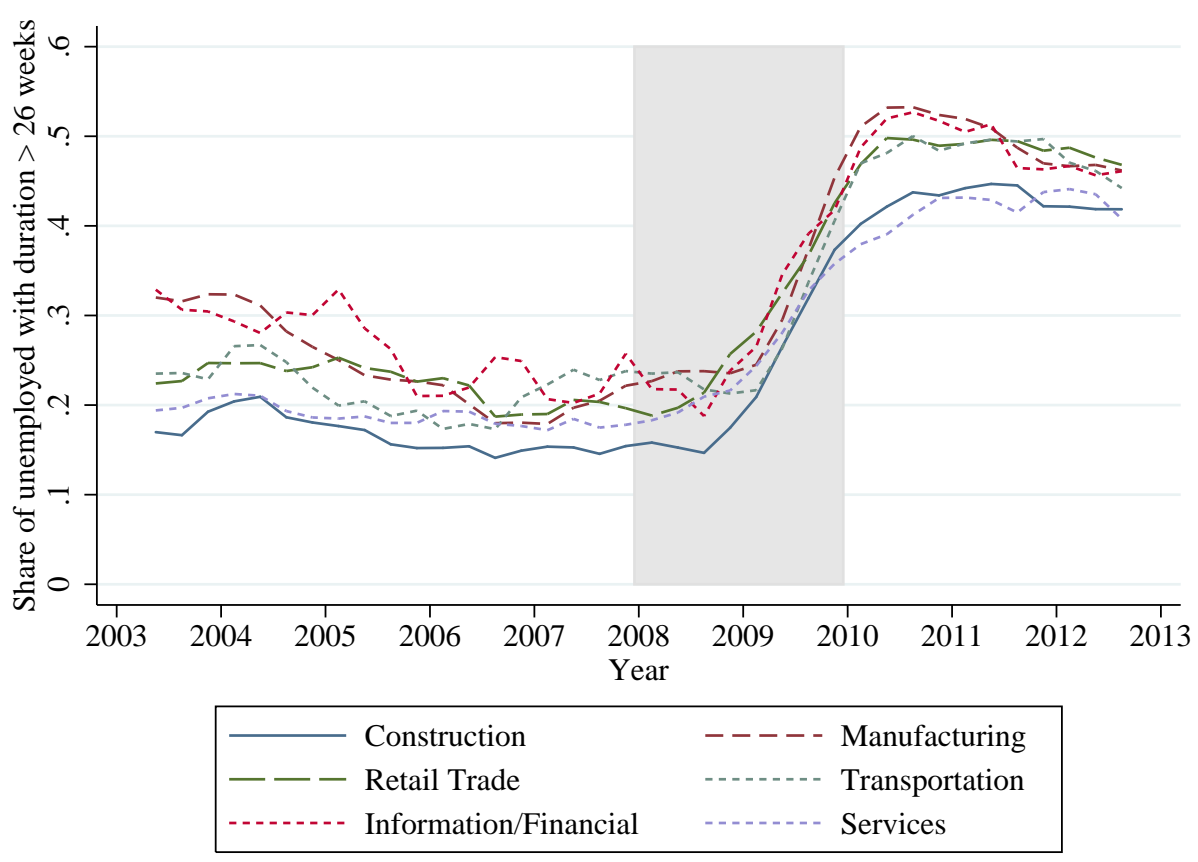

Panel B: Relative share of unemployed

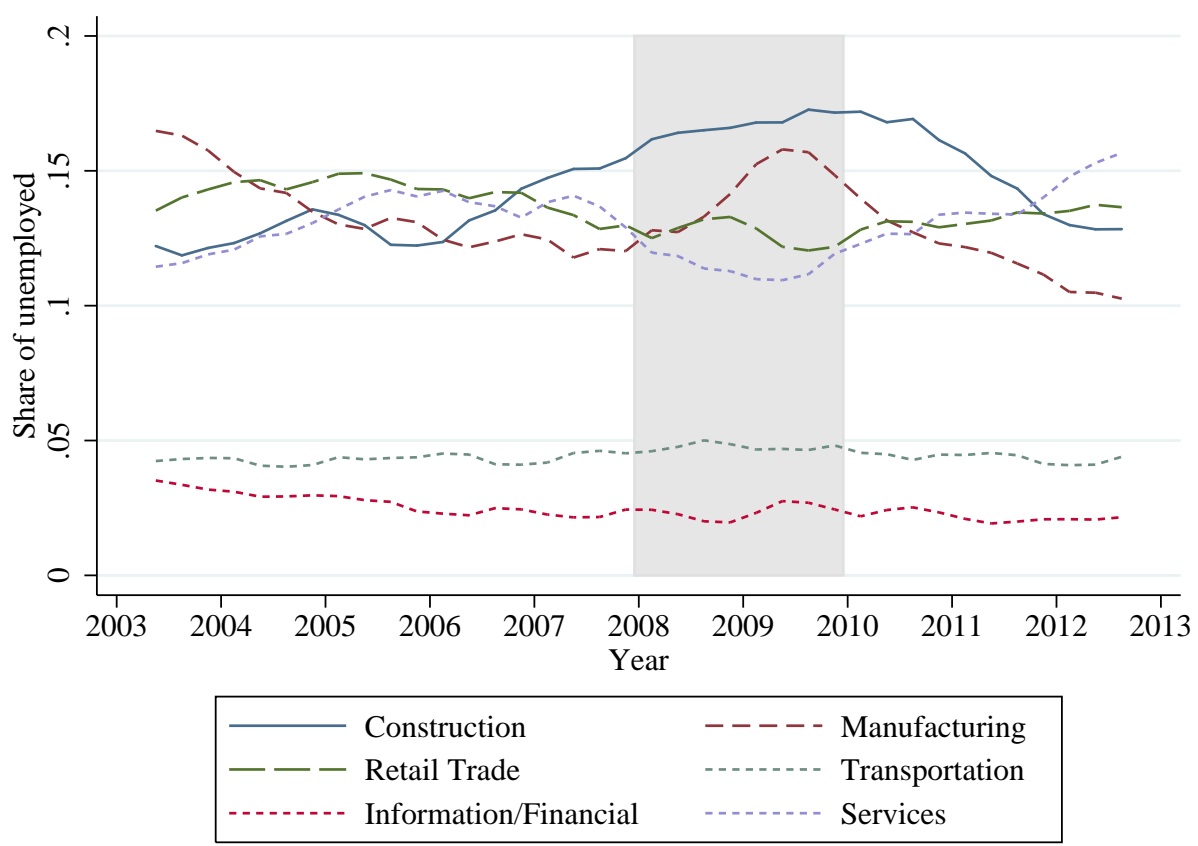

Notes: These figures use data from the CPS. See notes to Figure 2 for more information. 
Panel A: Long-term unemployment share

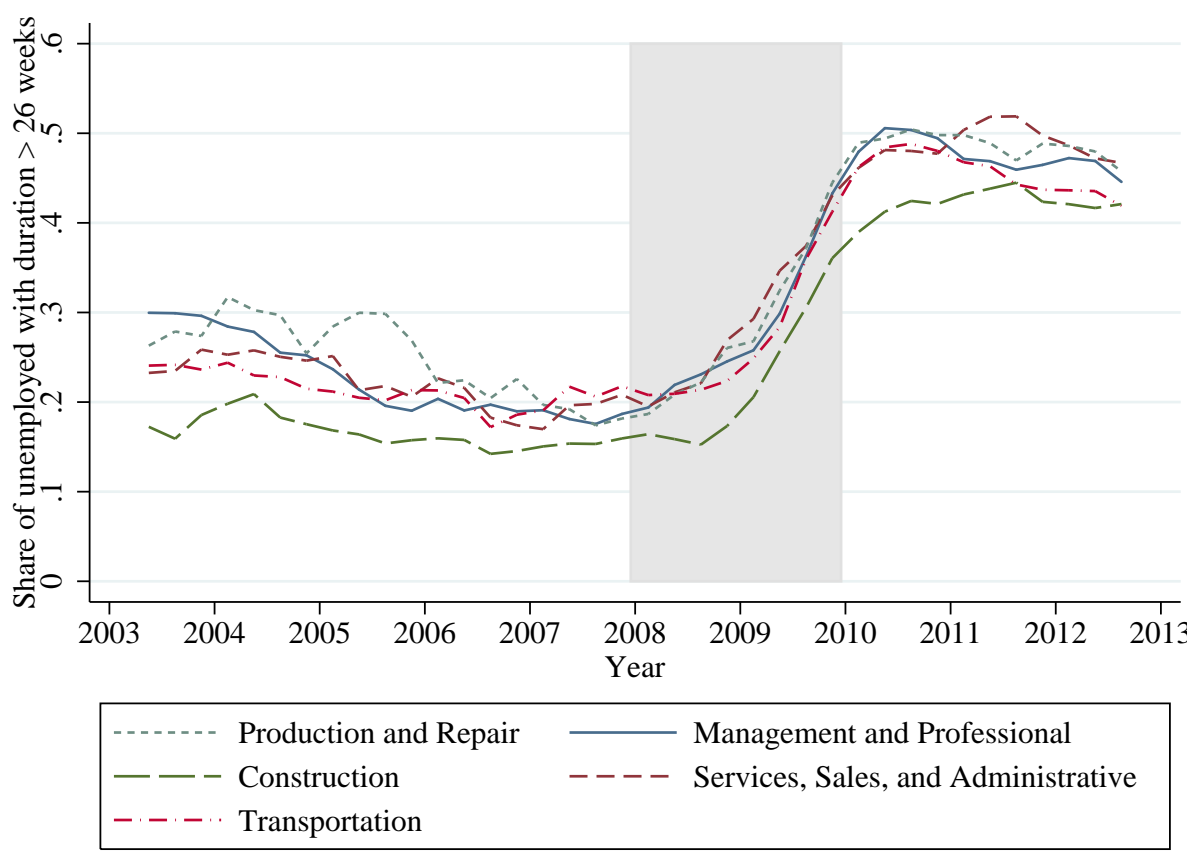

Panel B: Relative share of unemployed

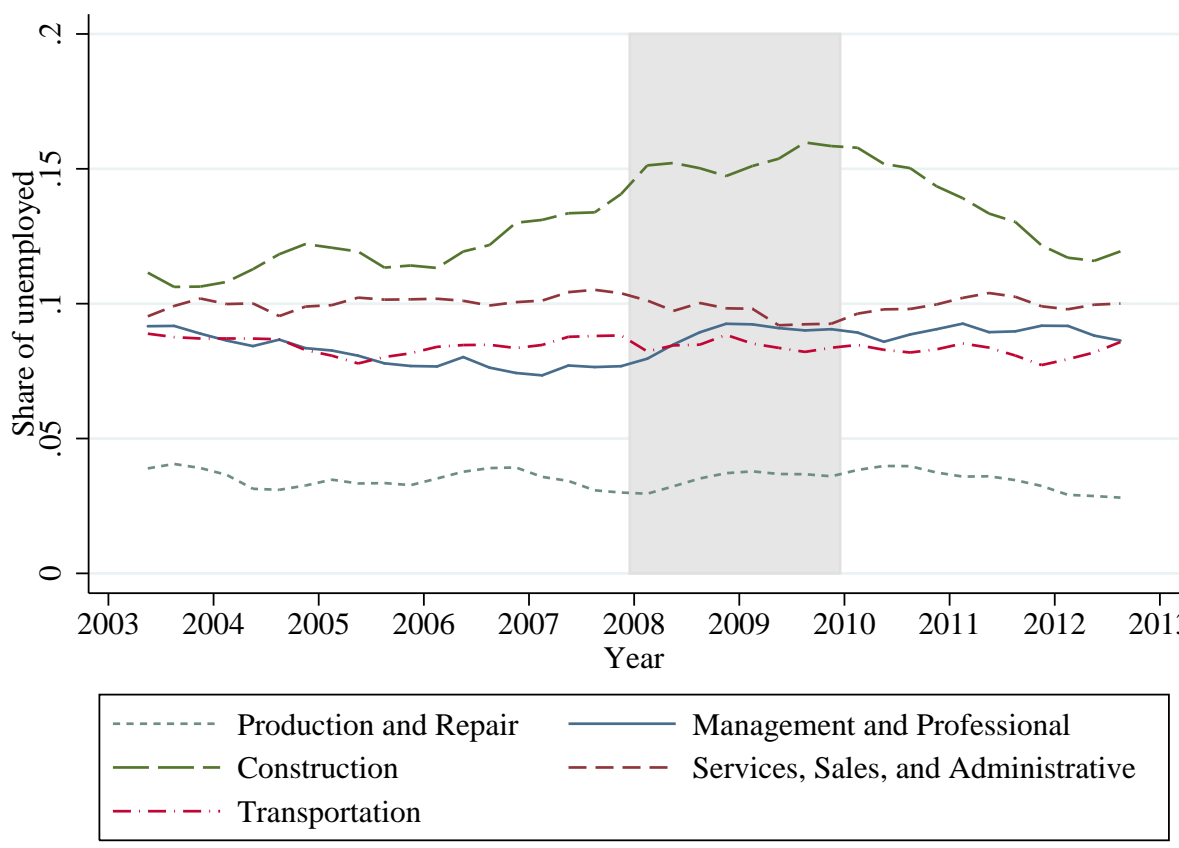

Notes: These figures use data from the CPS. See notes to Figure 2 for more information. 
Panel A: Long-term unemployment share

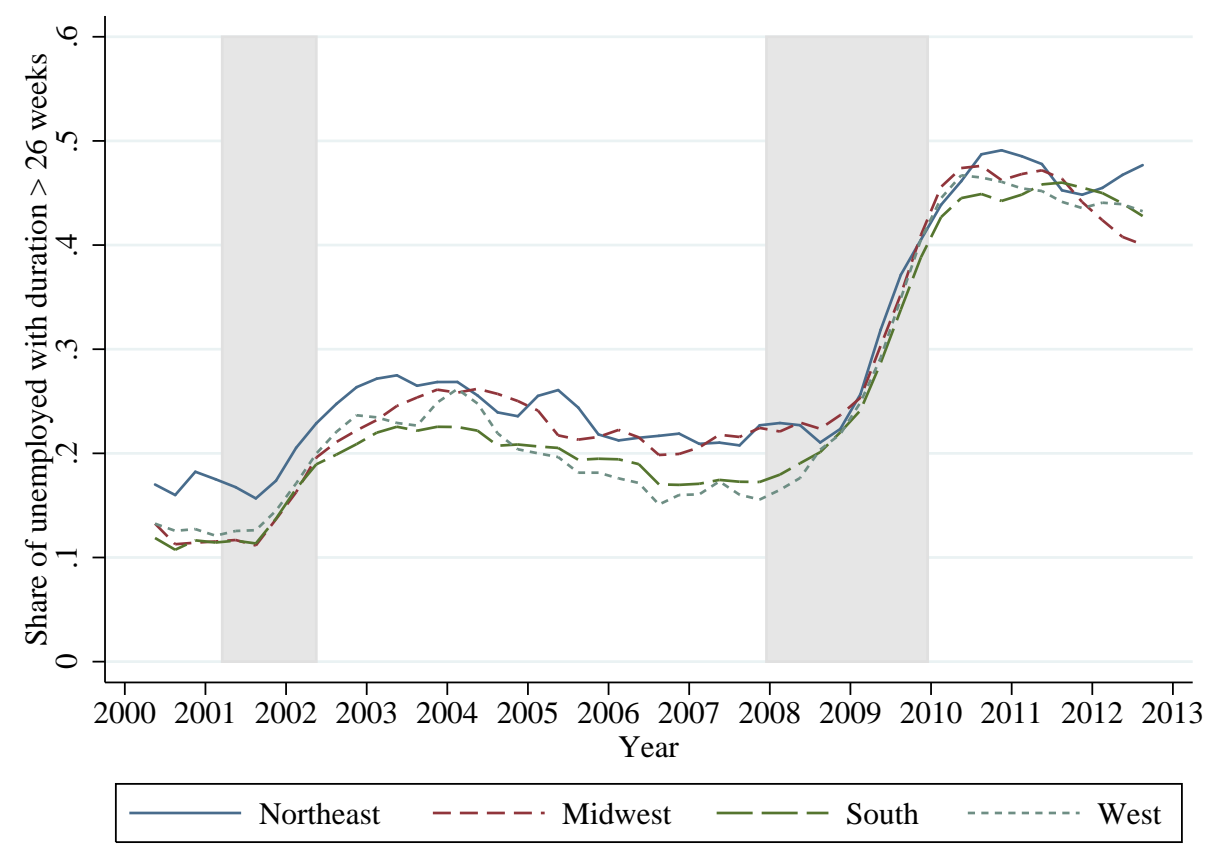

Panel B: Relative share of unemployed

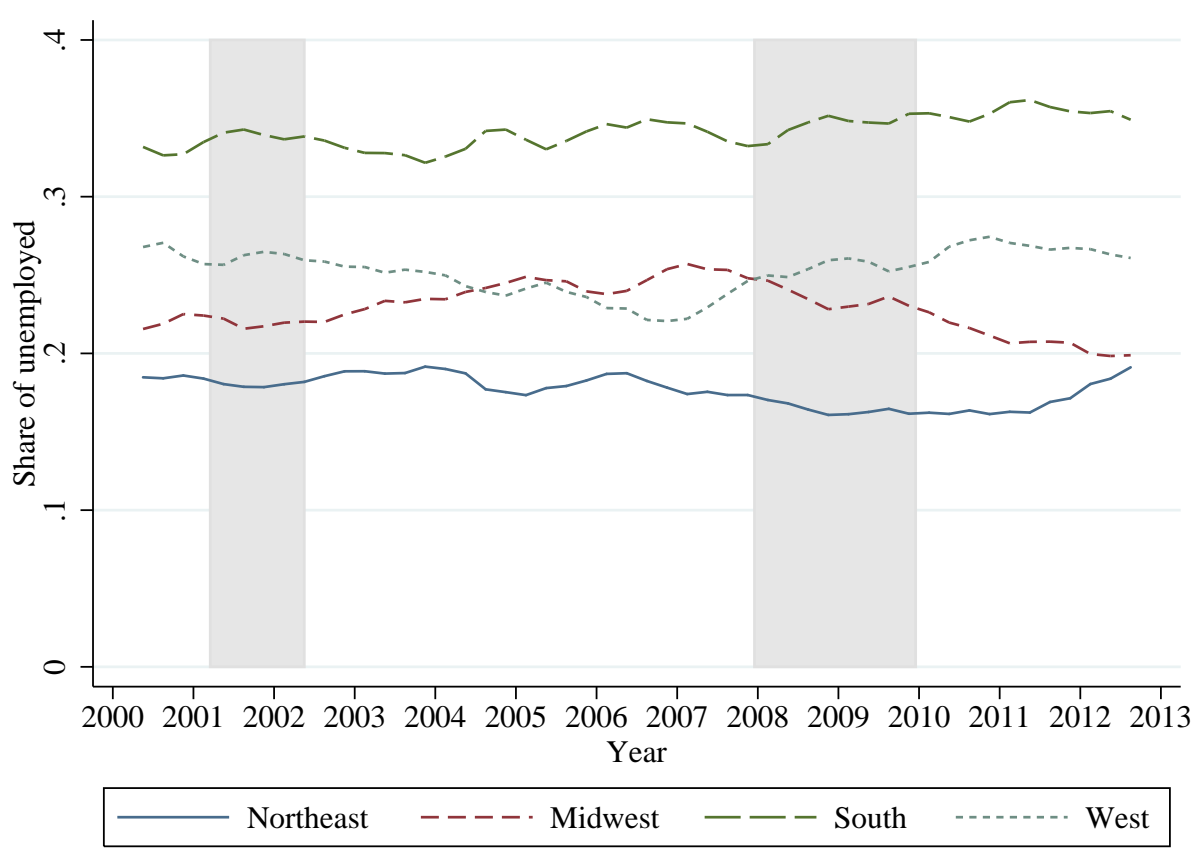

Notes: These figures use data from the CPS. See notes to Figure 2 for more information. 
Online Appendix Figure A7: Long-term Unemployment by Reason for Unemployment

Panel A: Long-term unemployment share

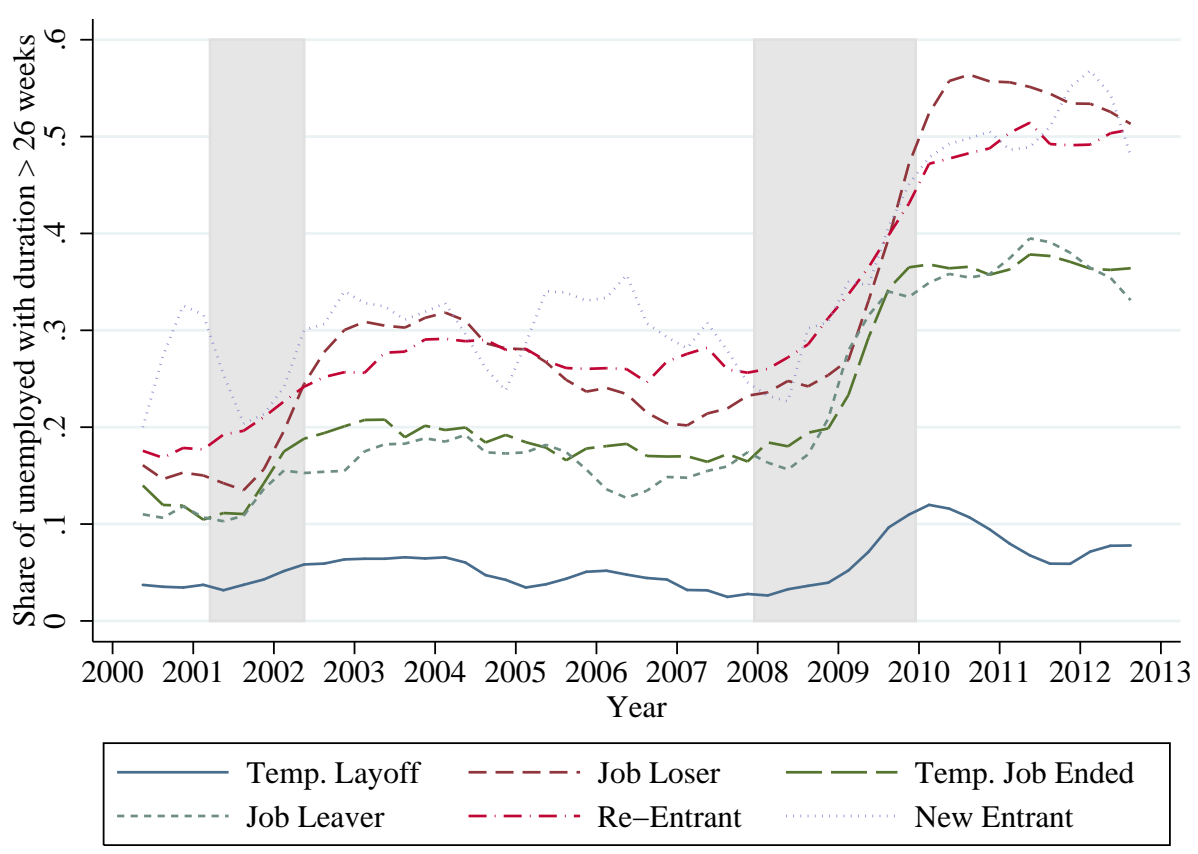

Panel B: Relative share of unemployed

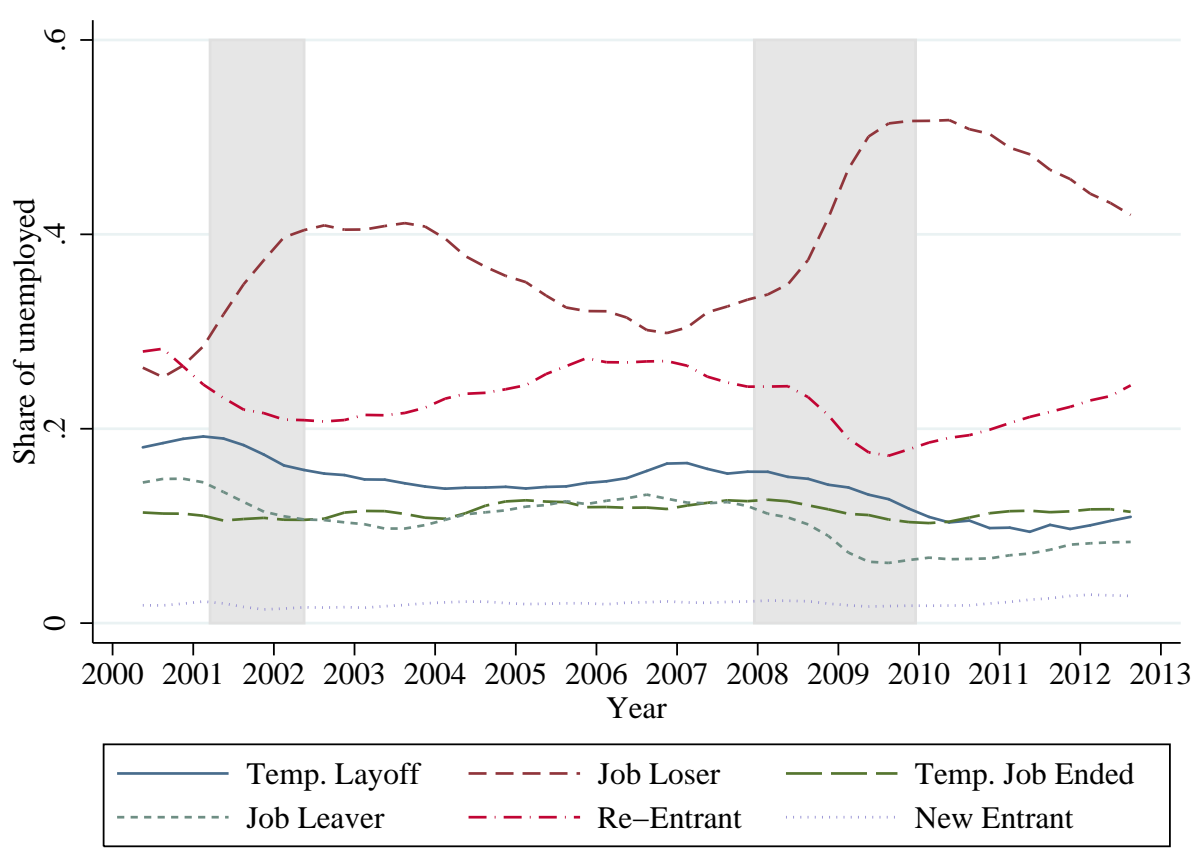

Notes: These figures use data from the CPS. See notes to Figure 2 for more information. 
Panel A: Long-Term Unemployment (> 26 weeks)

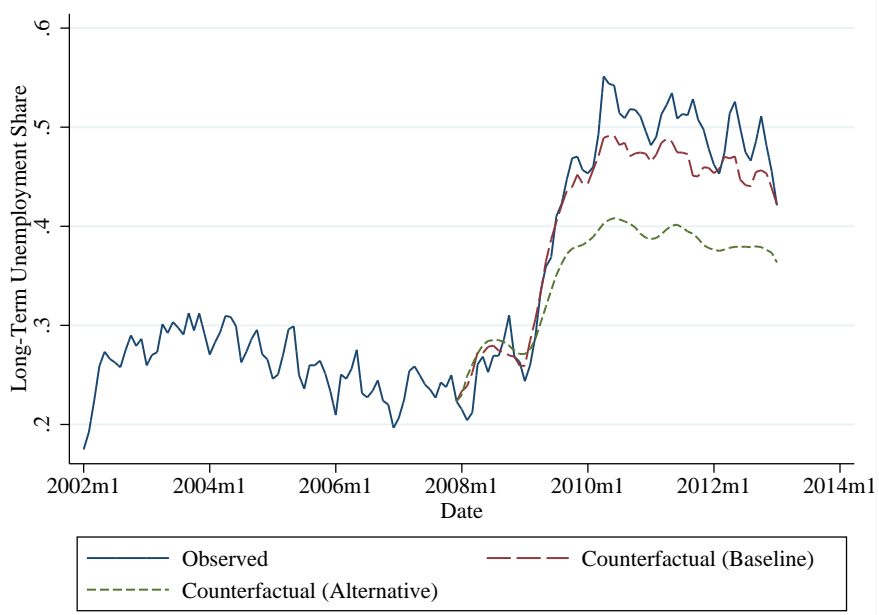

Panel C: Beveridge Curve

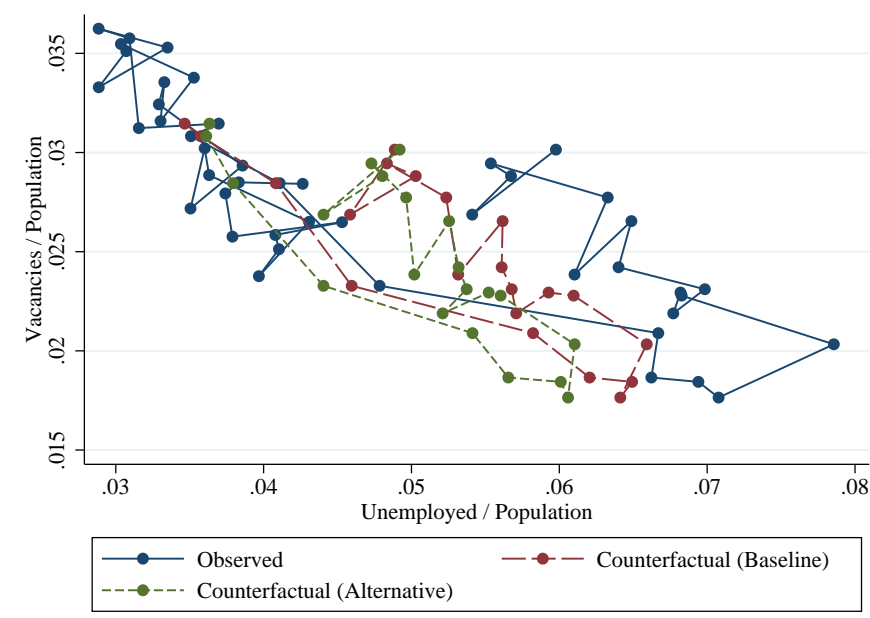

Panel B: Long-Term Unemployment (> 52 weeks)

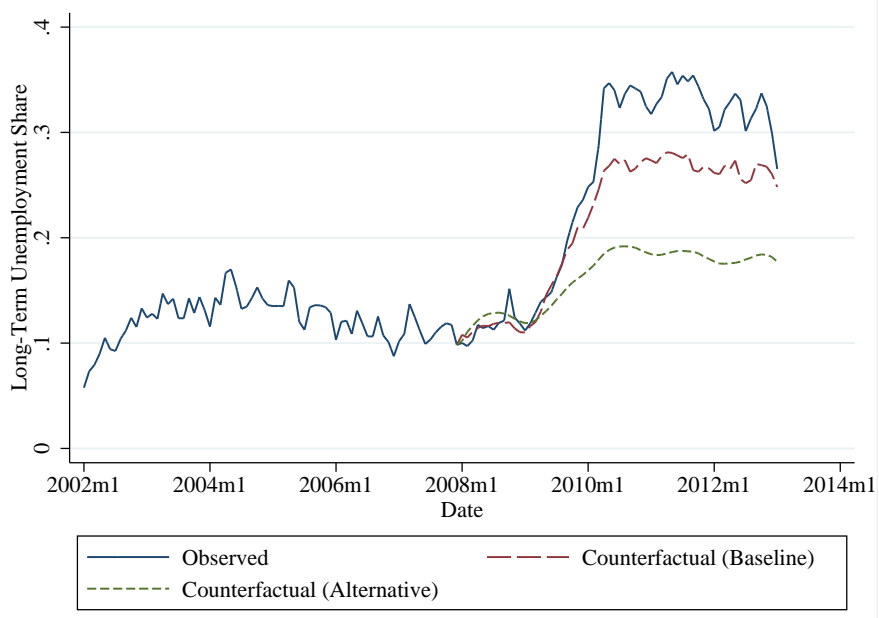

Panel D: Model Predictions for $N-V$ Curve

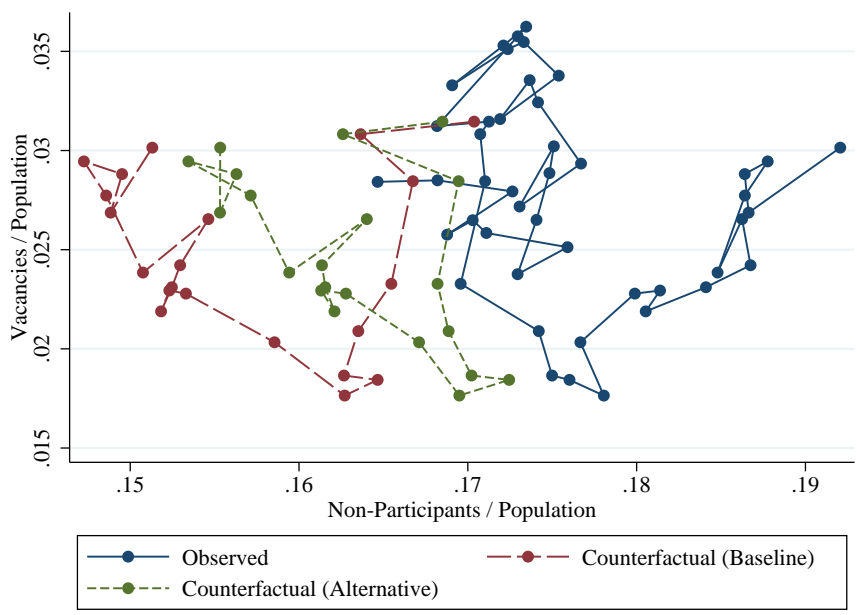

Notes: These figures use data from the CPS and JOLTS. See main text for more details on model calibration. 
Panel A: Long-Term Unemployment (> 26 weeks)

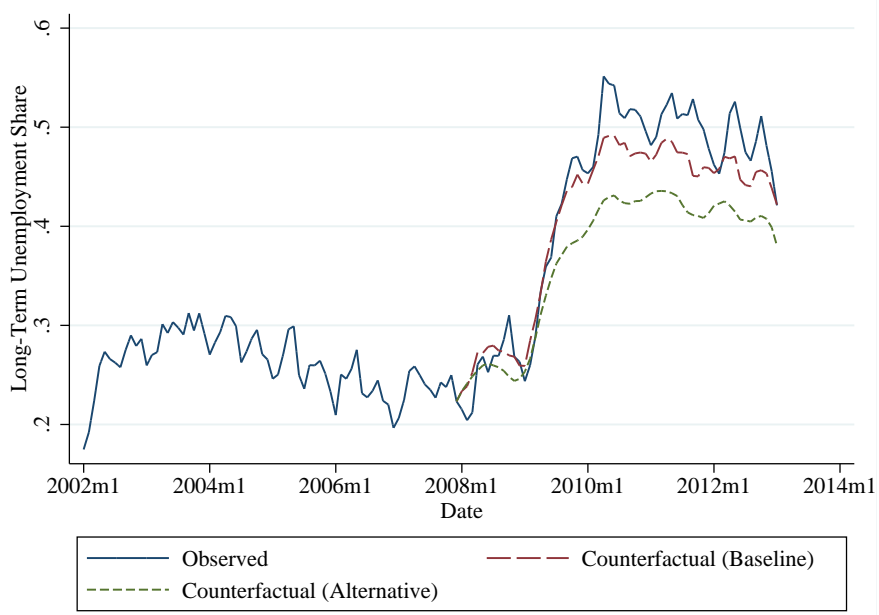

Panel C: Beveridge Curve

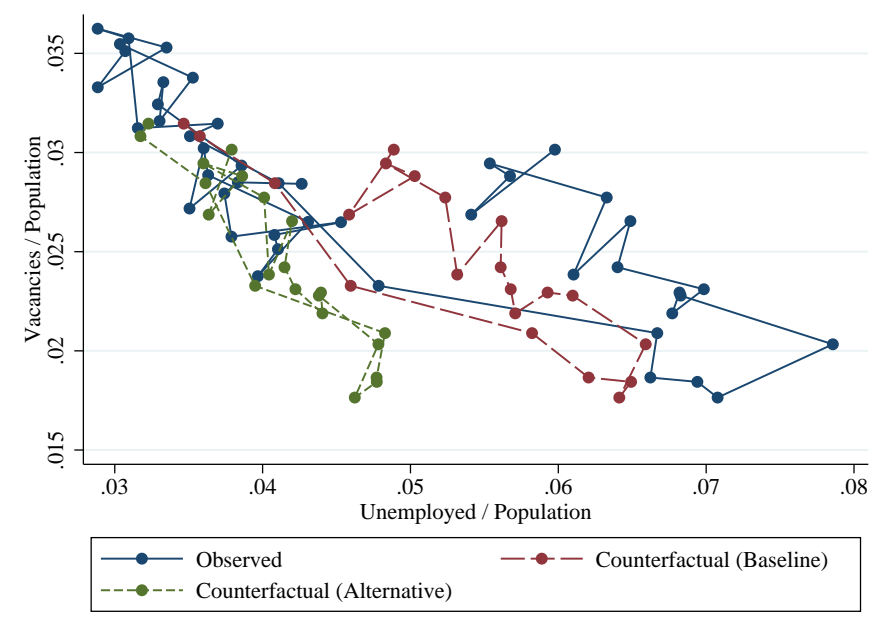

Panel B: Long-Term Unemployment (> 52 weeks)

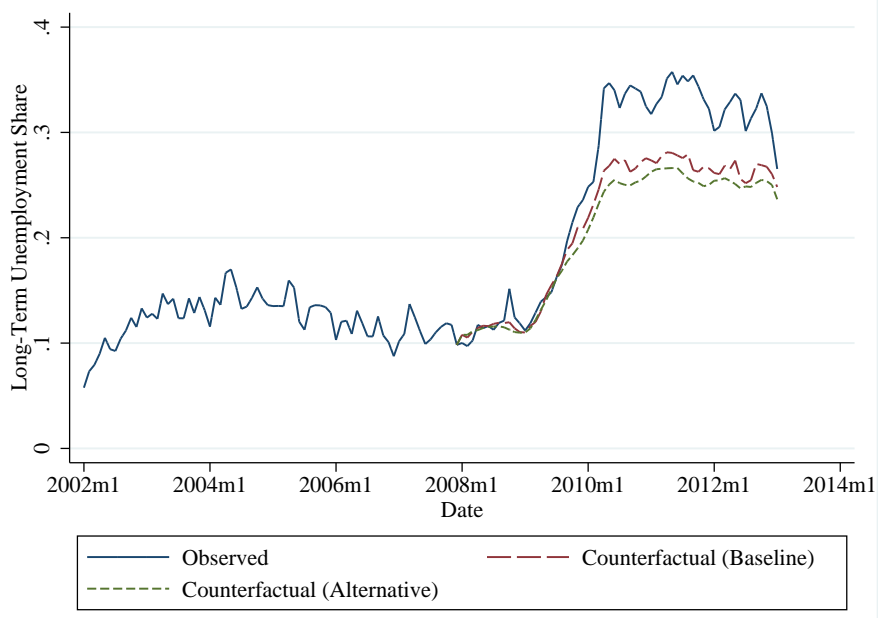

Panel D: Model Predictions for $N-V$ Curve

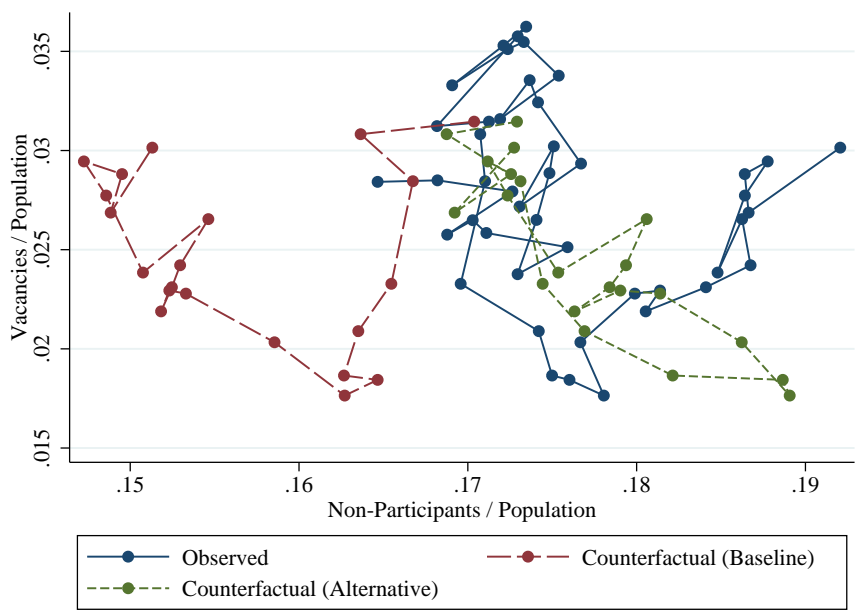

Notes: These figures use data from the CPS and JOLTS. See main text for more details on model calibration. 
Panel A: Long-Term Unemployment (> 26 weeks)

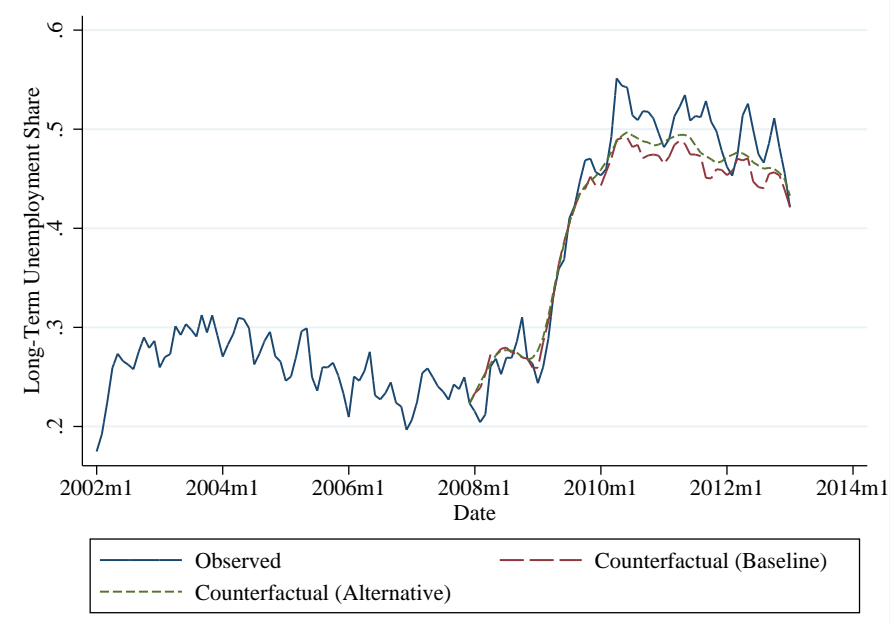

Panel C: Beveridge Curve

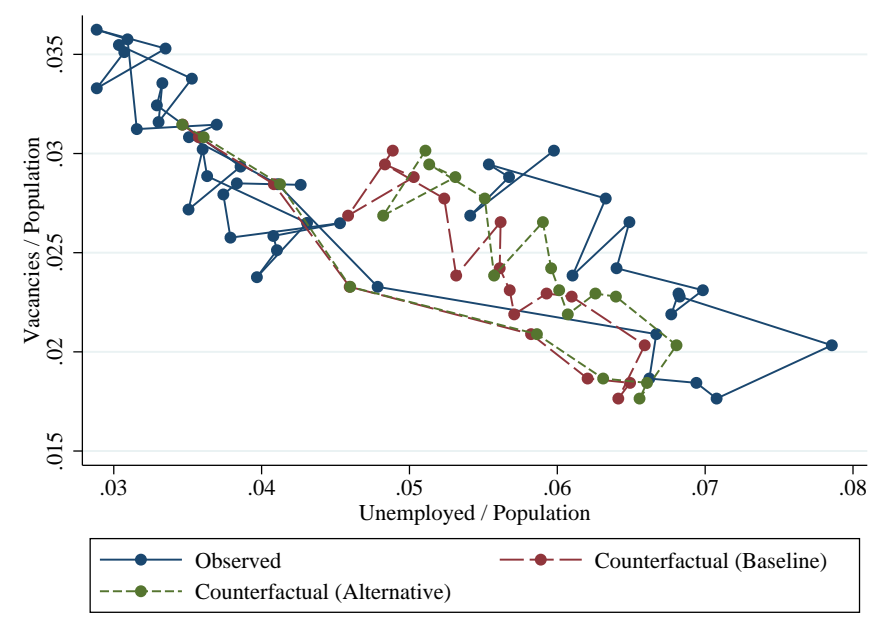

Panel B: Long-Term Unemployment (> 52 weeks)

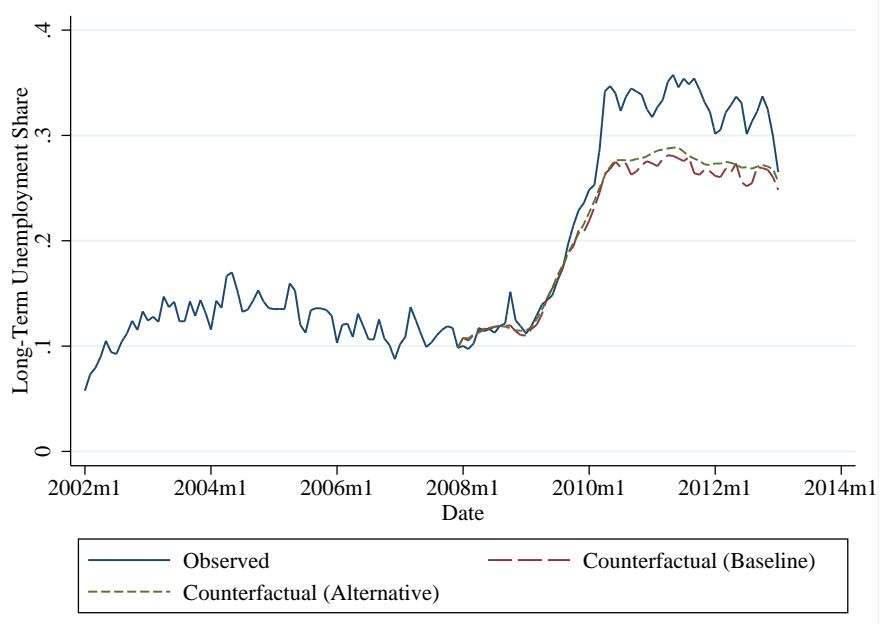

Panel D: Model Predictions for $N-V$ Curve

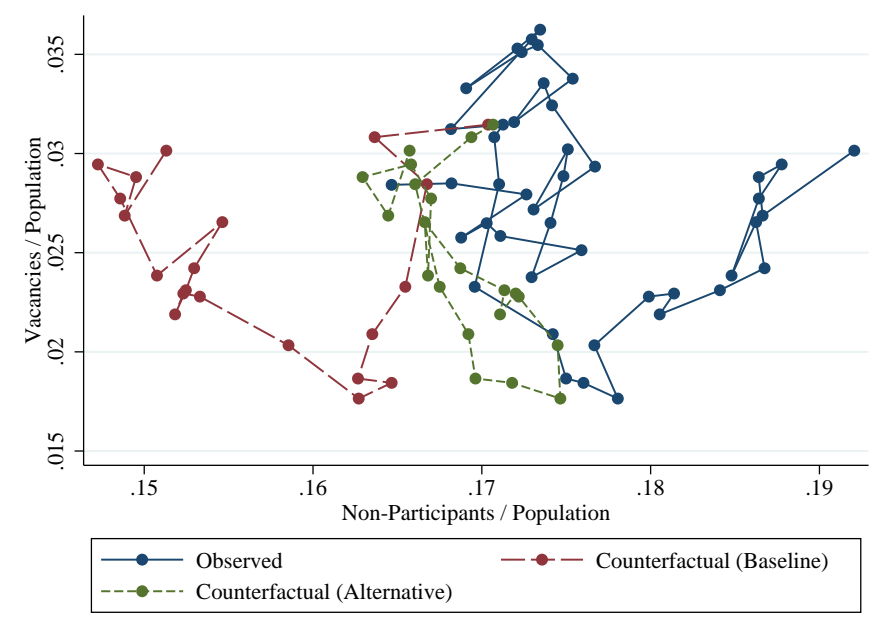

Notes: These figures use data from the CPS and JOLTS. See main text for more details on model calibration. 
Panel A: Short-Term Unemployed Beveridge Curve

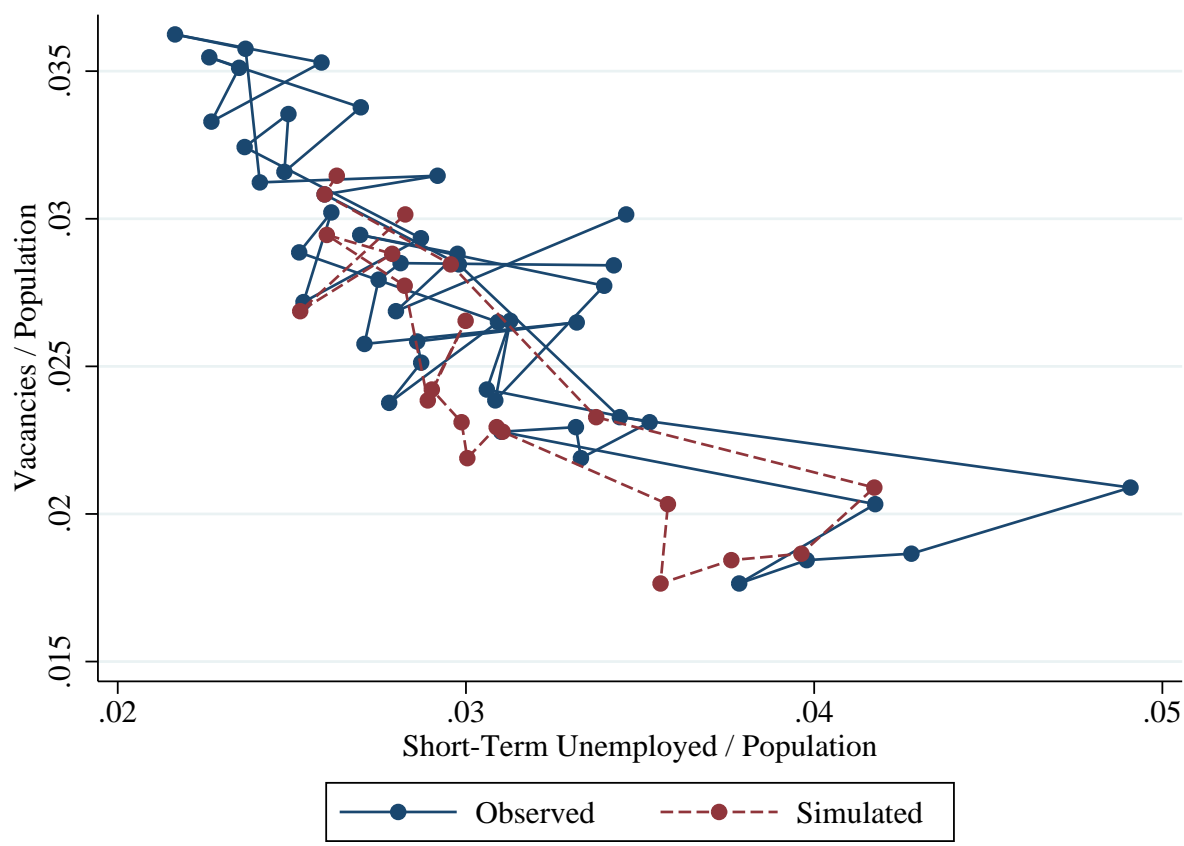

Panel B: Long-Term Unemployed Beveridge Curve

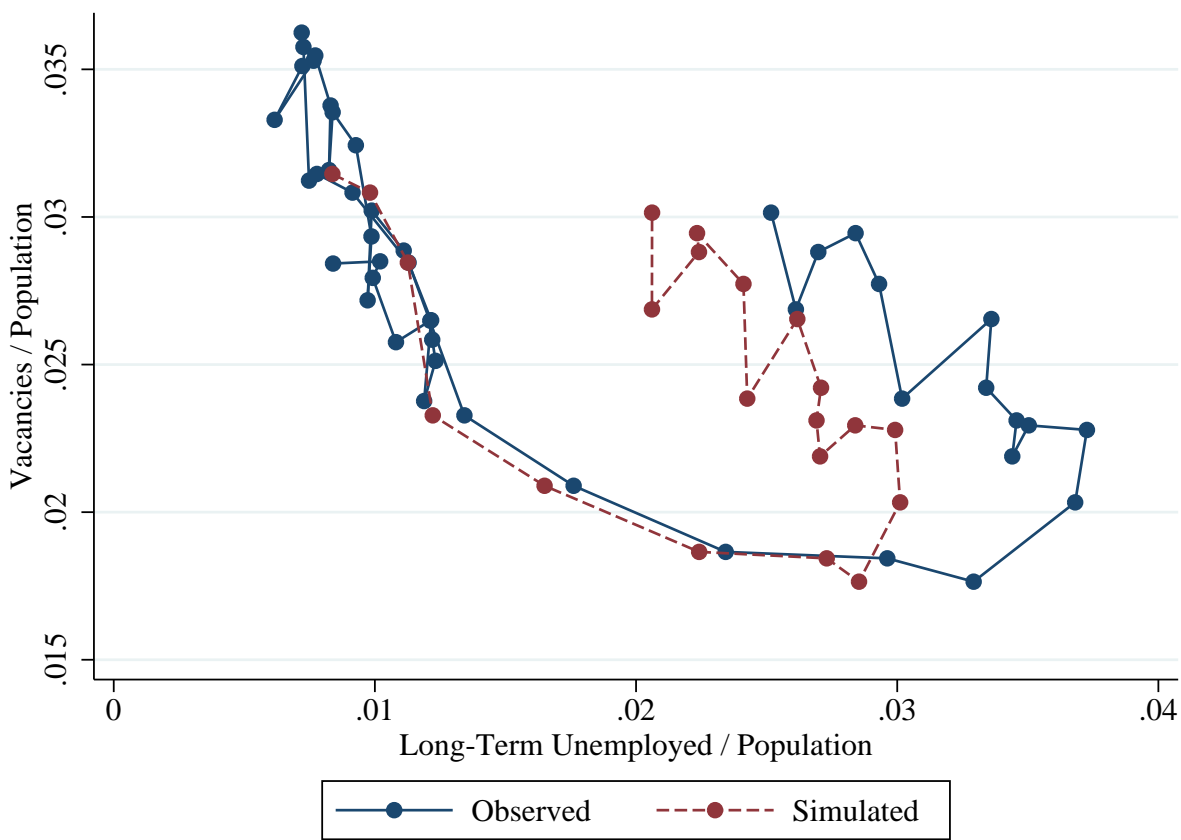

Notes: These figures use data from the CPS and JOLTS. The Short-Term Unemployed Beveridge Curve uses unemployment rate for those with less than 26 weeks; the Long-Term Unemployed Beveridge Curve uses unemployment rate for those with more than 26 weeks. Both unemployment rates and the vacancy rate are defined relative to the total population (labor force + non-participants). See main text for more details on model calibration. 